NBER WORKING PAPER SERIES

\title{
REAL CREDIT CYCLES
}

\author{
Pedro Bordalo \\ Nicola Gennaioli \\ Andrei Shleifer \\ Stephen J. Terry \\ Working Paper 28416 \\ http://www.nber.org/papers/w28416 \\ NATIONAL BUREAU OF ECONOMIC RESEARCH \\ 1050 Massachusetts Avenue \\ Cambridge, MA 02138 \\ January 2021, Revised December 2021
}

We thank audiences at FRB Minneapolis, Yale Finance, Harvard Business School Finance, NBER Behavioral Macro, Northwestern Kellogg Finance, Stanford SITE Uncertainty, NHH, the European Central Bank, Boston University, Harvard Economics, University of Oregon, University of Virginia Darden, NBER Impulse and Propagation Mechanisms, FRB Chicago, AEAs, Queen Mary University of London, Econometric Society, Green Line Macro Meeting, Dartmouth Macro Mini-Conference, CREi-UPF, and the Macro Finance Society, our discussants Alp Simsek, Cosmin Ilut, Ryan Chahrour, and Stefan Niemann, as well as Spencer Kwon, for valuable comments and suggestions. The views expressed herein are those of the authors and do not necessarily reflect the views of the National Bureau of Economic Research.

NBER working papers are circulated for discussion and comment purposes. They have not been peer-reviewed or been subject to the review by the NBER Board of Directors that accompanies official NBER publications.

(C) 2021 by Pedro Bordalo, Nicola Gennaioli, Andrei Shleifer, and Stephen J. Terry. All rights reserved. Short sections of text, not to exceed two paragraphs, may be quoted without explicit permission provided that full credit, including $\odot$ notice, is given to the source. 
Real Credit Cycles

Pedro Bordalo, Nicola Gennaioli, Andrei Shleifer, and Stephen J. Terry

NBER Working Paper No. 28416

January 2021, Revised December 2021

JEL No. E03,E32,E44

\section{$\underline{\text { ABSTRACT }}$}

We incorporate diagnostic expectations into a workhorse neoclassical business cycle model with heterogeneous firms and risky debt. A realistic degree of diagnostic overreaction estimated from US firm forecasts generates economic fragility during good times, countercyclical credit spreads, and boom-bust credit cycles at the firm and aggregate levels. Good times predict future disappointment, spread increases, low bond returns, and investment declines. To generate the size of spread increases observed during 2008-9, the model requires only disappointment of overoptimistic beliefs rather than large negative shocks. Diagnostic expectations offer a realistic, parsimonious way to produce financial reversals in business cycle models.

Pedro Bordalo

Saïd Business School

University of Oxford

Park End Street

Oxford, OX1 1HP

United Kingdom

pedro.bordalo@sbs.ox.ac.uk

Nicola Gennaioli

Department of Finance

Università Bocconi

Via Roentgen 1

20136 Milan, Italy

nicola.gennaioli@unibocconi.it
Andrei Shleifer

Department of Economics

Harvard University

Littauer Center M-9

Cambridge, MA 02138

and NBER

ashleifer@harvard.edu

Stephen J. Terry

Department of Economics

Boston University

270 Bay State Road

Boston, MA 02215

and NBER

stephenjamesterry@gmail.com 


\section{Introduction}

Developed economies experience recurrent boom-bust cycles in real and financial activity. Periods in which investment, output, and leverage are high, and credit spreads are low, tend to be followed by reversals in which credit spreads rise, while investment, output growth, and leverage decline (Schularick and Taylor, 2012; López-Salido et al., 2017). Events such as the Lehman crisis of 2008-9 and the Great Recession are an extreme form of such instability. Conventional accounts view these episodes as the amplification of a shock through financial frictions, fire sales, or demand externalities (Bernanke and Gertler, 1989; Kiyotaki and Moore, 1997; Eggertsson and Krugman, 2012). In some analyses, the triggering shock hits fundamentals (Bianchi, 2011), in other analyses it is a "financial shock" such as a spike in investors' required returns (Korinek and Simsek, 2016), uncertainty (Arellano et al., 2019), or a bank run (Diamond and Dybvig, 1983). ${ }^{1}$ It is however difficult to detect significant fundamental shocks, especially of the magnitude needed to account for large crises, and financial shocks remain a black box. The sources of and magnitude of financial instability remain an open problem.

A longstanding approach views non-rational beliefs as the chief driver of macro-financial instability (Minsky, 1977; Kindleberger, 1978). During good times, the argument goes, investors are too optimistic, so credit and investment overexpand. When beliefs subsequently cool off, credit markets tighten, real activity declines, and default rates rise. Recent work finds that the measured expectations of a broad range of economic agents systematically depart from rationality and in particular overreact to current conditions: they are too optimistic in good times and then systematically revert (Gennaioli et al., 2016; Bordalo et al., 2020). In turn, such belief overreaction helps explain excess volatility in the credit and stock markets (Bordalo et al., 2018, 2019).

In this paper, we assess the ability of non-rational expectations to account for boombust macroeconomic cycles. We take a workhorse real business cycle (RBC) model with defaultable debt and modify it by a single parameter capturing the overreaction of beliefs to total factor productivity (TFP) news. We discipline departures from rationality by using data on managers' expectations about their firms' profitability. We show that an empirically realistic degree of overreaction produces realistic boom-bust cycles, in which sharp reversals occur even in the absence of negative TFP shocks. The model satisfactorily matches several nontargeted moments, including the dynamics of spreads, investment, and the predictability of realized bond returns at the firm and aggregate levels without assuming other ingredients such as exotic risk preferences.

\footnotetext{
${ }^{1}$ Shleifer and Vishny (1992) offer the original treatment of fire sales, and this amplification is also in Lorenzoni (2008), Stein (2012), and Dávila and Korinek (2017). Demand externalities are also studied by Farhi and Werning (2020), Guerrieri and Lorenzoni (2017), Korinek and Simsek (2016), and Rognlie et al. (2018).
} 
In Section 2 we present novel evidence on boom-bust cycles in expectations, bond returns, and investment at the firm level. We show that managers' expectations of the profits of their firms overreact: they are too optimistic in good times and too pessimistic in bad times. In turn, excess optimism predicts a one year-ahead increase in the firm's credit spread, lower realized bond returns, and lower investment growth. In the rest of the paper we investigate whether these boom-bust dynamics can be explained by a disciplined departure from belief rationality.

In Section 3 we present our model of overreaction, diagnostic expectations (DE) (Bordalo et al., 2018), which is founded in the psychology of selective recall: good news does not only increase the true likelihood of good future outcomes but also causes such outcomes to be top of mind and thus overweighted in beliefs. In our setting diagnostic beliefs give rise to the expectations formula:

$$
\mathbb{E}_{t}^{\theta}\left(A_{t+1}\right)=\mathbb{E}_{t}\left(A_{t+1}\right)+\theta\left[\mathbb{E}_{t}\left(A_{t+1}\right)-\mathbb{E}_{t-1}\left(A_{t+1}\right)\right]
$$

where $A_{t+1}$ is future $\mathrm{TFP}, \mathbb{E}_{t}(\cdot)$ is the rational expectation at time $t$, and $\theta \geq 0$ is a diagnosticity parameter. When $\theta=0$ expectations are rational. When $\theta>0$ agents overreact, becoming too optimistic after good news and too pessimistic after bad news. DE have three advantages relative to mechanical models of non-rational beliefs such as adaptive expectations. First, they are forward-looking, so they are not directly vulnerable to the Lucas (1976) critique. Second, due to the same feature, they better account for the measured expectations of financial analysts (Bordalo et al., 2019) and macroeconomic forecasters (Bordalo et al., 2020). Third, the diagnosticity parameter $\theta$ has been estimated in several datasets, offering an important out of sample check for our results.

In Sections 4 and 5 we build and estimate a RBC model in which agents hold diagnostic expectations about TFP. A distribution of heterogeneous firms are subject to idiosyncratic and common TFP shocks and decide whether to default, how much labor to hire, how much to invest subject to adjustment costs, as well as how much equity and debt to issue. Deeppocket risk-neutral lenders provide credit. In our main analysis the wage and the interest rate are fixed, but we endogenize an equilibrium wage in Section 7.2. We structurally estimate the model by matching firm-level moments on profitability, spreads, debt, investment, and forecast errors. The estimated degree of diagnosticity $\theta \approx 1$ is in the ballpark of previous estimates (Bordalo et al., 2019; Pflueger et al., 2020; D'Arienzo, 2020). As a benchmark, we also estimate a rational expectations (RE) model with $\theta$ fixed at 0 , which of course cannot match predictable forecast errors at the firm level.

The estimated model yields two key results. First, under DE, but not under RE, the reaction of aggregate investment to TFP shocks is highly nonlinear. In good times, even a small negative TFP shock causes a large drop in aggregate investment, whereas in normal times, the effect of the same shock is muted. Second, and related, in the DE model sharp 
increases in credit spreads occur after good times when TFP growth slows down. Under RE, by contrast, they occur after a bad TFP shock. The DE model thus offers a theory of "financial shocks:" waning of excess optimism causes sudden inward shifts in the supply of capital and spread increases (Jermann and Quadrini, 2012; Gilchrist and Zakrajšek, 2012).

In Section 6 we assess the model's ability to match untargeted facts. We first look at traditional macro comovements. The DE model outperforms the RE model in matching: i) a strong positive comovement of debt issuance with output and investment growth, which is due to belief-driven outward shifts of the demand and supply of capital in good times, and ii) a negative correlation between spreads and output, which is because the supply of capital is more volatile than demand.

Next, we circle back to the boom-bust cycles documented in Section 2. We use modelsimulated data to run firm-level regressions linking current overoptimism to future increases in the spread, reductions in investment, and disappointing bond returns. We show that the DE model offers a good quantitative account of the firm-level cycles, while the RE model cannot do so due to its inability to match systematic disappointment of expectations. We then document that the boom-bust cycles of Section 2 also occur at the sectoral level and show that the DE model (but again not the RE model) displays a remarkable ability to match these dynamics.

As a final exercise, we ask how large a TFP shock is required in the DE model to produce the massive increase in credit spreads observed during 2007-09 and investigate the macroeconomic implications of such a shock. We find that a moderate decline in TFP growth, not implying an absolute decline in TFP but only disappointment relative to optimistic expectations, is sufficient to generate the observed increase in credit spreads. The RE model is entirely incapable of matching this performance. The DE model also produces declines in aggregate investment, credit, and earnings expectations that are quantitatively consistent with the data.

We conclude the paper with two robustness exercises in Section 7. First, we endogenize the real wage in general equilibrium by adding to the model a household labor choice with convex effort cost. As expected, this modification dampens volatility but does not eliminate sizable fragility after good times, even with fully flexible wages. Second, we perform sensitivity analysis by varying a range of model parameters. Again, our key results appear to be robust.

Our paper contributes to two strands of work in macroeconomics. The first studies macrofinancial instability. This work maintains rational expectations but produces time-varying risk attitudes through habits (Campbell and Cochrane, 1999), long-run risk (Bansal and Yaron, 2004), or disaster risk (Barro, 2006). One problem with these accounts is that timevarying risk attitudes are not directly measured. Another problem is that the predictions of these models stand in sharp contrast with survey expectations. For instance, habit formation 
models predict countercyclical expected returns while survey expectations of returns are procyclical (Greenwood and Shleifer, 2014). Disaster risk models predict high expected returns when disaster risk is perceived to be high but the opposite is true in expectations data (Giglio et al., 2021). We pursue an orthogonal approach: we assume standard preferences, in particular constant required returns, and relax belief rationality in a manner disciplined by micro data. Future work may combine the two ingredients.

The second strand of work studies departures from full information rational expectations in macro models. The leading approach maintains rationality but relaxes full information, often via limited attention (Sims, 2003; Mankiw and Reis, 2002). Coibion and Gorodnichenko (2015) study inflation forecasts using information rigidities as in Woodford (2003). Kohlhas and Walther (2021) model asymmetric attention paid to distinct macroeconomic variables. Kozlowski et al. (2017) links belief dynamics to the persistence of the Great Recession. Angeletos et al. (2020) models dispersed information and overextrapolation of macroeconomic outcomes. A different approach emphasizes ambiguity aversion (Hansen and Sargent, 2001; Ilut and Schneider, 2014). This mechanism can generate excess volatility in beliefs, but it has a hard time explaining overoptimism, unless a preference for ambiguity is added, as in Bhandari et al. (2019). ${ }^{2}$

The key innovation of our approach is to allow for a departure from rationality, belief overreaction, discipline it using micro data, and study its macro-financial implications. We show that overreacting beliefs create significant excess macro-financial volatility and systematic reversals through disappointment. Enriching our setup with realistic ingredients such as bank runs, shifts in aggregate demand (Farhi and Werning, 2020), time-varying capacity utilization (King and Rebelo, 1999), or sharp cuts to firm-level employment in bad times (Ilut et al., 2018) may offer a more realistic model of macroeconomic volatility. Along these lines Maxted (2020) introduces DE into He and Krishnamurthy (2019)'s model. Krishnamurthy and Li (2020) also study beliefs and intermediation in a DE framework. Bianchi et al. (2021) and L'Huillier et al. (2021) develop techniques to introduce DE into the New Keynesian model.

\section{Data}

We present new evidence on the connection between belief overreaction and boom-bust cycles in spreads, investment and bond returns at the firm level, even controlling for macro shocks.

We use micro data on firm-level forecasts from the IBES manager guidance database. This

\footnotetext{
${ }^{2}$ See also Falato and Xiao (2020) and Schaal and Taschereau-Dumouchel (2020) on dispersed information. Jaimovich and Rebelo (2007) study the impact of other belief distortions in macro models without financial frictions. Caballero and Simsek (2020) study demand externalities in models with extrapolative beliefs. Behavioral finance has studied credit cycles Greenwood et al. (2019), including under DE (Bordalo et al., 2018), without however assessing the quantitative performance of these accounts.
} 
panel records, for an individual firm-fiscal year, a manager's forecast for their company's profits or earnings over the next year. We exploit forecasts made concurrently with the release of the year's financials, in a sample spanning the 1999-2018 period. We link this data to Compustat, which provides standard financial information. We also use the Mergent Fixed Income Securities Database (FISD), which contains issuance information including spreads on individual securities, and the FINRA's Trade Reporting and Compliance Engine (TRACE) dataset, which contains data on secondary market transactions from bond dealers and hence allows us to compute realized bond returns. The FISD-TRACE sample covers the years 2003-2018. Appendix B provides more information on data sources and sample construction, as well as descriptive statistics.

We first assess whether expectations overreact to current conditions. We regress a firm's next year's forecast errors, defined as realized minus predicted profits, on current-year firmlevel investment and debt issuance, controlling for time effects. Under rational expectations, the manager's forecast errors should be unpredictable based on any information available to them when the forecast is made. If instead beliefs overreact, displaying overoptimism during good times and pessimism during bad times, then future forecast errors should be negatively correlated with the firm's current fundamentals, proxied by investment and debt issuance. ${ }^{3}$

Table 1 reports the results. The results in columns (1) and (3) are consistent with overreaction: firms investing more or issuing more debt today on average experience more negative earnings surprises in the future. These results may be contaminated by constant heterogeneity in optimism across firms. The degree of overreaction to news is exaggerated if firms that are always more optimistic than others also invest more, and it is dampened otherwise. Trying to solve this problem by adding firm fixed effects would induce the downward dynamic panel bias of Nickell (1981) in finite samples, overstating the extent of overreaction. ${ }^{4}$

To address this issue, we switch our focus to changes in forecast errors and fundamentals: if beliefs overreact, then higher current growth in investment or debt will predict higher future growth in forecast errors. Growth in current investment and debt proxies for good news, so it is associated, under overreaction, with disappointment next period. Following disappointment, forecasts are revised down, which increases the growth in forecast errors two periods from now. In Appendix B we formally derive this relationship. Exploiting such growth moments, columns (2) and (4) of Table 1 report GMM estimates of an asymptotic regression comparable to the specification of columns (1) and (3), but controlling for fixed

\footnotetext{
${ }^{3}$ We obtain similar results if we use the current level of expectations as a predictor of future forecast errors. However, we prefer using investment and debt because they reflect the manager's beliefs without being affected by the measurement error that may contaminate expectations data (see for instance Gennaioli et al. (2016)).

${ }^{4}$ Intuitively, the forecast errors on the left hand side of these regressions include profit innovations which in finite samples may influence the mean forecast errors subtracted by the OLS fixed effects estimator. If firm financial outcomes on the right hand side are correlated with these profit innovations, then there will be a mechanical negative correlation resulting in downward bias of the OLS fixed effect estimator.
} 
Table 1: Predictable Forecast Errors

\begin{tabular}{|c|c|c|c|c|}
\hline & (1) & $(2)$ & $(3)$ & (4) \\
\hline & & Forecast & Error $_{t+1}$ & \\
\hline Estimation Method: & OLS & GMM & OLS & GMM \\
\hline Investment $_{t}$ & $\begin{array}{c}-0.618^{* * *} \\
(0.119)\end{array}$ & $\begin{array}{c}-1.459^{* * *} \\
(0.061)\end{array}$ & & \\
\hline Debt $_{t}$ & & & $\begin{array}{c}-0.562^{* * *} \\
(0.187)\end{array}$ & $\begin{array}{c}-0.887^{* * *} \\
(0.056)\end{array}$ \\
\hline Firm Effects & & $\mathrm{X}$ & & $\mathrm{X}$ \\
\hline Year Effects & $\mathrm{X}$ & $\mathrm{X}$ & $\mathrm{X}$ & $\mathrm{X}$ \\
\hline Years & $1999-2018$ & $1999-2018$ & $1999-2018$ & $1999-2018$ \\
\hline Firm-Years & 4449 & 4449 & 4449 & 4449 \\
\hline
\end{tabular}

Notes: The table reports panel OLS and GMM estimates from the merged Compustat-IBES sample of the coefficients of a regression of forecast errors on the indicated variable. The standard errors are clustered at the firm level. All variables are scaled by the firm's tangible capital stock and measured at the firm-fiscal year level. Forecast errors in $t+1$ are realized earnings in $t+1$ minus firm forecasts in $t$. Investment in $t$ is capital expenditures. Debt is long-term and short-term liabilities at the end of t. $*=10 \%$ level, $* *=5 \%$ level, and $* * *=1 \%$ level. The standard deviations of each variable are 0.305 (forecast errors), 0.067 (investment), and 0.056 (debt), where $0.01=1 \%$ relative to the firm's capital stock.

heterogeneity across firms.

Columns (2) and (4) show that firms investing more or issuing more debt today are more likely to have disappointing profits tomorrow. Compared to columns (1) and (3), the results indicate that - if anything - ignoring firm-level heterogeneity understates the actual degree of overreaction. The magnitudes are meaningful. In column (2) a one-standard deviation higher firm investment rate, about 7 percentage points higher, on average predicts $7 \times 1.459$ $\approx 10$ percentage points stronger disappointment in earnings next year. Similarly, in column (4) a one-standard deviation higher debt issuance rate, around 6 percentage points higher, is associated with $6 \times 0.887 \approx 5$ percentage points stronger disappointment in earnings next year. This evidence is at odds with rational expectations and confirms the findings obtained by Gennaioli et al. (2016) and Barrero (Forthcoming) using different data. ${ }^{56}$

These results are robust to additional sample and specification choices, as reported in Appendix Table B.2. We exclude the Great Recession (to avoid the influence of outlier periods), exclude firms with less than five years of earnings guidance (which appear to be more likely to manipulate earnings forecasts (Bertomeu et al., 2021)), and we exclude firms

\footnotetext{
${ }^{5}$ The recent literature on overreaction stresses the predictability of forecast errors from forecast revisions (Bordalo et al., 2020, 2019; Coibion and Gorodnichenko, 2015). Since manager profit forecasts are released less frequently, and for fewer horizons, we do not have enough data to perform this type of revision-based analysis.

${ }^{6}$ Bouchaud et al. (2019) study equity analysts' forecasts. They document that these forecasts, while correlated with managerial forecasts, display a form of underreaction.
} 


\section{Table 2: Linking Forecast Errors and Firm Reversals}

\begin{tabular}{lcccc}
\hline \hline & $(1)$ & $(2)$ & $(3)$ & $(4)$ \\
& $\begin{array}{c}\text { Forecast Error }_{t+1} \\
\text { IV Stage: }\end{array}$ & $\begin{array}{c}\text { Return }_{t+1} \\
\text { Second }\end{array}$ & $\begin{array}{c}\Delta \text { Spread }_{t+1} \\
\text { Second }^{*}\end{array}$ & $\begin{array}{c}\Delta \text { Investment }_{t+1} \\
\text { Second }\end{array}$ \\
\hline Forecast Error & & $0.007^{*}$ & $-0.011^{* * *}$ & $0.485^{* * *}$ \\
& & $(0.004)$ & $(0.004)$ & $(0.061)$ \\
Investment $_{t}$ & $-0.562^{* * *}$ & & & \\
& $(0.105)$ & & $\mathrm{X}$ & $\mathrm{X}$ \\
\hline Year Effects & $\mathrm{X}$ & $\mathrm{X}$ & $2003-2018$ & $2003-2018$ \\
Years & $2003-2018$ & $2003-2018$ & 2852 \\
Firm-Years & 2852 & 2852 & 2852 & \\
First Stage F & 28.94 & & & \\
\hline \hline
\end{tabular}

Notes: The table reports estimates of specifications on the merged Compustat - IBES - FISD/TRACE sample at the firm-fiscal year level. Column (1) reports IV first-stage estimates, and the remaining columns report IV second-stage estimates. Column (3) controls for lagged spreads, and column (4) controls for current profits in the second stage. Standard errors are clustered at the firm level. $*=10 \%$ level, $* *=5 \%$ level, and $* * *=1 \%$ level. The standard deviation of the bond return is 0.014 , the standard deviation of spread growth is 0.024 , the standard deviation of investment growth is 0.090 , the standard deviation of the forecast error is 0.438 , and the standard deviation of lagged investment is 0.133 . For all series, $0.01=1 \%$ relative to a firm's tangible capital stock.

with high-yield debt (to verify that overreaction is not restricted to the riskiest firms). In each case, we continue to uncover evidence of forecast overreaction.

If overreaction produces boom-bust cycles, predictable disappointment or positive surprises in expectations should be correlated with reversals in firm-level outcomes. To assess this prediction, Table 2 performs a two-stage regression exercise. In the first stage, reported in column (1), we regress future forecast errors on current investment, analogous to Table 1 for this sample. This first stage identifies times of excess optimism (pessimism) as those in which investment is so high (low) that it ex-ante predicts future disappointment in beliefs, captured by negative (positive) forecast errors.

In the second stage, reported in columns (2), (3), and (4), we regress future bond returns, the future change in credit spreads, and future investment growth on predicted forecast errors from the first stage controlling for time effects. Belief-driven boom-bust cycles then imply that periods of overoptimism (negative predicted errors) and of overpessimism (positive predicted errors) are followed by reversals in bond returns, credit spreads and investment growth. ${ }^{7}$ This test is not causal: reversals may be produced by "rational" mean reversion in fundamentals, which correlates with "irrational" disappointment. To partially account

\footnotetext{
${ }^{7}$ In Appendix B we also check that these firm-level cycles are not driven by highly risky firms, which may display a stronger reaction to macro shocks. We thus repeat the exercise in Table B.3 for the subset of investment grade firms, excluding all firms with high-yield debt. Our results are confirmed.
} 
for this possibility, the spread regressions control for the lagged spread and the investment regressions control for current profits. ${ }^{8}$ More rigorously, simulated data from our RBC model will later reveal that belief overreaction is needed to account for these firm-level patterns.

The results are consistent with belief driven boom-bust cycles. Good times, periods with high investment, are systematically followed by disappointment (column 1). In turn, the latter correlates with low future bond returns (column 2), rising future credit spreads (column 3), and low future investment growth (column 4). The opposite occurs after bad times. The magnitudes are meaningful. For example, in column (2) a firm predictably disappointed with a one standard deviation lower forecast error sees its bond returns fall by $0.007 \times 0.438 \approx 0.3$ percentage points on average, a sizable decline relative to the standard deviation of around 1.4 percentage points for bond returns in our sample. Column (3) reveals that credit spreads grow by $-0.011 \times 0.438 \approx 0.5$ percentage points at the same firm, and the investment rate declines by $0.485 \times 0.438 \approx 21.2$ percentage points according to the estimates in column (4). The rest of the paper draws out the aggregate consequences of these firmlevel patterns by introducing diagnostic expectations, a model of belief overreaction, into a standard RBC model.

\section{Diagnostic Expectations and Neglected Risk}

\subsection{Diagnostic Expectations}

Diagnostic expectations are a model of non-Bayesian beliefs that accounts for a broad range of well documented departures from rationality, starting from the work of Kahneman and Tversky in the 1970s. DE were developed by Bordalo et al. (2018) building on Gennaioli and Shleifer (2010). To see how DE work, consider an agent forecasting a future variable $X_{t+1}$, say TFP, on the basis of its history. The true distribution is Markovian, denoted by $f\left(X_{t+1} \mid X_{t}\right)$. Under DE, the agent's beliefs follow the distorted distribution:

$$
f^{\theta}\left(X_{t+1} \mid X_{t}\right) \propto f\left(X_{t+1} \mid X_{t}\right)\left[\frac{f\left(X_{t+1} \mid X_{t}\right)}{f\left(X_{t+1} \mid \mathbb{E}_{t-1}\left(X_{t}\right)\right)}\right]^{\theta}
$$

where $\theta \geq 0$ and $\mathbb{E}_{t-1}\left(X_{t}\right)$ is the rational expectation of $X_{t}$ conditional on information at $t-1 .^{9}$ Equation (2) captures the idea that beliefs overweight future outcomes that have

\footnotetext{
${ }^{8}$ The lagged spread and current profit controls, while reassuring, are not necessary for our results. Table B.4 in the empirical Appendix B reproduces Table 2 without such controls, with little resulting change in our estimates.

${ }^{9}$ Equation (2) simplifies the general DE formulation in order to focus on the basic overreaction mechanism. There are two main simplifications. First, we assume that $X_{t}$ is perfectly observable. Bordalo et al. (2019, 2020, 2021b) allow for information frictions such as dispersed information about $X_{t}$. Second, we model overreaction to current news only. Other applications of DE allow for overreaction to a longer streak of news (Bordalo et al., 2019; D'Arienzo, 2020; Maxted, 2020). These features are psychologically plausible and can match persistent belief distortions, such as slowly brewing asset price bubbles (Bordalo et al., 2021c).
} 
become more likely on the basis of current news. Overweighting is captured by the likelihood ratio on the right hand side, which measures the current increase in the probability of $X_{t+1}$ relative to the case of neutral news $X_{t}=\mathbb{E}_{t-1}\left(X_{t}\right)$. Parameter $\theta$ captures the strength of overweighting. When $\theta=0$ expectations are rational, but when $\theta>0$ beliefs overreact.

Equation (2) is founded on the psychology of selective recall. The idea is that the true density $f\left(X_{t+1} \mid X_{t}\right)$ is stored in the agent's memory database. Upon receiving news, the agent selectively recalls outcomes that are historically most associated with it and fails to recall outcomes that are less associated with it. Judgments overreact to news because they overweight what is top of mind. Bordalo et al. (2021a) offer a model of selective memory that founds overreaction in Equation (2) and find support for it in two experiments. See also Bordalo et al. (2021b) for related evidence on memory and probability assessments.

To see the implications of Equation (2), suppose that the TFP of a firm follows an AR(1) process, $\ln A_{t}=\rho \ln A_{t-1}+\varepsilon_{t}$, where $\rho \in(0,1)$ and $\varepsilon_{t}$ is Gaussian with mean zero and variance $\sigma^{2}$. At time $t$ the diagnostic distribution of next period productivity is also Gaussian, with mean:

$$
\mathbb{E}_{t}^{\theta}\left(\ln A_{t+1}\right)=\rho \ln A_{t}+\theta \rho \varepsilon_{t}
$$

and variance $\sigma^{2}$. DE are too optimistic after good news $\varepsilon_{t}>0$ and too pessimistic after bad news $\varepsilon_{t}<0$. Future forecast errors are negatively predicted by current TFP:

$$
\operatorname{Cov}\left[\ln A_{t+1}-\mathbb{E}_{t}^{\theta}\left(\ln A_{t+1}\right), \ln A_{t}\right]=-\theta \rho \sigma^{2}<0
$$

which allows DE to account for the error predictability in Table 1. This cannot occur under RE, with $\theta=0$, which implies a zero covariance above.

DE offer two advantages relative to other models of non-rational expectations used in macroeconomics and finance. First, they are forward-looking: updating depends on the data generating process $f\left(X_{t+1} \mid X_{t}\right)$. This is important both methodologically (Lucas, 1976) and empirically. Indeed, belief revisions by professional forecasters are stronger for more persistent variables, as predicted by Equation (3) (Bordalo et al., 2019, 2020; Afrouzi et al., 2020; Azeredo da Silveira et al., 2020). In a setting with dispersed information forward-looking DE allow us to reconcile individual-level overreaction with the sluggishness of consensus forecasts (Bordalo et al., 2020; Coibion and Gorodnichenko, 2015). DE also account for the fact that overreaction is stronger in longer-term, truly more uncertain, outcomes (D'Arienzo, 2020). The sensitivity of beliefs to the data generating process is not achieved in mechanical models of belief formation such as adaptive or extrapolative expectations. ${ }^{10}$

Bianchi et al. (2021) show that longer streaks of overreaction can generate hump-shaped dynamics in New Keynesian models.

${ }^{10}$ Greenwood and Hanson (2013) and Angeletos et al. (2020) model overreaction as inflating the persistence of an $\mathrm{AR}(1)$ process. In this case, after a piece of good news the agent on average stays over-optimistic forever. 
A second advantage of DE is that they discipline departures from rationality by a single parameter $\theta$ which has been estimated in settings ranging from financial analysts forecasting firm-level earnings (Bordalo et al., 2019), to professional forecasters predicting macroeconomic variables (Bordalo et al., 2020), to beliefs about interest rates inferred from prices (D'Arienzo, 2020), to stock price volatility (Pflueger et al., 2020). These estimates point to a value of $\theta$ between 0.5 and 1.5, providing a valuable external benchmark to discipline our quantitative exercise and assess its reliability.

\subsection{Diagnostic Expectations and Supply-Driven Bond Pricing: A Toy Model}

To see how diagnosticity infects the supply of capital, which plays a key role in our results, consider a stylized example. A firm seeks to roll over one-period defaultable bonds. Deeppocket risk-neutral lenders demand a constant expected return $R=1$. If the probability of

default perceived by lenders for next period is $\delta_{t}^{\theta}$, the interest rate is $\widehat{R}_{t}=\frac{1}{1-\delta_{t}^{\theta}}$, so the credit spread is:

$$
\widehat{R}_{t}-1 \equiv s_{t}=\frac{\delta_{t}^{\theta}}{1-\delta_{t}^{\theta}},
$$

which increases in the default risk $\delta_{t}^{\theta}$ perceived by lenders.

Suppose that the firm defaults at time $t$ if and only if its productivity is lower than a threshold, $A_{t}<A^{*}$. Then, the perceived probability of default is given by:

$$
\delta_{t}^{\theta}=\Phi\left[\frac{\ln A^{*}-\mathbb{E}_{t}^{\theta}\left(\ln A_{t+1}\right)}{\sigma}\right]
$$

where $\Phi(\cdot)$ is the standardized Gaussian CDF. Due to DE, perceived risk is too low after good news and too high after bad news.

Equation (5) has implications for the path of credit spreads. Substituting $\delta_{t}^{\theta}$ in (4) and linearizing with respect to $\mathbb{E}_{t}^{\theta}\left(\ln A_{t+1}\right)$ around its long run mean yields:

$$
s_{t} \approx s_{\infty}-s \mathbb{E}_{t}^{\theta}\left(\ln A_{t+1}\right)
$$

where $s_{\infty}>0$ is the long run spread and $s$ is a positive scalar. The spread falls when creditors are more optimistic about future productivity. Inserting (3) into (6) we obtain:

$$
s_{t} \approx s_{\infty}(1-\rho)+\rho s_{t-1}-s \rho(1+\theta) \varepsilon_{t}+s \theta \rho^{2} \varepsilon_{t-1} .
$$

Under RE, with $\theta=0$, spreads mirror TFP and follow an AR(1) process with persistence $\rho$. Under DE, with $\theta>0$, there are two differences. First, current TFP shocks are amplified,

This is not so under DE, which produce sharp reversals. Furthermore, DE offer a general formula that applies more parsimoniously (i.e. with fewer parameters) to any process not only AR(1)'s. 
as captured by the term $-s \rho(1+\theta) \varepsilon_{t}$. This is a source of excess volatility: after a positive TFP shock, beliefs become too optimistic and the spread declines too much. Second, there is reversal of past TFP shocks, as captured by the term $s \theta \rho^{2} \varepsilon_{t-1}$. This is a source of boom-bust dynamics: in the future, current optimism wanes and the spread increases. ${ }^{11}$

Due to the latter mechanism, DE generate predictable bond returns, which arise because the current spread $s_{t}$ can differ from its RE counterpart $s_{t}^{*}$. In particular, Equation (7) implies:

$$
s_{t}-s_{t}^{*} \approx-s \rho \theta \varepsilon_{t} .
$$

When current expectations are overly optimistic, $\theta \varepsilon_{t}>0$, bonds are overpriced. In the future, bond payouts are systematically disappointing, causing low returns. The converse holds when expectations are pessimistic.

In sum, DE account for: i) overoptimism in good times, and ii) excess shifts in the supply of capital and hence in spreads, which then revert. We now assess whether this mechanism can account for macro instability when the demand for credit can also overreact, when there are idiosyncratic and aggregate TFP shocks, and when wages flexibly adjust.

\section{$4 \quad$ RBC Model with Diagnostic Firms and Lenders}

A unit mass of firms with different and persistent productivities decides whether to default, hire labor, invest, issue equity, and borrow subject to capital adjustment costs. Credit is supplied by a continuum of risk-neutral lenders. The only difference relative to a workhorse neoclassical model with firm heterogeneity and risky debt (Khan and Thomas, 2008; Arellano et al., 2019; Gilchrist et al., 2014) is that firms and lenders form expectations diagnostically.

We start from a partial equilibrium analysis: we take the risk-free rate $R$ and the wage rate $W$ as given. In Section 7 we endogenize the wage. Doing so is useful because overoptimistic beliefs may boost labor demand and the real wage, which could dampen the cycle. We maintain the risk-free rate $R$ fixed to sharply distinguish our approach from the conventional mechanism of time-varying risk premia. This allows us to assess how far we can go by relaxing rational expectations only. In addition, while the DE model can be disciplined using expectations data, there is no external measurement of time-varying risk premia, and the predictions of rational time-varying risk premia models are inconsistent with measured expectations of returns (Greenwood and Shleifer, 2014): these models predict high risk premia and hence high expected returns in bad times, but the opposite is true in the data ${ }^{12}$

\footnotetext{
${ }^{11}$ Equation (7) shows that the spread reversals documented in Table 2 conflate fundamental mean reversion in TFP (the term $\rho s_{t-1}$ in (7)), and waning of past optimism (the term $s \theta \rho^{2} \varepsilon_{t-1}$ ). This is why controlling for past spreads $s_{t-1}$ in Table 2 helps single out belief-driven reversals.

${ }^{12}$ Consumption-based models also produce cyclical changes in the risk-free rate that are counterfactual relative to those observed in the data (Winberry, 2017; Cooper and Willis, 2015; Bachmann et al., 2013). Our use of quadratic adjustment costs, together with an estimation strategy detailed below linked to the
} 


\subsection{Firms}

Time is discrete. We use ${ }^{\prime}$ to denote future values and ${ }_{-1}$ to indicate lagged values. Uppercase letters refer to macro or common values, lowercase letters refer to idiosyncratic objects. The generic firm has micro-level TFP $z$ and is subject to macro level TFP $A$. It uses capital $k$ and labor $n$ as inputs to produce output according to a decreasing returns technology

$$
y=A z k^{\alpha} n^{\nu}, \quad \alpha+\nu<1
$$

Capital evolves based on investment $i$, which entails a one-period time to build

$$
k^{\prime}=i+(1-\delta) k, \quad 0<\delta<1 .
$$

Investment entails quadratic adjustment costs $A C(i, k)=\frac{\eta_{k}}{2}\left(\frac{i}{k}\right)^{2} k$, where $\eta_{k}>0$. The $\log$ of micro TFP follows the $\mathrm{AR}(1)$ process

$$
\log z^{\prime}=\rho_{z} \log z+\varepsilon_{z}^{\prime}, \quad \varepsilon_{z}^{\prime} \sim N\left(0, \sigma_{z}^{2}\right), \quad 0<\rho_{z}<1
$$

while the log of macro TFP follows

$$
\log A^{\prime}=\rho_{A} \log A+\varepsilon_{A}^{\prime}, \quad \varepsilon_{A}^{\prime} \sim N\left(0, \sigma_{A}^{2}\right), \quad 0<\rho_{A}<1
$$

Firms and lenders form diagnostic beliefs about a firm's future productivity. Given the $\mathrm{AR}(1)$ processes (9) and (10), and given Equation (2), diagnostic beliefs over micro and macro TFP are described by the lognormal processes:

$$
\begin{aligned}
\log z^{\prime} \mid\left(\log z, \varepsilon_{z}\right) & \sim N\left[\rho_{z}\left(\log z+\theta \varepsilon_{z}\right), \sigma_{z}^{2}\right] \\
\log A^{\prime} \mid\left(\log A, \varepsilon_{A}\right) & \sim N\left[\rho_{A}\left(\log A+\theta \varepsilon_{A}\right), \sigma_{A}^{2}\right] .
\end{aligned}
$$

When $\theta>0$ the agent forecasts future productivity by overweighting current news, as if the true productivity process follows an $\operatorname{ARMA}(1,1) \cdot{ }^{13} \theta>0$ is the only difference between our model and a workhorse heterogeneous firms macro-financial model of fluctuations.

Firms act competitively. In each period, the timing of events is as follows. First, each firm decides whether to default on its debt. If a firm defaults, its assets net of deadweight default costs are recovered by lenders, and the firm restarts with zero capital and debt after

observed covariance matrix of investment and profitability, results in realistically moderate elasticities of investment to price changes along the lines of those suggested by Koby and Wolf (2020).

${ }^{13}$ Another approach to capture extrapolation is Fuster et al. (2010)'s Natural Expectations, in which long lags in the data generating process are neglected by agents who end up overestimating short-term persistence in processes with long-term mean reversion. In the current AR(1) setting, such beliefs would be indistinguishable from RE. 
one period. If a firm repays, it also hires labor at wage $W$, chooses how much to invest, how much one-period debt to issue, and finally pays a dividend to its shareholders or issues equity. Firms maximize the expected discounted sum of current and future payouts, where the discount rate $(1+R)^{-1}<1$ reflects the risk-free rate $R$.

Consider the firm's problem, starting from the last stage. The firm's dividend $d$ is given by the standard formula

$$
d=(1-\tau)[y-W n-A C(i, k)-\phi]+q^{\theta}\left(s, k^{\prime}, b^{\prime}\right) b^{\prime}-i-b+\tau(R+\delta k),
$$

which includes profits, given by the firm's output minus the wage bill, the adjustment cost, and a fixed production cost $\phi>0$, net of the corporate income tax rate $\tau \in(0,1)$. It also includes the resources raised by issuing new debt $b^{\prime}$ priced by the schedule $q^{\theta}$, minus the investment cost $i$ and debt repayment $b$. Finally, it includes the tax rebates for capital depreciation and interest expenses on debt. ${ }^{14}$

If dividends are negative, $d<0$, the firm issues equity. Following Gomes (2001), this entails a cost $I C(d)=I(d<0)\left(\eta_{f}+\eta_{d}|d|\right)$, where $\eta_{f}>0$ is the fixed and $\eta_{d}>0$ is the variable cost of issuance.

The firm makes its other decisions considering four state variables: its current micro TFP $z$, macro TFP $A$, the micro shock $\varepsilon_{z}$ and the macro shock $\varepsilon_{A}$. The exogenous news states are relevant for forming diagnostic expectations, and we collect all of the firm's exogenous states in the vector $s=\left(z, \varepsilon_{z}, A, \varepsilon_{A}\right)$. A firm is also identified by two endogenous states, its inherited capital stock $k$ and debt $b$. Given an overall state $(s, k, b)$, the firm's problem can be written recursively. Upon entering the current period, the value of the firm is given by:

$$
V^{\theta}(s, k, b)=\max \left[V_{D}^{\theta}(s), V_{N D}^{\theta}(s, k, b)\right],
$$

where $V_{N D}^{\theta}(s, k, b)$ is the continuation value from not defaulting and $V_{D}^{\theta}(s)$ the continuation from defaulting. Condition $V_{N D}^{\theta}(s, k, b)<V_{D}^{\theta}(s)$ identifies states in which the firm optimally defaults. The continuation value from not defaulting is recursively determined as:

$$
V_{N D}^{\theta}(s, k, b)=\max _{k^{\prime}, b^{\prime}, n}\left\{d-I C(d)+\frac{1}{1+R} \mathbb{E}^{\theta}\left[V^{\theta}\left(s^{\prime}, k^{\prime}, b^{\prime}\right) \mid s\right]\right\} .
$$

If the firm does not default, it hires labor $n$, sets future capital $k^{\prime}$ and debt $b^{\prime}$ to maximize its current dividend plus its diagnostically expected discounted future value $V^{\theta}\left(s^{\prime}, k^{\prime}, b^{\prime}\right) .{ }^{15}$

\footnotetext{
${ }^{14}$ For computational simplicity, we assume the rebate is on average equal to the risk-free rate $R$.

${ }^{15}$ We apply DE to the recursive formulation of the problem, Equation (15). The diagnostic agent believes that productivity follows an $\operatorname{ARMA}(1,1)$ and correctly thinks that they will continue to believe the same in the future. The recursive problem is equivalent to an optimal control problem in which the probability distribution of $A_{t+s}$ at time $t$ is the product $\Pi_{j=1}^{s} f^{\theta}\left(A_{t+j} \mid A_{t+j-1}, \varepsilon_{A, t+j-1}\right)$ of the conditional distributions between times $t$ and $t+s-1$. This distribution has the same mean as the time $t$ diagnostic distribution
} 
The labor choice $n$ is statically optimized, leaving only the intertemporal choices of $k^{\prime}$ and $b^{\prime}$.

If the firm defaults, its assets $k$ net of deadweight costs are claimed by lenders during a period of reorganization in which no production occurs. The firm then restarts with zero debt and assets:

$$
V_{D}^{\theta}(s)=\left\{0+\frac{1}{1+R} \mathbb{E}^{\theta}\left[V\left(s^{\prime}, 0,0\right) \mid s\right]\right\}
$$

After defaulting, a firm must borrow in order to invest. Equations (14), (15), and (16) determine both the optimal firm default policy by $d f^{\theta}(s, k, b)$ and, for those firms which choose not to default with $d f^{\theta}(s, k, b)=0$, the policies for endogenous states $k^{\prime \theta}(s, k, b)$ and $b^{\prime \theta}(s, k, b)$.

\subsection{Lenders}

Firms borrow from risk-neutral deep-pocket lenders who require an expected return equal to the risk-free rate $R$. If a firm $(s, k, b)$ defaults on its debt $b$, the lender receives the recovery rate

$$
\mathcal{R}(k, b)=(1-\tau) \gamma \frac{(1-\delta) k}{b}
$$

which reflects, net of tax, an exogenous fraction $\gamma$ of the liquidation value $(1-\delta) k$ of the firm's capital stock. The remaining fraction $1-\gamma$ is a deadweight loss.

The price of debt $q^{\theta}\left(s, k^{\prime}, b^{\prime}\right)$ adjusts endogenously so that the diagnostically expected bond return is equal to the risk free rate $R$ :

$$
q^{\theta}\left(s, k^{\prime}, b^{\prime}\right)=\frac{1}{1+R} \mathbb{E}^{\theta}\left[1+d f^{\theta}\left(s^{\prime}, k^{\prime}, b^{\prime}\right)\left(\mathcal{R}\left(k^{\prime}, b^{\prime}\right)-1\right) \mid s\right] .
$$

To equalize expected bond returns across firms, riskier firms promise a higher interest rate. ${ }^{16}$ Thus, the firm's interest rate spread relative to the risk-free rate is given by:

$$
S^{\theta}\left(s, k^{\prime}, b^{\prime}\right)=\frac{1}{q^{\theta}\left(s, k^{\prime}, b^{\prime}\right)}-(1+R)
$$

These equations illustrate how diagnosticity affects spreads. On the demand side, diagnosticity affects the firm's default $d f^{\theta}(s, k, b)$, debt $b^{\prime \theta}(s, k, b)$, and investment $k^{\prime \theta}(s, k, b)$ policies. On the supply side, diagnosticity affects the probability of default perceived by lenders, as captured by the operator $\mathbb{E}^{\theta}(\cdot)$ in (17). The interaction between demand and supply plays a key role in producing macroeconomic fluctuations.

\footnotetext{
$f^{\theta}\left(A_{t+s} \mid A_{t}, \epsilon_{A t}\right)$ but has larger variance. This is due to overreaction to news (which are zero on average) in the intermediate periods.

${ }^{16}$ The realized firm bond return is given by $R^{f i r m}\left(s, s^{\prime}, k^{\prime}, b^{\prime}\right)=\frac{1+d f^{\theta}\left(s^{\prime}, k^{\prime}, b^{\prime}\right)\left(\mathcal{R}\left(k^{\prime}, b^{\prime}\right)-1\right)}{q^{\theta}\left(s, k^{\prime}, b^{\prime}\right)}$.
} 


\subsection{Solving the Model}

A partial equilibrium of our model is a collection of i) firm policies ${b^{\prime}}^{\theta}, k^{\prime \theta}$, and $d f^{\theta}$, ii) firm values $V_{N D}^{\theta}, V_{D}^{\theta}$, and $V^{\theta}$, and iii) a lender debt price schedule $q^{\theta}$ such that iv) taking as given lender debt prices $q^{\theta}$, firm policies and values satisfy Equations (14), (15), and (16), v) taking as given firm policies, lender debt prices satisfy the zero-profit condition in Equation (17), and vi) expectations in the firm and lender problems $\mathbb{E}^{\theta}$ reflect the dynamics in Equations (11) and (12).

We solve the model numerically. In addition to the set of Bellman equations for $V^{\theta}, V_{N D}^{\theta}$, and $V_{D}^{\theta}$, the model features an equilibrium fixed point between firm default policies $d f^{\theta}$ and credit prices $q^{\theta}$ in Equation (17). We employ an iterative approach detailed in Appendix A. First, we guess a firm default rule $d f^{\theta}$, computing the implied debt price schedule $q^{\theta}$ according to the lenders' zero-profit condition. Then, we solve the Bellman equations for $V^{\theta}, V_{D}^{\theta}$, and $V_{N D}^{\theta}$ using discretization and policy iteration. If the implied default states, i.e., those with $V_{N D}^{\theta}<V_{D}^{\theta}$, match the set of initial guesses, then the iteration is complete. Otherwise, we compute the newly implied default states and repeat the process. The algorithm we employ is standard within the literature solving quantitative dynamic corporate finance models and follows the implementation in Strebulaev and Whited (2012). ${ }^{17}$

Effectively, DE create a wedge between the value functions of two firms reaching the same current productivity via different news: the firm experiencing good recent news displays overoptimism and hence an inflated continuation value relative to a firm experiencing bad recent news (see Appendix Figure A.1). As we will see this effect on the firm or demand side for credit creates, combined with diagnostic shifts in the supply of capital by lenders, substantial aggregate effects.

\section{Estimating the Model \& Inspecting the Mechanism}

\subsection{Estimation}

Our model has sixteen parameters, listed in Tables 3 and 4. The six parameters in Table 3 are set to conventional values for a model like ours.

We then structurally estimate the remaining ten parameters by matching a set of micro and macro moments. Parameters $\rho_{z}$ and $\sigma_{z}$ govern the micro-level TFP process, $\eta_{k}$ and $\phi$ the adjustment and operating costs, $\gamma$ the lenders' recovery rate, $\sigma_{A}$ macro volatility, $\eta_{f}$ and $\eta_{d}$ the equity issuance costs. $\theta$ is the key diagnosticity parameter. We also allow for

\footnotetext{
${ }^{17}$ Our numerical approach here is highly computationally intensive, given the presence of four exogenous states, two endogenous states, an endogenous default rule, and a debt-pricing fixed point. However, judicious application of parallelization and an economical approach to storage of micro-level outcomes following Young (2010) and Terry (2017a) allow for solution of the model in several minutes on a desktop computer.
} 


\section{Table 3: Externally Fixed Parameters}

\begin{tabular}{cclcl}
\hline \hline & Parameter & Role & Value & Source \\
\hline 1 & $\delta$ & Depreciation rate & 0.100 & Annual Solution \\
2 & $R$ & Risk-free rate & 0.04 & Annual Solution \\
3 & $\alpha$ & Capital elasticity & 0.25 & Bloom et al. (2018) \\
4 & $\nu$ & Labor elasticity & 0.5 & Bloom et al. (2018) \\
5 & $\rho_{A}$ & Macro TFP autocorrelation & 0.95 & Bloom et al. (2018) \\
6 & $\tau$ & Corporate income tax & 0.200 & Effective rates, CBO (2017) \\
\hline \hline
\end{tabular}

Notes: The table reports the parameter symbol, numerical value, a description, and source information for each of the externally fixed parameters. Outside of the unit-free persistence or normalized parameters, all reported values are in proportional units, e.g. $0.01=1 \%$.

and estimate the volatility $\sigma_{\pi}$ of iid measurement noise in profits, which captures spurious variability in measured profits due to accounting conventions.

We structurally estimate these ten parameters through a simulated method of moments (SMM) procedure targeting sixteen moments. We target three macro moments: the average credit spread, the average frequency of default, and GDP growth volatility. Mean default and spreads encode information about the fixed cost $\phi$ and recovery rate $\gamma$, GDP growth volatility is informative about macro shocks $\sigma_{A}$.

The remaining thirteen moments are at the firm level. Ten moments are given by the variance-covariance matrix of current profits, investment rates, spreads, and debt issuance. Profits and their correlations yield information about firm-level productivity and noise, helping to identify $\sigma_{z}, \rho_{z}$, and $\sigma_{\pi}$. Firm investment also reflects adjustment costs, helping to identify $\eta_{k}$. Debt issuance, together with credit spreads, aid in the identification of equity issuance costs $\eta_{f}$ and $\eta_{d}$.

Three additional moments use data on forecast errors. The use of such data is the key innovation in our estimation, directly disciplining the degree of overreaction $\theta$. One moment is the standard deviation of forecast errors. The other two moments are the correlation of the change in future forecast errors with current changes in the investment rate and debt issuance. As discussed in Section 2, moments based on within-firm changes allow for systematic heterogeneity across firms. Suppose that investment $i_{t}$, debt issuance $b_{t}^{\prime}$ and profits $\pi_{t}$ are linearly increasing in expected log TFP, with positive slope coefficients respectively given by $a_{i}, a_{b}$, and $a_{\pi}$. Then, using Equation (3) the covariance between the future change in forecast errors and the current change in investment and debt is given by:

$$
\operatorname{cov}\left[\left(\pi_{t+2}-E_{t+1}^{\theta} \pi_{t+2}\right)-\left(\pi_{t+1}-E_{t}^{\theta} \pi_{t+1}\right), x_{t}-x_{t-1}\right]=a_{\pi} a_{x} \rho \theta(1+\theta), \quad x=i, b .
$$

Equation (18) is positive if and only if expectations are diagnostic, $\theta>0$. If beliefs overreact, 


\section{Table 4: Parameter Estimates}

\begin{tabular}{cclcc}
\hline \hline & Parameter & Role & DE Model & RE Model \\
\hline 1 & $\theta$ & Diagnosticity & $0.991(0.074)$ & - \\
2 & $\rho_{z}$ & Micro TFP autocorrelation & $0.785(0.004)$ & $0.920(0.001)$ \\
3 & $\sigma_{z}$ & Micro TFP volatility & $0.111(0.010)$ & $0.107(0.015)$ \\
4 & $\eta_{k}$ & Capital adjustment cost & $3.627(0.261)$ & $3.804(0.695)$ \\
5 & $\phi$ & Fixed operating cost & $0.131(0.007)$ & $0.078(0.009)$ \\
6 & $\gamma$ & Recovery rate & $0.250(0.057)$ & $0.125(0.237)$ \\
7 & $\sigma_{A}$ & Macro TFP volatility & $0.006(0.000)$ & $0.009(0.002)$ \\
8 & $\eta_{f}$ & Equity fixed cost & $0.022(0.069)$ & $0.077(0.173)$ \\
9 & $\eta_{d}$ & Equity linear cost & $0.094(0.018)$ & $0.064(0.045)$ \\
10 & $\sigma_{\pi}$ & Earnings noise & $0.761(0.067)$ & $0.352(0.042)$ \\
\hline \hline
\end{tabular}

Notes: The table reports point estimates and standard errors for each of the parameters in our SMM estimation of both the DE model and the RE model. The moment covariance matrix is based on firm-level clustering in the micro block and a stationary block bootstrap in the macro block. The moment Jacobian is computed numerically. In the SMM estimation, the weighting matrix is optimal, i.e., the inverse of the moment covariance matrix.

good news leads to systematic disappointment next period, but no disappointment two periods from now, causing forecast errors to grow between $t+1$ and $t+2 .{ }^{18}$ The RE model is instead unable - because of its more general failure to generate forecast error predictability - to generate any comovement between future forecast error growth and investment or debt changes of the firm.

Table 5 reports the moments we target in the Data column. We obtain these moments using our combined datasets with firm financials, earnings forecasts, and credit spreads described in Section 2. Just as in Section 2 we focus on idiosyncratic variation, residualizing the underlying investment, debt, and spread series with respect to firm and time effects. As seen in Section 2, the micro data shows overreaction, as reflected in the positive forecast error growth covariances.

To estimate the model parameters, we minimize the deviation of the empirical moments in Table 5 from those computed in a comparable unconditional simulation of the model. We weight the moments optimally using the inverse of our estimate of the moment covariance matrix, implying an asymptotically efficient SMM estimator. See Appendix B for a more detailed description of the variable definitions, sample construction, and our approach to computing the SMM point estimates and standard errors. Given our use of ten parameters

\footnotetext{
${ }^{18}$ Appendix B offers a detailed analysis of this property and further derivations of moment conditions in closed form in the linear case discussed above. Note that while our quantitative model is clearly nonlinear, and the formula in Equation (18) is therefore approximate, the intuition still holds in the more general model and proves useful for identification of the parameter $\theta$. In particular, the covariance moments grow with the value of $\theta$ in our DE simulations.
} 
to target sixteen moments, we note at the outset that this is a highly overidentified structural estimation of a nonlinear model. We can exploit a great deal of information but are not in general able to deliver an exact fit.

\section{Table 5: Estimated Model Fit}

\begin{tabular}{|c|c|c|c|c|}
\hline & Moment & Data & DE Model & RE Model \\
\hline \multicolumn{5}{|c|}{ Panel A: Micro Moments } \\
\hline 1 & 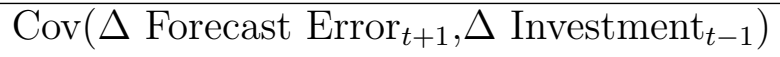 & 0.003 & 0.002 & 0.000 \\
\hline 2 & 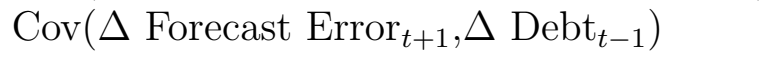 & 0.001 & 0.004 & 0.000 \\
\hline 3 & 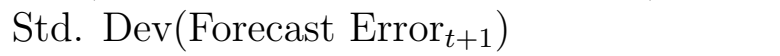 & 0.304 & 0.266 & 0.224 \\
\hline 4 & Std. Dev $\left(\right.$ Profit $\left._{t}\right)$ & 0.262 & 0.263 & 0.225 \\
\hline 5 & 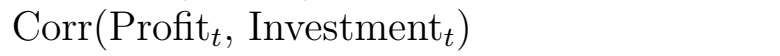 & 0.257 & 0.114 & 0.090 \\
\hline 6 & $\operatorname{Corr}\left(\right.$ Profit $_{t}$, Debt $\left._{t}\right)$ & 0.111 & 0.129 & 0.114 \\
\hline 7 & 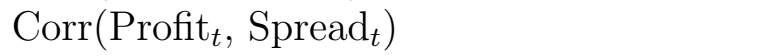 & -0.159 & -0.024 & 0.087 \\
\hline 8 & Std. Dev( Investment $\left._{t}\right)$ & 0.067 & 0.052 & 0.035 \\
\hline 9 & Corr $\left(\right.$ Investment $_{t}$, Debt $\left._{t}\right)$ & 0.183 & 0.739 & 0.489 \\
\hline & $\operatorname{Corr}\left(\operatorname{Investment}_{t}, \operatorname{Spread}_{t}\right)$ & -0.057 & -0.054 & 0.083 \\
\hline & Std. Dev $\left(\right.$ Debt $\left._{t}\right)$ & 0.056 & 0.134 & 0.066 \\
\hline & $\operatorname{Corr}\left(\right.$ Debt $\left._{t}, \operatorname{Spread}_{t}\right)$ & 0.015 & 0.061 & 0.003 \\
\hline & Std. Dev $\left(\operatorname{Spread}_{t}\right)$ & 0.011 & 0.013 & 0.006 \\
\hline \multicolumn{5}{|c|}{ Panel B: Macro Moments } \\
\hline & $\mathbb{E}\left(\right.$ Spread $\left._{t}\right)$ & 0.029 & 0.028 & 0.030 \\
\hline & $\mathbb{E}\left(\right.$ Default $\left._{t}\right)$ & 0.003 & 0.006 & 0.005 \\
\hline & $\operatorname{Std} . \operatorname{Dev}\left(\Delta \mathrm{GDP}_{t}\right)$ & 0.015 & 0.012 & 0.017 \\
\hline
\end{tabular}

Notes: The moments were computed on a sample combining information from the Compustat, IBES Manager Guidance, and FISD/Trace Bond databases from 2002-2017, with 4,697 firm-years spanning 493 firms. For the micro moments, the forecast error, profit, investment, and debt issuance series are expressed relative to firm tangible capital stocks, while the spread is in proportional units. For the macro moments, the mean spread is the average across years of the mean spread across firms in the FISD/Trace Bond-Compustat merged database, mean default is the average across years of the mean default rate across firms in the FISD/Trace-Compustat merged database. The GDP series in annual GDP in chained 2012 dollars.

Table 4 reports the SMM point estimates and standard errors for our DE model. The diagnosticity parameter $\theta \approx 1$ is in the ballpark of the values found by Bordalo et al. (2018) using data on professional forecasts of credit spreads $(\theta=0.9)$, by Bordalo et al. (2019) using analyst expectations of US listed firms' long-term earnings growth $(\theta=0.9)$, by Pflueger et al. (2020) using stock price-derived measures of risk perception $(\theta=1)$, by D'Arienzo (2020) using bond prices $(\theta=1)$, and by Bordalo et al. (2020) using professional forecasts of several macro series $(\theta=0.5)$. A value of $\theta$ close to 1 means that forecast errors are roughly equal to the size of incoming news.

The estimated values governing physical factors such as micro TFP volatility $\sigma_{z}$ and capital adjustment costs $\eta_{k}$ are close to those from other work estimating firm-level shock 
processes with similar data (Gourio and Rudanko, 2014; Terry, 2017b; Khan and Thomas, 2008; Saporta-Eksten and Terry, 2018). The parameters governing financial frictions indicate equity issuance costs $\eta_{f}, \eta_{d}$ and recovery rates $\gamma$ comparable to those in Hennessy and Whited (2007). The fixed operating costs $\phi$ in model units is linked to average default rates and spreads. Finally, the estimated measurement error in profits $\sigma_{\pi}$ suggests that a high degree of noise in accounting conventions is needed to match the covariance of profits and other firm-level outcomes.

Using the same micro and macro moments, we also conduct a constrained SMM structural estimation exercise to estimate the nine parameters of a $\mathrm{RE}$ model in which we set $\theta=0$, eliminating diagnosticity in beliefs. By comparing the performance of this estimated RE model and the estimated DE model, we can isolate the role of overreacting beliefs. The SMM point estimates and standard errors for the parameters of the RE model are also reported in Table 4. Comparing parameter estimates, in the DE model we estimate a substantially lower persistence $\rho_{z}$ of micro TFP shocks, and a lower volatility $\sigma_{A}$ of aggregate TFP compared to the RE model. After good news, the DE manager becomes overoptimistic about the future, which boosts investment "as if" the current shocks were more persistent. DE is also a source of "shocks," which reduces the estimated $\sigma_{A}$ : when optimism wanes, investment is cut "as if" a negative shock hit. In addition, DE also inflates perceived volatility. Because production function-based payoffs are convex, this implies that a firm's average incentive to default are also lower. To match the observed default frequency, the DE model estimates a higher fixed operating cost $\phi$.

Table 5 reports fit with simulated moment values for both the estimated DE and RE models. The DE model offers an excellent match of the micro moments, especially considering its strong nonlinearity and the overidentified SMM estimation. It accounts for the predictability of forecast error growth and for the negative correlation of investment and profits with the spread. The RE version fails to do so. Under RE, managers and lenders do not become overoptimistic after good news, and their forecast errors are unpredictable. Furthermore, lenders do not become very willing to lend after good news, causing the spread to rise in good times at odds with countercyclical spreads. We return to this point later. The DE model also produces a realistically higher correlation between investment and profits than the RE model, again due to overoptimism in good times. The main discrepancy of the DE model with the data is that the former produces a counterfactually high correlation between debt and investment. We speculate that an extended version of our model allowing for empirically realistic costs of debt financing, such as restrictive contractual covenants, would moderate debt movements and further improve the DE model's fit.

These differences between the DE and RE models prove critical to account for boom-bust cycles, both at the aggregate and firm levels. To see this, we next examine the qualitative mechanisms of the estimated DE model, with particular emphasis on nonlinearities in the 


\section{Figure 1: Investment Response to a Negative TFP Shock}
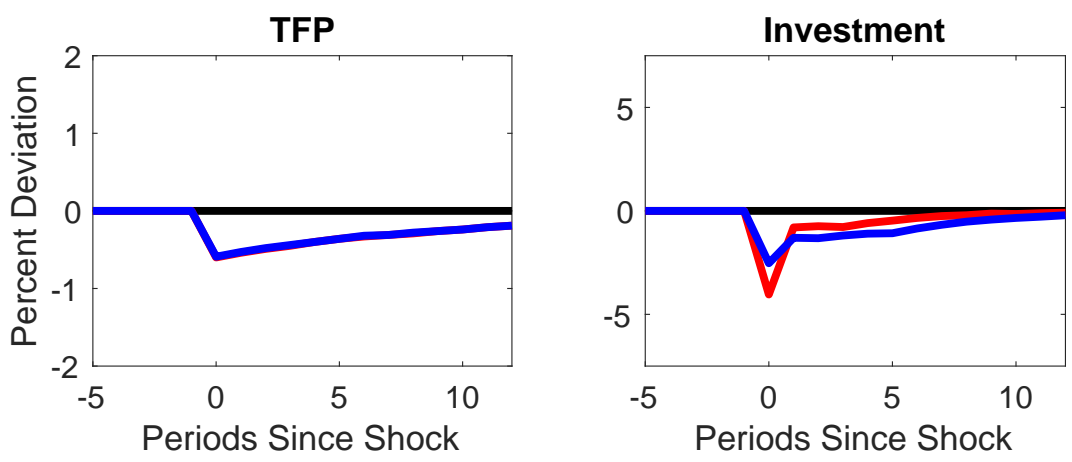

Notes: The figure plots the simulated generalized impulse responses of investment (right panel) to a onestandard deviation negative shock to macro TFP (left panel) occurring at period 0. The DE model (red) and RE model (blue) paths are based on identical shocks to TFP over 10,000 simulated experiments following the Koop et al. (1996) methodology.

macro investment response to a TFP shock.

\subsection{Model Mechanisms}

\subsubsection{Nonlinearity in the Investment Response to TFP shocks}

To study the real implications of DE, we simulate the contemporaneous response of macro investment to a negative macro TFP shock. We compute this response for different initial conditions, captured by TFP shocks of varying magnitudes in the previous period. This exercise highlights one important consequence of DE: fragility after good times. This nonlinearity is critical in our framework to account for boom-bust credit cycles.

Figure 1 plots the average impulse response of investment to a negative shock to macro TFP in both the DE model (red line) and RE model (blue line). ${ }^{19}$ These responses reflect "typical times," based on simulated reactions to negative TFP shocks across 10,000 experiments following the methodology of Koop et al. (1996). In normal times, the investment responses to TFP shocks differ only slightly across the DE and RE models. As usual in RBC models, a negative shock to TFP causes a large decline in investment. There is some amplification of the DE model relative to the RE model, but the paths are otherwise fairly similar.

We next simulate the impact of the same negative shock to macro TFP varying the initial conditions. Figure 2 reports the investment response in the DE model (vertical axis,

\footnotetext{
${ }^{19}$ The shock is identically sized in the two experiments as a one standard deviation shock to macro TFP using the parameter estimate $\hat{\sigma}_{A}$ from the DE model.
} 


\section{Figure 2: Investment Nonlinearity}

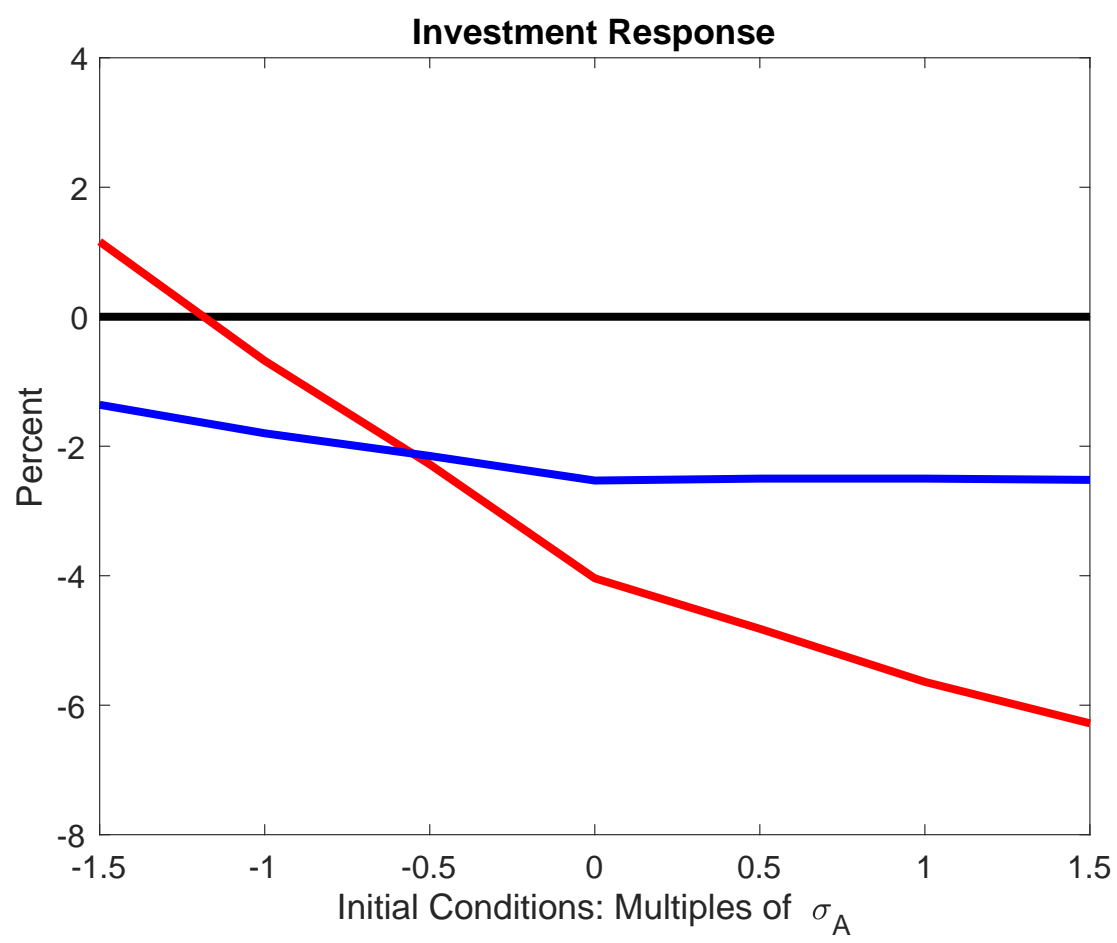

Notes: The vertical axis in the figure reports the simulated impulse response of macro investment to a one-standard deviation negative shock to macro TFP, and the horizontal axis reports the initial conditions, i.e., the magnitude of the shock to macro TFP in the previous period. Both the DE model (red line) and $\mathrm{RE}$ model (blue line) are reported on the figure.

red line) as a function of the magnitude of the previous period's macro TFP shock (horizontal axis). There is a strong nonlinearity taking the form of "fragility in good times:" the same adverse TFP shock is much more damaging for aggregate investment when it occurs in good times. Figure 2 adds to the same diagram the response of investment in the RE model (blue line). The latter is almost the same across different initial conditions, with little nonlinearity or excess fragility in good times. Recent work on investment dynamics over the business cycle (Bachmann et al., 2013; Winberry, 2017; Bloom et al., 2018) suggests that investment exhibits more sensitivity to shocks during booms than during normal times. Figure 2 shows that overreacting beliefs may play a key role in producing this feature.

The investment response in Figure 2 combines two forces: the demand for capital reflecting managers' expectations of future profits, and the supply of capital reflecting lenders' expectations of default. In good times, diagnostic managers are overly optimistic, so they borrow and invest more than under RE. Diagnostic lenders are also overly optimistic, and hence are more willing to lend than under RE. Under DE, then, both the demand and the supply of credit overreact in good times, which causes a leverage and investment boom. 
When a negative shock hits, managers and lenders become too pessimistic, both the demand and the supply of credit contract, and firms drastically cut investment. ${ }^{20}$ The effect is drastic because, starting from a position of overoptimism, firms are overindebted to begin with. ${ }^{21}$

One question arising here is whether credit supply vs credit demand play a larger role in creating real fragility after good times under DE. We therefore consider a version of the model in which lenders are rational with $\theta=0$, while allowing for $\theta$ to be unconstrained for firms. Reestimating the model for this special case, with parameter estimates in Appendix Table A.3, we simulate a set of "rational pricing" responses of investment to a negative TFP shock comparable to those in Figure 2. Qualitatively, the response of investment displays the nonlinearity typical of the DE model. Quantitatively, though, shutting down the overreaction of credit supply sharply reduces the magnitude of the effect as displayed in Appendix Figure A.2. We conclude that under DE shifts in the supply of credit play an important role in creating fragility during booms, a pattern which is also evident in the next exercise.

\subsubsection{Financial Shocks}

A second related implication is that DE can produce "financial shocks," namely strong macro-financial reversals in the absence of large negative TFP shocks. We simulate the model unconditionally for 250,000 periods and consider large financial reversals, defined as periods in which spread growth is in the top $5 \%$ of the distribution and credit growth is in the bottom $5 \%$. We extract the average dynamics of TFP, leverage, investment and spreads around these episodes (labelled as period " 0 ") for both the DE and the RE model and report them in Figure 3.

Consistent with existing evidence, in the DE model (red lines) reversals arise after a strong expansion in leverage (top right panel) which is instead mild under RE (blue lines). Critically, in the DE model a financial reversal arises in good times when TFP stops growing, while in the RE model reversals arise with a large negative TFP shock (top left panel). That is, the DE model produces a pure "financial shock," namely a reversal due to the sudden waning of overoptimism in a boom. The role of credit supply shifts is critical here. Leverage expands because in the boom overoptimistic lenders keep the cost of borrowing low (bottom right panel). In the DE model, when overoptimism wanes the contraction in credit supply is very sharp, which causes strong boom-bust cycles in financial and real outcomes such as investment (bottom left panel).

\footnotetext{
${ }^{20}$ Interestingly, state-dependence in Figure 2 also generates a positive response during bad times under DE, when even a moderate negative shock to TFP can be considered "good news" relative to overpessimistic beliefs. Under RE, the response curve is uniformly negative.

${ }^{21}$ One can decompose the DE nonlinearity in Figure 2 into contributions from direct belief reversals versus endogenous increases in the riskiness of overoptimistic firms' states $k$ and $b$. Appendix Figure A.3 reveals that both channels play a meaningful quantitative role.
} 


\section{Figure 3: Financial Disruptions on Average}
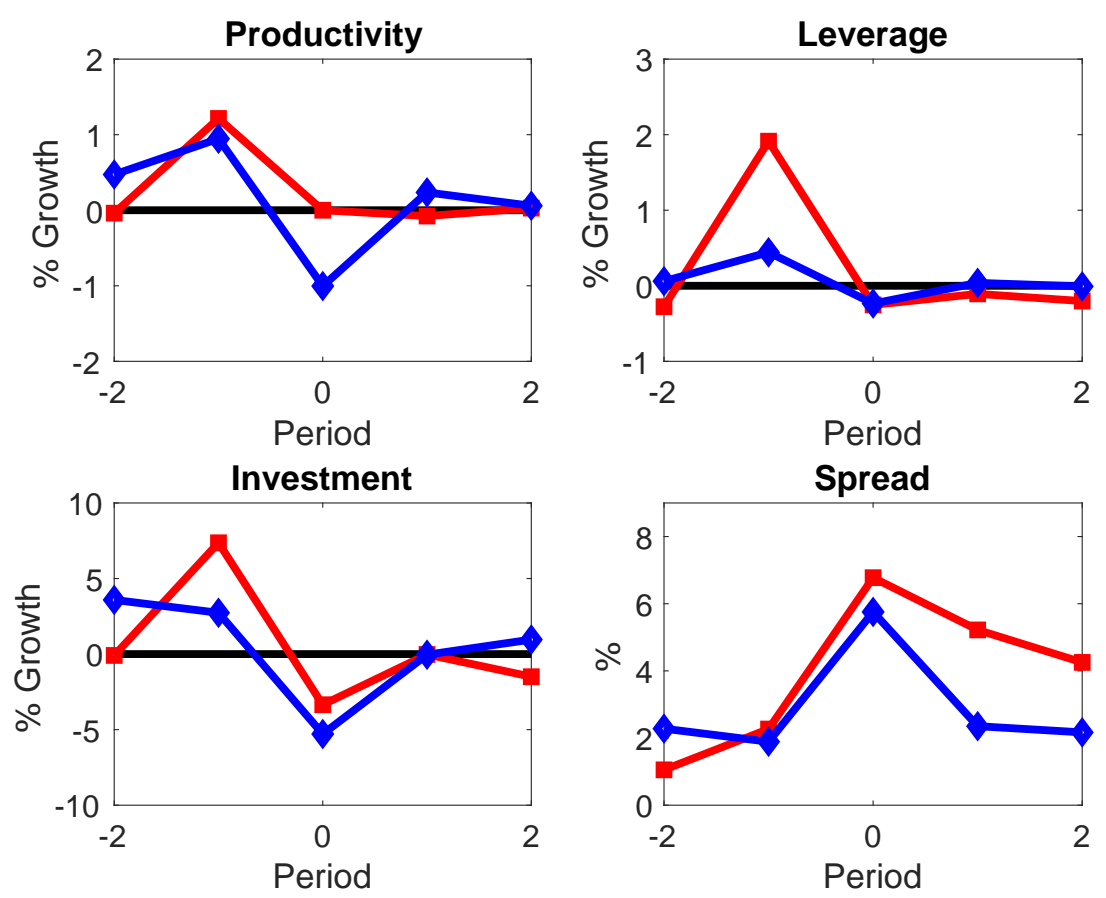

Notes: The figure plots the average path of macro TFP growth $\Delta A$ (top left), macro leverage growth $\Delta \frac{B^{\prime}}{K}$ (top right), macro investment growth $\Delta I$ (bottom left), and the macro spread level $\mathbb{E}$ Spread (bottom right) around periods of financial disruption from an unconditional simulation of the DE model (red line) versus the RE model (blue line). A financial disruption, dated at period $t$ on the horizontal axis, is a period with spread growth in the top 5\% and credit growth in the bottom $5 \%$ of realizations in the simulated data for each model.

\section{Quantitative Implications}

We now simulate the model and examine its ability to quantitatively match three sets of untargeted facts: i) traditional macro correlations, ii) the boom-bust dynamics of beliefs, spreads, and investment documented in Section 2, and iii) the movements of credit spreads and aggregate quantities around the financial crisis of 2008.

\subsection{Business Cycle Moments}

Consider the ability of our model to reproduce macro business cycle correlations, which are entirely untargeted in our calibration procedure. Table 6 reports the annual business cycle correlations and volatilities of output, debt, investment, and average credit spreads in the empirical data (top panel), simulated data from the DE model (middle panel), and simulated data from the RE model (bottom panel). The DE and RE model moments are computed based on an identical set of exogenous shocks. 


\section{Table 6: Business Cycle Moments}

\begin{tabular}{|c|c|c|c|c|c|}
\hline Correlation: & Output & Debt & Investment & Spread & (Standard Deviation) \\
\hline \multicolumn{6}{|c|}{ Panel A: Data } \\
\hline Output & 1.000 & 0.891 & 0.803 & -0.105 & $(0.017)$ \\
\hline Debt & & 1.000 & 0.755 & -0.169 & $(0.048)$ \\
\hline Investment & & & 1.000 & -0.107 & $(0.053)$ \\
\hline Spread & & & & 1.000 & $(0.010)$ \\
\hline \multicolumn{6}{|c|}{ Panel B: DE Model } \\
\hline Output & 1.000 & 0.820 & 0.505 & -0.011 & $(0.012)$ \\
\hline Debt & & 1.000 & 0.628 & 0.058 & $(0.007)$ \\
\hline Investment & & & 1.000 & 0.345 & $(0.036)$ \\
\hline Spread & & & & 1.000 & $(0.019)$ \\
\hline \multicolumn{6}{|c|}{ Panel C: RE Model } \\
\hline Output & 1.000 & 0.632 & 0.559 & 0.003 & $(0.016)$ \\
\hline Debt & & 1.000 & 0.485 & 0.077 & $(0.007)$ \\
\hline Investment & & & 1.000 & 0.144 & $(0.042)$ \\
\hline Spread & & & & 1.000 & $(0.009)$ \\
\hline
\end{tabular}

Notes: The table reports business cycle correlations (left) and standard deviations (right) from the data (top panel), the diagnostic expectations model (middle panel), and the rational expectations model (bottom panel). The empirical sample is 2003-18 at annual frequency. Real GDP and private nonresidential fixed investment are from the US NIPA accounts. Total credit to US non-financial corporations is from the BIS. The BAA-Treasury spread is based on Moody's ratings. The model moments are computed from an unconditional simulation of 250 years. Model quantities refer to total values (output, debt, and investment) or average values (spread) computed from the distribution of firms. Output, debt, and investment are HP-filtered in logs with smoothing parameter 100.

The DE model does a good job at capturing: i) the positive covariance between aggregate output and debt, ii) the positive covariance between investment and debt, and crucially iii) the negative covariance of spreads with output. It also offers a good account of the standard deviation of macro output and investment. The RE model makes the counterfactual prediction of procyclical credit spreads and also produces insufficient comovement of debt with output and investment.

The DE model can produce procyclical variation in debt but countercyclical variation in spreads because in good times overoptimistic investors are willing to expand lending at low interest rates. Such strong supply shifts do not occur in the RE model. The DE model fails to capture the negative correlation of spreads with investment and debt, and the high volatility of debt. We speculate that a version of DE allowing for more persistent overreaction, as in Bordalo et al. (2019) and in Bianchi et al. (2021), might help address these issues by allowing for even stronger shifts in the supply of credit. ${ }^{22}$

\footnotetext{
${ }^{22}$ The failure of RE to generate meaningful aggregate volatility is even further exaggerated when comparing the estimated DE model to a counterfactual rational expectations model in which we set $\theta=0$ but otherwise
} 


\subsection{Boom-Bust Cycles in Financial and Real Activity}

We now assess the explanatory power of the model for the firm-level boom-bust cycles documented in Section 2 but also address its ability to account for aggregate (i.e., sectorlevel) cycles.

Consider firm-level cycles first. We simulate the DE and RE models for many periods and then use the simulated data to re-estimate the two-stage regressions of Table 2 in Section 2. In the first stage, we regress future profit forecast errors on current investment. In the second stage, we use these fitted errors as an explanatory variable for future bond returns, spread growth, and investment growth. Table 7 reports the results. In line with the estimates of Table 2, in the DE model high investment predicts future negative forecast errors in column (2), indicating that expectations are overly optimistic in good times. Unsurprisingly, the RE model fails completely in column (1) to reproduce this first stage due to belief rationality.

Table 7: Linking Forecast Errors and Micro Reversals in the Model

\begin{tabular}{lccccc}
\hline \hline & $(1)$ & $(2)$ & $(3)$ & $(4)$ & $(5)$ \\
& Fcst. Error $_{t+1}$ & Fcst. Error $_{t+1}$ & Return $_{t+1}$ & $\Delta$ Spread $_{t+1}$ & $\Delta$ Investment $_{t+1}$ \\
IV Stage: & First & First & Second & Second & Second \\
Simulated Model: & RE & DE & DE & DE & DE \\
\hline Forecast Error & & & $0.070^{* * *}$ & $-2.314^{* * *}$ & $1.575^{* * *}$ \\
& & & $(0.008)$ & $(0.209)$ & $(0.011)$ \\
Investment $_{t}$ & 0.005 & $-0.515^{* * *}$ & & & \\
& $(0.006)$ & $(0.012)$ & & & 1000 \\
Years & 1000 & 1000 & 1000 & 1000 & 250000 \\
Firm-Years & 250000 & 250000 & 250000 & 250000 & \\
First Stage F & 0.69 & 1946 & & & \\
\hline \hline
\end{tabular}

Notes: The table reports first- and second-stage estimates based on simulated firm-level data from the diagnostic expectations model (DE) and the constrained rational expectations model (RE). Columns (1)-(2) report the first stages, and columns (3)-(5) report second-stage regressions. Standard errors are clustered at the firm level. $*=10 \%$ level, $* *=5 \%$ level, and $* * *=1 \%$ level. Forecast error is realized minus expected profits normalized by the firm's capital stock. Investment is the investment rate, i.e., capital expenditures normalized by the firm's capital stock. Return is the realized bond return, and spread is the realized bond spread relative to the risk-free rate. Column (4) controls for the lagged spread, and column (5) controls for current profits. For all series, $0.01=1 \%$.

In Columns (3), (4), and (5) the DE model also captures the positive correlation between predicted forecast errors, bond returns, spread growth, and investment growth: when borrowers and lenders are overly optimistic (their profit forecasts are systematically above reality), realized bond returns and investment growth are lower, and equilibrium credit spreads rise in line with the data.

keep the parameters fixed at their DE estimates. See Table A.2 in the Model Appendix. 
Quantitatively, comparing Table 7 from simulated data to the estimates from Table 2, the DE model matches almost exactly the first-stage link between investment and forecast errors and does a fair job at capturing the second-stage link between errors and investment growth. It strongly overstates the magnitude of the coefficient for spread growth and returns, while matching the corresponding signs of each in the data. This result is unsurprising, given that there are likely many sources of volatility in firm-level bond returns and credit spreads in the data which our model does not include.

Firm-level reversals need not translate into aggregate reversals. First, firm managers may be particularly attentive to firm-level news, not aggregate news, and hence overreact only to the former. Second, and related, the effect of overoptimism may be amplified during extreme conditions such as a firm's financial distress, but the aggregate-level consequences may be muted due to the paucity of defaulting firms. Investigating these patterns at a more aggregated level therefore offers an important test.

Studying belief dynamics at the macroeconomic level is difficult due to the relatively short post-2000 time window for our annual manager expectations dataset. As an alternative, we implement our two-stage empirical approach at the 3-digit sector level, which offers meaningful aggregation while also allowing us to exploit cross-sectoral variation. Panel A of Table 8 reports the results. In column (1), our first stage reveals that periods of high average investment in a sector predict lower average forecast errors in the subsequent year, i.e., good times beget excess optimism. In columns (2)-(4), we see that periods of excess optimism are followed by lower bond returns, rising spreads, and lower investment growth in the same sector. An industry in which overoptimistic firms are predictably disappointed by one standard deviation more on average (0.32) sees average bond returns decline by -0.32 $\times 0.049 \approx 1.6$ percentage points (column 2 ), higher mean spread growth by $-0.32 \times-0.121$ $\approx 3.9$ percentage points (column 3 ), and average investment rate declines of $-0.32 \times 1.274$ $\approx 41$ percentage points. ${ }^{23}$ There are significant boom-bust sectoral cycles in the data.

Even though our model lacks an explicit industry structure, we assess its ability to produce sector-level cycles by grouping simulated aggregate data from our model into nonoverlapping sequential blocks or "industries." We then run panel two-stage regressions, carefully maintaining symmetry between our simulated data and empirical work by: i) including industry effects and ii) only considering blocks or industries with average length at just above 10 years as in the data.

Panel B reports the estimates based on simulated data from our estimated DE model, and Panel $\mathrm{C}$ reports estimates based on the RE model. In Panel B, we see that the DE

\footnotetext{
${ }^{23}$ The empirical results in Panel A of Table 8 are quite robust. The exact level of aggregation turns out to not be crucial for our results. Appendix Table B.5 reports similar results based on industry data aggregated to the 2-digit level. In columns (2)-(4) we control for lagged spreads and profits, to maintain comparability with our firm-level analysis, but this is not essential as shown in Appendix Table B.6. Including industry effects is also not essential, as shown in Appendix Table B.7.
} 


\section{Table 8: Linking Forecast Errors and Aggregate Reversals}

\begin{tabular}{|c|c|c|c|c|}
\hline IV Stage: & $\begin{array}{c}(1) \\
\text { Forecast Error }_{t+1} \\
\text { First }\end{array}$ & $\begin{array}{c}(2) \\
\text { Return }_{t+1} \\
\text { Second }\end{array}$ & $\begin{array}{c}(3) \\
\Delta \text { Spread }_{t+1} \\
\text { Second }\end{array}$ & $\begin{array}{c}(4) \\
\Delta \text { Investment }_{t+1} \\
\text { Second }\end{array}$ \\
\hline \multicolumn{5}{|l|}{ Panel A: Industry Data } \\
\hline Forecast Error $_{t+1}$ & & $\begin{array}{c}0.049^{* * *} \\
(0.015)\end{array}$ & $\begin{array}{c}-0.121^{* * *} \\
(0.028)\end{array}$ & $\begin{array}{c}1.274^{* * *} \\
(0.052)\end{array}$ \\
\hline Investment $_{t}$ & $\begin{array}{c}-0.457^{* * *} \\
(0.150)\end{array}$ & & & \\
\hline Industry Effects & $\mathrm{X}$ & $\mathrm{X}$ & $\mathrm{X}$ & $\mathrm{X}$ \\
\hline Industries & 111 & 111 & 111 & 111 \\
\hline Industry-Years & 1291 & 1291 & 1291 & 1291 \\
\hline First Stage F & 9.23 & & & \\
\hline \multicolumn{5}{|l|}{ Panel B: DE Model } \\
\hline Forecast Error $_{t+1}$ & & $\begin{array}{c}0.043^{* * *} \\
(0.003)\end{array}$ & $\begin{array}{c}-0.151^{* *} \\
(0.080)\end{array}$ & $\begin{array}{c}2.692^{* * *} \\
(0.020)\end{array}$ \\
\hline Investment $_{t}$ & $\begin{array}{c}-0.474^{* * *} \\
(0.005)\end{array}$ & & & \\
\hline Industry Effects & $\mathrm{X}$ & $\mathrm{X}$ & $\mathrm{X}$ & $\mathrm{X}$ \\
\hline Years & 25000 & 25000 & 25000 & 25000 \\
\hline First Stage F & 8893 & & & \\
\hline \multicolumn{5}{|l|}{ Panel C: RE Model } \\
\hline Forecast Error $_{t+1}$ & & $\begin{array}{c}-0.039^{* * *} \\
(0.002)\end{array}$ & $\begin{array}{c}-5.191^{* * *} \\
(0.177)\end{array}$ & $\begin{array}{c}10.925^{* * *} \\
(0.074)\end{array}$ \\
\hline Investment $_{t}$ & $\begin{array}{c}-0.087^{* * *} \\
(0.006)\end{array}$ & & & \\
\hline Industry Effects & $\mathrm{X}$ & $\mathrm{X}$ & $\mathrm{X}$ & $\mathrm{X}$ \\
\hline Years & 25000 & 25000 & 25000 & 25000 \\
\hline First Stage F & 207 & & & \\
\hline
\end{tabular}

Notes: The table reports first- and second-stage estimates based on industry data from the CompustatIBES-FISD/TRACE sample at the SIC3 $\times$ fiscal year level $($ Panel A), simulated aggregate data from the estimated DE model (Panel B), and simulated aggregate data from the RE model (Panel C). Forecast error is average realized minus expected profits normalized by capital stocks. Investment is the average investment rate, i.e., capital expenditures normalized by the capital stock. Return is the average realized bond return, and spread is the average realized bond spread relative to the risk-free rate. Column (1) reports the first stage, and columns (2)-(4) report second-stage regressions. Standard errors are clustered at the industry level. For the purposes of rough comparison with industry data in Panel A, simulated aggregate data in Panels $\mathrm{B}$ and $\mathrm{C}$ is grouped into sequential blocks or industries with the same average length as in the data. So in Panels B and C "industry effects" refers to fixed effects for these groupings. $*=10 \%$ level, $* *=5 \%$ level, and $* * *=1 \%$ level. Columns (2)-(4) control for the lagged spread and current profits relative to the capital stock. For all series, $0.01=1 \%$.

model reproduces the aggregate link between good times (in which investment is high) and negative future forecast errors, reversals in spreads, investment growth, and in realized bond 
returns. Quantitatively, the DE model matches very well the estimated coefficients in Panel A, which is remarkable given the entirely untargeted nature of these aggregate boom-bust patterns. By contrast, Panel $\mathrm{C}$ reveals a quantitative failure of the $\mathrm{RE}$ model to capture aggregate belief-linked reversals. The first stage estimates in column (1) suggest a weak and spurious predictability of aggregate forecast errors not present in the underlying model, a result which is natural in short panels with industry effects given the source of panel bias we highlighted in Section 2. This spurious predictability implies second-stage estimates which are either the wrong sign (column 2) or orders of magnitude different from their empirical counterparts (columns 3-4).

We conclude that the DE model offers a good account of systematic or aggregated sources of boom-bust cycles in real and financial activity at the firm and aggregate levels, while the RE model does not. Targeting beliefs data improves quantitative macro models' match to the data in a parsimonious way.

\subsection{The Financial Crisis of 2007-09}

Finally, we study the ability of the DE model to generate the increase in credit spreads associated with the Lehman crisis in September 2008. Our model misses some important elements of large crises such as gradual and persistent asset price inflation and runs on financial intermediaries. Asset price bubbles can be obtained under DE by introducing information frictions as in Bordalo et al. (2021c), but here we abstract from them to isolate the role of overreaction in the sharpest way. For the same reason, we abstract from financial intermediaries considered in Maxted (2020) and Krishnamurthy and Li (2020).

What type of TFP shock does the DE model need to produce the jump in spreads in the late 2000's? What are the other macro consequences of such shocks? To answer these questions, we perform a "crisis decomposition" exercise. We separate the 2004-2009 period into a "pre-crisis" period, 2004 - 2007, and a "crisis" period, 2008 - 2009 (as said before, our model yields neither a gradual path of asset price inflation nor the gradual reduction in spreads during 2004-2007). Across these periods, US credit spreads jumped from an average of $1.6 \%$ to $4.5 \%$.

We use the simulated DE model to reverse engineer the TFP path needed to produce this jump. Figure 4 plots this TFP path along with its implications for the growth of credit, output, investment, and corporate profit forecasts. We reports results for both the DE and the RE model. The red (blue) lines connect the pre-crisis and crisis outcomes produced by the DE (RE) model, and the green lines report the data.

In the top left panel, the DE model by construction perfectly matches the pre-crisis and crisis spreads. Remarkably, though, the bottom left panel shows that the DE model explains the increase with a path for TFP growth that is similar to but more moderate than 
measured TFP growth. This fact is noteworthy because the TFP dynamics are untargeted and because the DE model does not actually require an outright decline in TFP to generate a financial reversal. Only a leveling out of TFP which is disappointing relative to expectations is required. Feeding in the same TFP path, the RE model does not produce any meaningful increase in the spread. Overoptimistic expectations appear critical to quantitatively account for "financial shocks," namely sudden stops in financial activity occurring with modest fundamental shocks.

Figure 4: The Financial Crisis of 2007-09
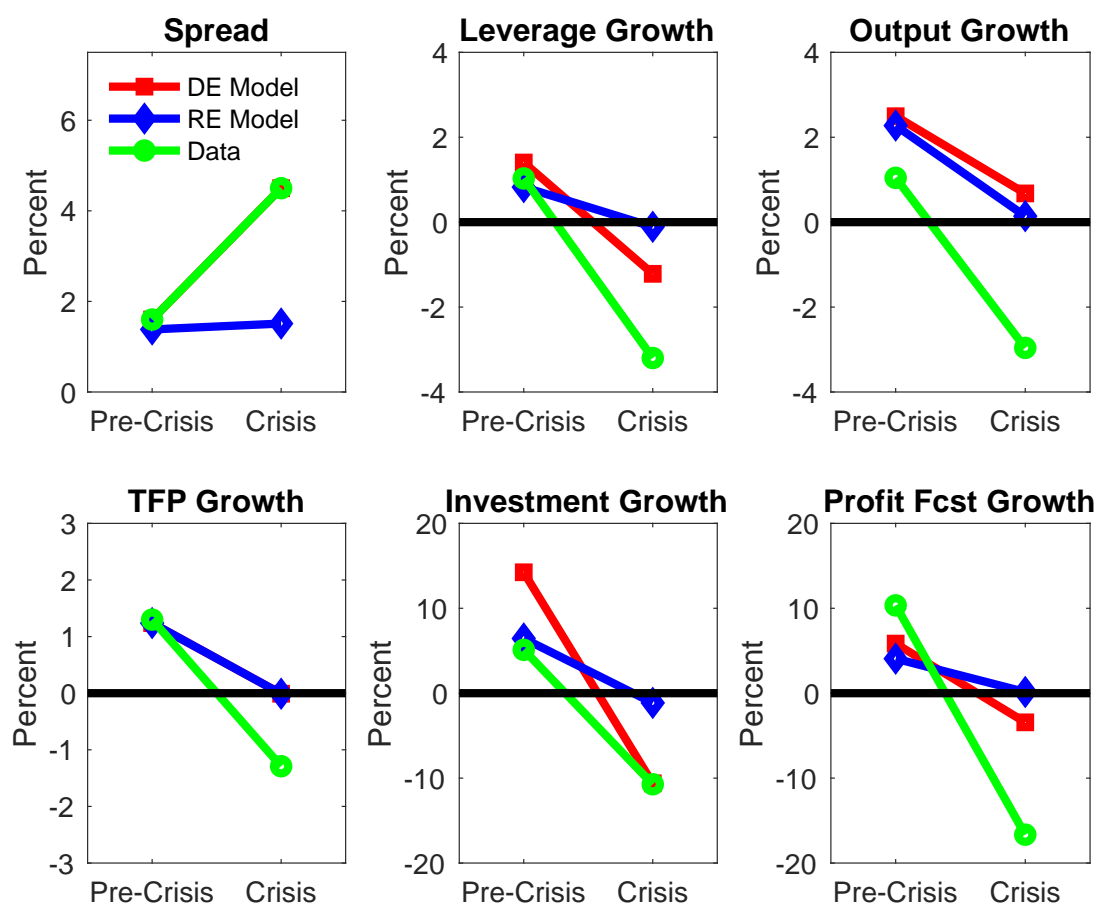

Notes: Each panel plots a macro series from our crisis decomposition exercise, with the data (green), DE model (red), and RE model (blue) included. "Pre-Crisis" is the 2004-07 period, and "Crisis" is the 2008-09 period. In the data, all empirical values are averages drawn from the pre-crisis or crisis periods. Spread is the average spread across firms in our Mergent FISD-TRACE-Compustat sample, leverage growth is the growth in total credit to non-financial corporations relative to the aggregate capital stock, real GDP and private nonresidential fixed investment are from NIPA, the macro TFP level is from John Fernald's website, and profit forecasts are the sum of predicted earnings across all firms in our Compustat-IBES guidance data. In the DE model, we choose the TFP growth series in the bottom left panel in order to exactly match the empirical spread values in the top left panel. We feed the resulting TFP growth series into the RE model to produce the RE line in each panel.

The reversal is due to the fragility built during good times. This fragility is in turn capable of producing realistic macro consequences: a large reduction in credit, investment, and output growth, together with a strong reduction in forecasts of profits. These macroeconomic changes in the DE model are not identical to those in the data, but the quantitative fit is 
noteworthy considering the simplicity of our model. Even with the same TFP shock, the RE model produces substantially more modest dynamics in leverage and investment. The fact that output differences between DE and RE are small is expected, since we feed in the same TFP path and in both neoclassical models capital is determined one period in advance. As evident from the impulse response analysis of Section 5.2, fragility during good times under DE offers a powerful amplifier of nonlinearities that can help quantitatively account for large crisis episodes even in our simple model.

This exercise shows that DE help account for the salient features of boom-bust cycles in macro-financial aggregates. The realism of the analysis and its fit can be improved by adding ingredients that have likely played a role, such as the housing bubble, intermediary leverage, and the link between household debt and consumption. Boom-bust belief dynamics, however, seem a realistic and parsimonious ingredient to generate overexpansion in good times, and a sharp financial and real contraction after modest TFP shocks.

\section{Robustness}

We conclude by reporting the results of two robustness exercises. First, we explore the robustness of our investment nonlinearity result to a range of alternative parameterizations. Second, we endogenize wages in general equilibrium, which can dampen volatility, and again assess the contemporaneous response of macro investment to TFP shocks.

\subsection{Robustness to Alternative Parameterization}

In Figure 5 we explore the robustness of our investment nonlinearity result to alternative parameterizations of the model. Starting from the DE parameter estimates in Table 4, a parameterization which we label Baseline, we vary each of the parameters to round higher and lower values, recomputing the sensitivity of investment to a negative shock over the full range of initial conditions. Nonlinearity remains meaningful in each of these robustness checks, with a downward-sloping response indicating more fragility during good times. Figure 5 also reveals some intuitive results: when firms face more persistent TFP processes (higher

$\rho$ ), more firm-level risk (higher $\sigma$ ), and less intense adjustment costs (lower $\eta_{k}$ ), business cycle nonlinearity becomes stronger.

\subsection{General Equilibrium}

Anticipated procyclical price movements may dampen changes in the anticipated marginal product of capital and hence push against volatility or nonlinearity in investment. To assess the importance of this mechanism, we now extend the model to general equilibrium. The general equilibrium exercise poses a Krusell and Smith (1998)-style challenge, pairing micro 


\section{Figure 5: Investment Nonlinearity with Alternative Parameters}

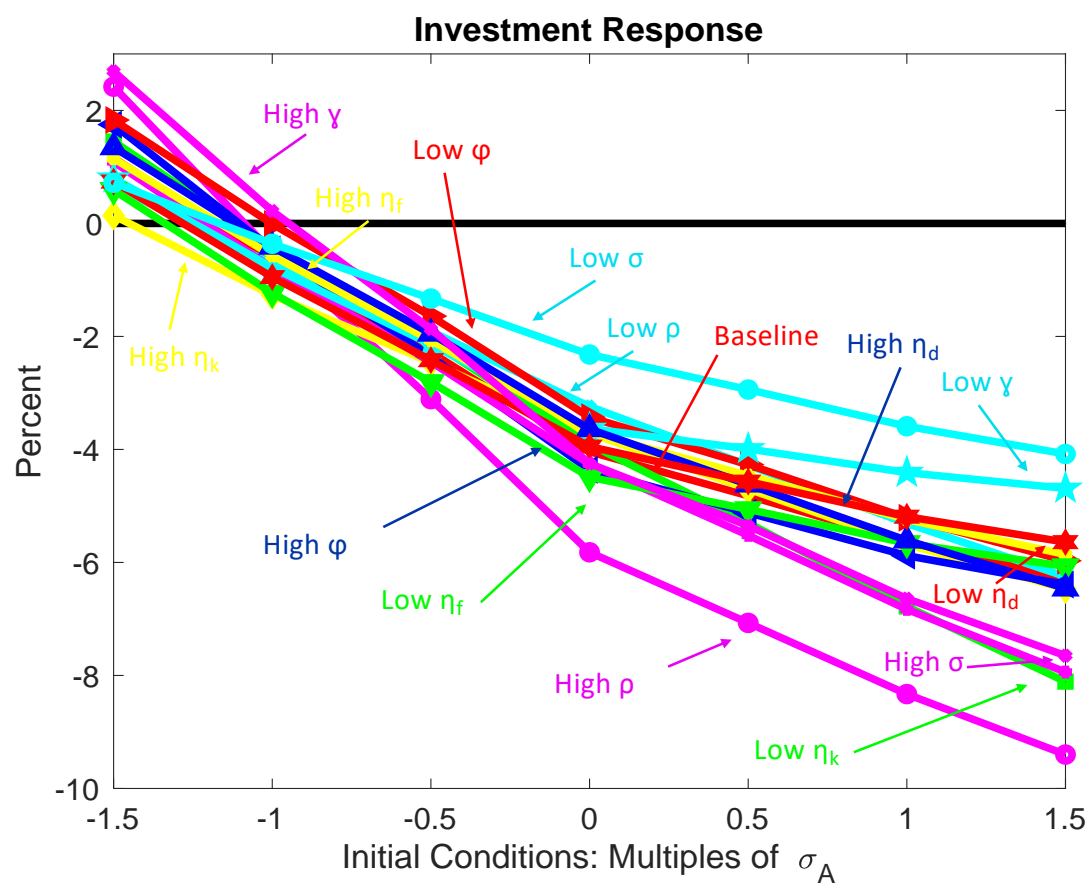

Notes: The vertical axis in the figure reports the simulated impulse response of macro investment to a one-standard deviation negative shock to macro TFP, and the horizontal axis reports the initial conditions, i.e., the magnitude of the shock to macro TFP in the previous period. All models are perturbations of the estimated Baseline DE model, with a single parameter shifted to round higher or lower values bracketing the parameter point estimate. The autocorrelation of micro TFP $\rho_{z}$ is set to 0.85 (high) and 0.73 (low). The volatility of micro TFP $\sigma_{z}$ is set to 0.12 (high) and 0.09 (low). The capital adjustment cost $\eta_{k}$ is set to 3.9 (high) and 3.3 (low). The fixed operating cost $\phi$ is set to 0.16 (high) and 0.10 (low). The recovery rate $\gamma$ is set to 0.30 (high) and 0.20 (low). The equity fixed cost $\eta_{f}$ is set to 0.03 (high) and 0.01 (low). The equity linear cost $\eta_{d}$ is set to 0.12 (high) and 0.06 (low). Macro TFP volatility $\sigma_{A}$, not reported, is held constant in order to keep the shock experiment constant. The magnitude of diagnosticity $\theta$, also held constant, is already varied in Figure 2 to extreme values. The noise in earnings $\sigma_{\pi}$, also not reported, affects only simulated micro moments.

heterogeneity with aggregate shocks and equilibrium price movements, and we develop a novel solution technique for overcoming this challenge detailed in Appendix A. Although our solution method proves accurate and preserves the nonlinearity of the model, the method is highly computationally intensive with a nested inner loop/outer loop alternation that makes structural estimation of the general equilibrium model infeasible.

For a representative household we model period utility as

$$
U(C, N)=C-\frac{\omega}{1+\frac{1}{\lambda}} N^{1+\frac{1}{\lambda}}
$$

where $C$ is consumption, the disutility of labor is governed by $\omega>0$, and the elasticity of 
labor supply is given by $\lambda>0$. See Appendix A for a full definition of general equilibrium, involving optimal labor supply and savings decisions by the household, optimal lending choices by a competitive group of lenders, optimal capital investment, labor demand, and risky borrowing decisions by a distribution of nonfinancial firms, and various market clearing and consistency conditions.

One aspect of the equilibrium is straightforward to characterize given linearity of the marginal utility of consumption. The real interest rate is constant and pinned down by the inverse of the household's subjective discount factor $0<\beta<1$, i.e.,

$$
R=\frac{1}{\beta}-1
$$

Recent work in the general equilibrium heterogeneous firms literature (Winberry, 2017; Koby and Wolf, 2020) emphasizes that imposing the large procyclical shifts in real interest rates implied by benchmark consumption-based models is likely to produce unrealistically smooth investment dynamics, while in fact more empirically realistic shifts in real interest rates may in fact amplify investment nonlinearities. We therefore view the choice of a fixed rate of return $R$ here as a conservative, parsimonious option, which still allows for substantial dampening of macro fluctuations through endogenous wage movements.

However, as usual in this class of heterogeneous firms models with anticipated macro shocks, general equilibrium presents two computational challenges (Krusell and Smith, 1998). In particular, let $\mu(s, k, b)$ be the cross-sectional distribution of micro states $s=\left(z, \varepsilon_{z}\right)$, capital $k$, and debt $b$. The macro state is $\left(\mu, A, \varepsilon_{A}\right)$. The first challenge is that the macro state $\left(\mu, A, \varepsilon_{A}\right)$ is intractable because $\mu$ is a distribution. The second challenge is that the mapping $W\left(\mu, A, \varepsilon_{A}\right)$ is a complicated implicit object which must be consistent with the firm-level decisions embedded in market clearing through

$$
\left(\frac{W\left(\mu, A, \varepsilon_{A}\right)}{\omega}\right)^{\lambda}=\int n\left(s, k, b, \mu, A, \varepsilon_{A} \mid W\right) d \mu(s, k, b)
$$

where the left hand side is the household's closed-form labor supply and the right hand side reflects labor demand generated by the current cross-sectional distribution of firms $\mu$.

We follow a novel computational approach tailored to our problem and detailed in Appendix A. Our approach is to replace the macro state $\left(\mu_{t}, A_{t}, \varepsilon_{A t}\right)$ with a truncated history of macro shocks $\left(A_{t}, A_{t-1}, \ldots, A_{t-K}\right)$, nonparametrically storing predictions of the wage $W_{t}$ given each shock history. We then follow an outer loop/inner loop approach, guessing a wage mapping, solving and simulating the model, and updating the wage predictions until convergence. Our solution technique proves tractable and accurate in practice. We parameterize the model based on the estimated values from Table 4. We further assume a conservative Frisch elasticity of labor supply of $\lambda=0.5$ and choose $\beta$ to deliver the same fixed $4 \%$ annual 


\section{Figure 6: Investment Nonlinearity with General Equilibrium}

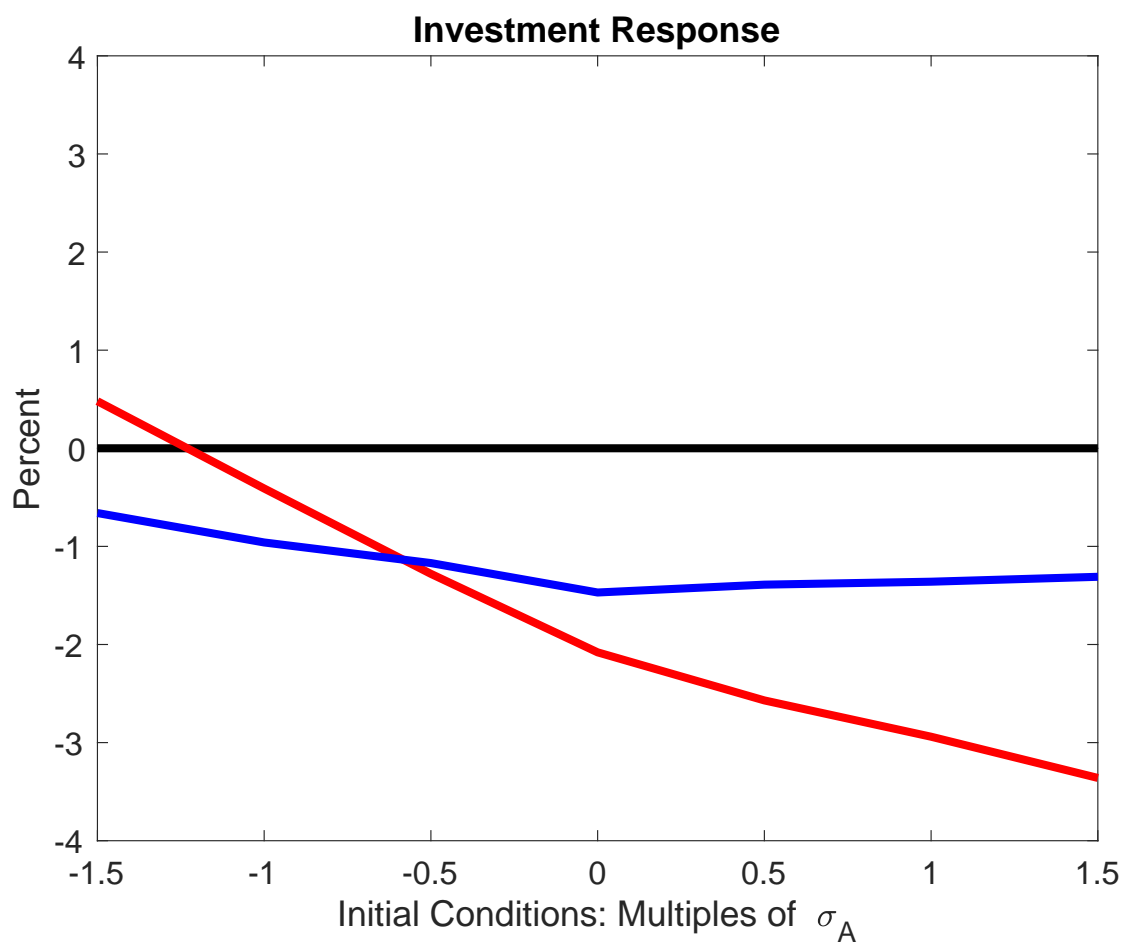

Notes: The vertical axis in the figure reports the simulated impulse response of macro investment to a one-standard deviation negative shock to macro TFP, and the horizontal axis reports the initial conditions, i.e., the magnitude of the shock to macro TFP in the previous period. Both the DE model (red line) and RE model (blue line) are reported on the figure. These results are computed in the general equilibrium model with labor market clearing.

real interest rate as considered above.

Wages in this equilibrium structure reflect an intratemporal mapping from the macro states to prices, so it might not be immediately clear how explicitly intertemporal DE interact with general equilibrium. In Appendix Figure A.4, we plot expected future wage growth as a function of current productivity growth in the DE and RE models. In the DE model, a positive productivity shock increases perceptions of the future demand for capital and labor and hence future wage growth relative to the RE model. These anticipated wage increases dampen investment today, a force that is stronger under DE than RE. Our general equilibrium solution investigates whether the investment nonlinearities highlighted above under DE survive these price movements.

Figure 6, the general equilibrium analog of Figure 2, reports the response of investment to a negative TFP shock for different initial conditions. Endogenous wages moderate the magnitude of the investment response relative to partial equilibrium. But the investment response continues to display substantial nonlinearity under DE (red line): the negative 
shock exerts a much larger negative impact in good times. The response to a negative TFP shock increases in size by a bit over $40 \%$ when arriving after a one standard deviation positive shock rather than in normal times. This increase matches the trough-to-peak growth in empirical investment sensitivity estimated in Bachmann et al. (2013). In the RE model (blue line), by contrast, the general equilibrium feedback working through wages eliminates the already very slight state dependence of investment almost entirely. In sum, even after allowing for fully flexible wages in general equilibrium, the DE economy proves more fragile than the RE economy in good times and hence more responsive to negative shocks due to the boom-bust mechanism created by overreacting beliefs.

\section{Conclusion}

The financial crisis of 2008 renewed economists' interest in financial instability. One key challenge is to understand where such instability comes from. We showed that non-rational beliefs, and in particular overreaction to news, can generate realistic credit cycles without relying on exogenous financial shocks. These boom-bust dynamics display elements of predictability in line with the evidence on cyclical movements in credit spreads (López-Salido et al., 2017) and on large financial crises (Greenwood et al., Forthcoming). Critically, our results are obtained in a standard $\mathrm{RBC}$ model in which a single new parameter, the degree of belief overreaction, is estimated using microdata on managers' errors in forecasts of the earnings growth of their firms. Realistic micro-level belief distortions can, once aggregated, generate realistic credit cycles with financial overexpansion in good times, fragility, and sharp reversals as small adverse news arrives.

Future work can enrich our approach. A key factor is the role of financial intermediaries, which recent work has already begun to investigate (Maxted, 2020; Krishnamurthy and $\mathrm{Li}, 2020)$. Another important aspect is household debt, which has been shown to be a key determinant of drops in aggregate demand during financial tightenings (Mian et al., 2017; Mian and Sufi, 2009). Prolonged asset price bubbles are another important element, especially to account for large crises Greenwood et al. (Forthcoming). These factors open exciting avenues for studying the transmission of beliefs to the real economy. As an initial step, our work shows that realistic departures from rationality disciplined by expectations data can be introduced into standard macroeconomic models and significantly improve their explanatory power. 


\section{References}

Afrouzi, Hassan, Spencer Kwon, Augustin Landier, Yueran Ma, and David Thesmar (2020), "Overreaction and working memory." Working paper.

Angeletos, George-Marios, Zhen Huo, and Karthik Sastry (2020), "Imperfect macroeconomic expectations: Evidence and theory." NBER Macroeconomics Annual, 35, 1-86.

Arellano, Cristina, Yan Bai, and Patrick Kehoe (2019), "Financial frictions and fluctuations in volatility." Journal of Political Economy, 127, 2049-2103.

Azeredo da Silveira, Rava, Yeji Sung, and Michael Woodford (2020), "Optimally imprecise memory and biased forecasts." Working paper.

Bachmann, Rüdiger, Ricardo Caballero, and Eduardo Engel (2013), "Aggregate implications of lumpy investment: new evidence and a dsge model." American Economic Journal: Macroeconomics, 5, 29-67.

Bansal, Ravi and Amir Yaron (2004), "Risks for the long run: A potential resolution of asset pricing puzzles." Journal of Finance, 59, 1481-1509.

Barrero, Jose (Forthcoming), "The micro and macro of manager beliefs." Journal of Financial Economics.

Barro, Robert (2006), "Rare disasters and asset markets in the twentieth century." Quarterly Journal of Economics, 121, 823-866.

Bernanke, Ben and Mark Gertler (1989), "Agency costs, net worth, and business fluctuations." American Economic Review, 79, 14-31.

Bertomeu, Jeremy, Iván Marinovic, Stephen Terry, and Felipe Varas (2021), "The dynamics of concealment." Journal of Financial Economics, 143, 227-246.

Bhandari, Anmol, Jaroslav Borovicka, and Paul Ho (2019), "Survey data and subjective beliefs in business cycle models." Working paper.

Bianchi, Francesco, Cosmin Ilut, and Hikaru Saijo (2021), "Diagnostic business cycles." Working paper.

Bianchi, Javier (2011), "Overborrowing and systemic externalities in the business cycle." American Economic Review, 101, 3400-3426.

Bloom, Nicholas, Max Floetotto, Nir Jaimovich, Itay Saporta-Eksten, and Stephen Terry (2018), "Really uncertain business cycles." Econometrica, 86, 1031-1065.

Bordalo, Pedro, Katherine Coffman, Nicola Gennaioli, Frederik Schwerter, and Andrei Shleifer (2021a), "Memory and representativeness." Psychological Review, 128, 71-85.

Bordalo, Pedro, John Conlon, Nicola Gennaioli, Spencer Kwon, and Andrei Shleifer (2021b), "Memory and probability." Working paper.

Bordalo, Pedro, Nicola Gennaioli, Spencer Yongwook Kwon, and Andrei Shleifer (2021c), "Diagnostic bubbles." Journal of Financial Economics, 141, 1060-1077.

Bordalo, Pedro, Nicola Gennaioli, Rafael LaPorta, and Andrei Shleifer (2019), "Diagnostic expectations and stock returns." Journal of Finance, 74, 2839-2874.

Bordalo, Pedro, Nicola Gennaioli, Yueran Ma, and Andrei Shleifer (2020), "Overreaction in macroeconomic expectations." American Economic Review, 110, 2748-82. 
Bordalo, Pedro, Nicola Gennaioli, and Andrei Shleifer (2018), "Diagnostic expectations and credit cycles." Journal of Finance, 73, 199-227.

Bouchaud, Jean-Philippe, Philipp Krueger, Augustin Landier, and David Thesmar (2019), "Sticky expectations and the profitability anomaly." Journal of Finance, 74, 639-674.

Caballero, Ricardo and Alp Simsek (2020), "A risk-centric model of demand recessions and speculation." Quarterly Journal of Economics, 135, 1493-1566.

Campbell, John and John Cochrane (1999), "By force of habit: A consumption-based explanation of aggregate stock market behavior." Journal of Political Economy, 107, 205-251.

CBO (2017), "International comparisons of corporate income tax rates." Exhibit 7.

Coibion, Olivier and Yuriy Gorodnichenko (2015), "Information rigidity and the expectations formation process: A simply framework and new facts." American Economic Review, 105, $2644-78$.

Cooper, Russell and Jonathan Willis (2015), "Discounting: Investment sensitivity and aggregate implications." Working paper.

D'Arienzo, Daniele (2020), "Maturity increasing overreaction and bond market puzzles." Working paper.

Dávila, Eduardo and Anton Korinek (2017), "Pecuniary externalities in economies with financial frictions." The Review of Economic Studies, 85, 352-395.

Den Haan, Wouter (2010), "Comparison of solutions to the incomplete markets model with aggregate uncertainty." Journal of Economic Dynamics and Control, 34, 4-27.

Diamond, Douglas and Philip Dybvig (1983), "Bank runs, deposit insurance, and liquidity." Journal of Political Economy, 91, 401-419.

Eggertsson, Gauti and Paul Krugman (2012), "Debt, deleveraging, and the liquidity trap: A fisher-minsky-koo approach." Quarterly Journal of Economics, 127, 1469-1513.

Falato, Antonio and Jasmine Xiao (2020), "The information driven financial accelerator." Working paper.

Farhi, Emmanuel and Ivan Werning (2020), "Taming a minsky cycle." Working paper.

Fuster, Andreas, David Laibson, and Brock Mendel (2010), "Natural expectations and macroeconomic fluctuations." Journal of Economic Perspectives, 24, 67-84.

Gennaioli, Nicola, Yueran Ma, and Andrei Shleifer (2016), "Expectations and investment." NBER Macroeconomics Annual, 30, 379-431.

Gennaioli, Nicola and Andrei Shleifer (2010), "What comes to mind." Quarterly Journal of Economics, 125, 1399-1433.

Giglio, Stefano, Matteo Maggiori, Johannes Stroebel, and Stephen Utkus (2021), "Five facts about beliefs and portfolios." American Economic Review, 111, 1481-1522.

Gilchrist, Simon and Egon Zakrajšek (2012), "Credit spreads and business cycle fluctuations." American Economic Review, 102, 1692-1720.

Gilchrist, Simon, Egon Zakrajšek, and Jae Sim (2014), "Uncertainty, financial frictions, and investment dynamics." Working paper.

Gomes, Joao F. (2001), "Financing investment." American Economic Review, 91, 1263-85. 
Gourio, Francois and Leena Rudanko (2014), "Customer capital." Review of Economic Studies, 81, 1102-36.

Greenwood, Robin and Samuel Hanson (2013), "Issuer quality and corporate bond returns." Review of Financial Studies, 26, 1483-1525.

Greenwood, Robin, Samuel Hanson, and Lawrence Jin (2019), "Reflexivity in credit markets." Working paper.

Greenwood, Robin, Samuel Hanson, Andrei Shleifer, and Jakob Ahm Sørensen (Forthcoming), "Predictable financial crises." Journal of Finance.

Greenwood, Robin and Andrei Shleifer (2014), "Expectations of returns and expected returns." Review of Financial Studies, 27, 714-746.

Guerrieri, Veronica and Guido Lorenzoni (2017), "Credit crises, precautionary savings, and the liquidity trap." Quarterly Journal of Economics, 132, 1427-1467.

Hansen, Lars Peter and Thomas Sargent (2001), "Acknowledging misspecification in macroeconomic theory." Review of Economic Dynamics, 4, 519-535.

He, Zhiguo and Arvind Krishnamurthy (2019), "A macroeconomic framework for quantifying systemic risk." American Economic Journal: Macroeconomics, 11, 1-37.

Hennessy, Christopher and Toni Whited (2007), "How Costly is External Financing? Evidence from a Structural Estimation." Journal of Finance, 62, 1705-1745.

Ilut, Cosmin, Matthias Kehrig, and Martin Schneider (2018), "Slow to hire, quick to fire: Employment dynamics with asymmetric responses to news." Journal of Political Economy, $126,2011-71$.

Ilut, Cosmin L and Martin Schneider (2014), "Ambiguous business cycles." American Economic Review, 104, 2368-99.

Jaimovich, Nir and Sergio Rebelo (2007), "Behavioral theories of the business cycle." Journal of the European Economic Association, 5, 361-68.

Jermann, Urban and Vincenzo Quadrini (2012), "Macroeconomic effects of financial shocks." American Economic Review, 102, 238-71.

Khan, Aubhik and Julia Thomas (2008), "Idiosyncratic Shocks and the Role of Nonconvexities in Plant and Aggregate Investment Dynamics." Econometrica, 76, 395-436.

Kindleberger, Charles (1978), Manias, Panics, and Crashes: A History of Financial Crises. John Wiley \& Sons.

King, Robert and Sergio Rebelo (1999), "Resuscitating real business cycles." Handbook of Macroeconomics, 1, 927-1007.

Kiyotaki, Nobuhiro and John Moore (1997), "Credit cycles." Journal of Political Economy, $105,211-248$.

Koby, Yann and Christian Wolf (2020), "Aggregation in heterogeneous-firm models: Theory and measurement." Working paper.

Kohlhas, Alexandre and Ansgar Walther (2021), "Asymmetric attention." American Economic Review, 111, 2879-2925.

Koop, Gary, Hashem Pesaran, and Simon Potter (1996), "Impulse response analysis in nonlinear multivariate models." Journal of Econometrics, 74, 119-147. 
Korinek, Anton and Alp Simsek (2016), "Liquidity trap and excessive leverage." American Economic Review, 106, 699-738.

Kozlowski, Julian, Laura Veldkamp, and Venky Venkateswaran (2017), "The tail that wags the economy: Beliefs and persistent stagnation." Working paper.

Krishnamurthy, Arvind and Wenhao Li (2020), "Dissecting mechanisms of financial crises: Intermediation and sentiment." NBER working paper 27088.

Krusell, Per and Anthony Smith, Jr (1998), "Income and wealth heterogeneity in the macroeconomy." Journal of Political Economy, 106, 867-896.

L'Huillier, Jean-Paul, Sanjay Singh, and Donghoon Yoo (2021), "Incorporating diagnostic expectations into the New Keynesian framework." Working paper.

López-Salido, David, Jeremy Stein, and Egon Zakrajšek (2017), "Credit-market sentiment and the business cycle." Quarterly Journal of Economics, 132, 1373-1426.

Lorenzoni, Guido (2008), "Inefficient credit booms." Review of Economic Studies, 75, 809833.

Lucas, Robert (1976), "Econometric policy evaluation: A critique." Carnegie-Rochester Conference Series on Public Policy, 1, 19-46.

Mankiw, Gregory and Ricardo Reis (2002), "Sticky information versus sticky prices: a proposal to replace the new keynesian phillips curve." Quarterly Journal of Economics, 117, $1295-1328$.

Maxted, Peter (2020), "A macro-finance model with sentiment." Working paper.

Mian, Atif and Amir Sufi (2009), "The Consequences of Mortgage Credit Expansion: Evidence from the U.S. Mortgage Default Crisis." Quarterly Journal of Economics, 124, $1449-96$.

Mian, Atif, Amir Sufi, and Emil Verner (2017), "Household debt and business cycles worldwide." Quarterly Journal of Economics, 132, 1755-1817.

Minsky, Hyman (1977), "The financial instability hypothesis: An interpretation of Keynes and an alternative to standard theory." Challenge, 20, 20-27.

Nickell, Stephen (1981), "Biases in dynamic models with fixed effects." Econometrica, 49, $1417-1426$.

Pflueger, Carolin, Emil Siriwardane, and Adi Sunderam (2020), "Financial market risk perceptions and the macroeconomy." Quarterly Journal of Economics, 135, 1443-1491.

Rognlie, Matthew, Andrei Shleifer, and Alp Simsek (2018), "Investment hangover and the great recession." American Economic Journal: Macroeconomics, 10, 113-53.

Saporta-Eksten, Itay and Stephen Terry (2018), "Short-term shocks and long-term investment." Working paper.

Schaal, Edouard and Mathieu Taschereau-Dumouchel (2020), "Herding cycles." Working paper.

Schularick, Moritz and Alan Taylor (2012), "Credit booms gone bust: Monetary policy, leverage cycles, and financial crises, 1870-2008." American Economic Review, 102, 102961.

Shleifer, Andrei and Robert Vishny (1992), "Liquidation values and debt capacity: A market equilibrium approach." Journal of Finance, 47, 1343-1366. 
Sims, Christopher (2003), "Implications of rational inattention." Journal of Monetary Economics, 50, 665-690.

Stein, Jeremy (2012), "Monetary policy as financial stability regulation." Quarterly Journal of Economics, 127, 57-95.

Strebulaev, Ilya and Toni Whited (2012), "Dynamic Models and Structural Estimation in Corporate Finance." Foundations and Trends in Finance, 6, 1-163.

Tauchen, George (1986), "Finite state markov-chain approximations to univariate and vector autoregressions." Economics Letters, 20, 177-181.

Terry, Stephen (2017a), "Alternative methods for solving heterogeneous firm models." Journal of Money, Credit and Banking, 49, 1081-1111.

Terry, Stephen (2017b), "The macro impact of short-termism." Working paper.

Winberry, Thomas (2017), "Lumpy investment, business cycles, and stimulus policy." Working paper.

Woodford, Michael (2003), "Imperfect common knowledge and the effects of monetary policy." In Knowledge, Information, and Expectations in Modern Macroeconomics (Philippe Aghion, Roman Frydman, Joseph Stiglitz, and Michael Woodford, eds.), Princeton University Press.

Young, Eric (2010), "Solving the Incomplete Markets Model with Aggregate Uncertainty Using the Krusell-Smith Algorithm and Non-Stochastic Simulations." Journal of Economic Dynamics and Control, 34, 36-41. 


\section{Appendices for Online Publication Only}

\section{A Model}

\section{A.1 Solving the Model}

The computational algorithm involves iteration on an outer loop (related to debt pricing) and an inner loop (related to firm policies). Before solving the model, we discretize the state space $(s, k, b)=\left(z, \varepsilon_{z}, A, \varepsilon_{A}, k, b\right)$ into $n_{z} \times n_{z} \times n_{A} \times n_{A} \times n_{k} \times n_{b}$ grid points. We then discretize the rational and perceived diagnostic transitions of the exogenous states according to Tauchen (1986). The computational algorithm - following Strebulaev and Whited (2012) - proceeds as follows:

\section{Start outer loop.}

1. Guess a default policy $d f^{\theta}(s, k, b)$, and compute the implied debt prices $q^{\theta}(s, k, b)$ according to the lenders diagnostic zero-profit condition Equation (17).

\section{Start inner loop.}

(a) Given the debt prices $q^{\theta}(s, k, b)$ and default policy $d f^{\theta}(s, k, b)$, solve the diagnostic firm's Bellman Equations (14), (15), and (16) for $V^{\theta}(s, k, b), V_{N D}^{\theta}(s, k, b)$, and $V_{D}^{\theta}(s)$ as well as the implied optimal policies for investment and debt issuance $k^{\prime \theta}(s, k, b), b^{\prime \theta}(s, k, b)$. Use standard discrete-state, discrete-policy dynamic programming policy iteration to do so.

2. Compute updated default policies $d f^{\theta}(s, k, b)$ according to the default choice defining $V^{\theta}$ in Equation (14), i.e., $V_{N D}^{\theta}(s, k, b)<V_{D}^{\theta}(s)$.

3. Compute the ergodic distribution $\mu(s, k, b)$ implied by the firm policies for default, capital, and debt $d f^{\theta}(s, k, b),{k^{\prime}}^{\theta}(s, k, b)$, and $b^{\prime}(s, k, b)$.

4. Compute the mass of states in which the guessed default policy differs from the updated default policy. If this set of states has mass lower than some tolerance, exit. If not, then go to top and restart with the updated set of default states as your new guess.

We implement this computationally intensive algorithm in heavily parallelized Fortran on a 2017 iMac Pro, with runtimes around 250 seconds. Table A.1 reports the value of several dimensions used for the baseline solution of the model. Figure A.1 plots the perceived value function $V^{\theta}$ in our estimated DE model for a range of different capital and productivity 
news realizations, with overreaction generating more perceived value after goods news even conditional upon today's productivity state. The value function in the RE model, also plotted, displays no such overreaction in the direction of recent news.

\section{Table A.1: Computational Choices}

\begin{tabular}{ccc} 
Quantity & Description & Value \\
\hline \hline$T^{\text {sim }}$ & Simulated periods & 6 \\
$T^{\text {erg }}$ & Initially discarded periods & 50 \\
$N^{\text {firm }}$ & Number of firms & 1000 \\
$N^{I R F}$ & Number of IRF economies & 10000 \\
$T^{I R F}$ & Length of IRF economies & 75 \\
$T^{\text {decomp }}$ & Length of historical decomposition & 2 \\
$n_{z}$ & Micro productivity grid size & 5 \\
$n_{A}$ & Macro productivity grid size & 5 \\
$n_{k}$ & Capital grid size & 30 \\
$n_{b}$ & Debt grid size & 30 \\
\hline \hline
\end{tabular}

Notes: The table reports various computational values used in discretizing and solving the model.

\section{A.2 Simulating the Model}

After the model is solved, we unconditionally simulate the model by drawing exogenous uniform random shocks and combining this information with the transition matrix for macro TFP to simulate the macro process for $A_{t}$ for some periods $t=1, \ldots, T^{s i m}+T^{e r g}$. At the micro level, we simulate the model "non-stochastically" according to the method of Young (2010), i.e., we store the dynamics of the weight of the cross-sectional distribution at each discretized point in the state space $(s, k, b)$ rather than simulating a large number of firms. Note that when simulating the model, all macro shocks and distributional dynamics are determined according to the rational or true representations of the driving process, even though debt pricing and firm polices may involve diagnostic expectations.

With the simulated distribution in hand for each period, macro series of interest are simply weighted sums of micro-level outcomes across this distribution, discarding the first $T^{e r g}$ periods to remove the influence of initial conditions. Note that we do in fact simulate a number of individual firms $N^{\text {firm }}$ for the purpose of computing moments within our SMM estimation algorithm, but this is not a step required for the purpose of solving the model or simulating within-period business cycle aggregates. 


\section{Figure A.1: Firm Value and Diagnosticity}

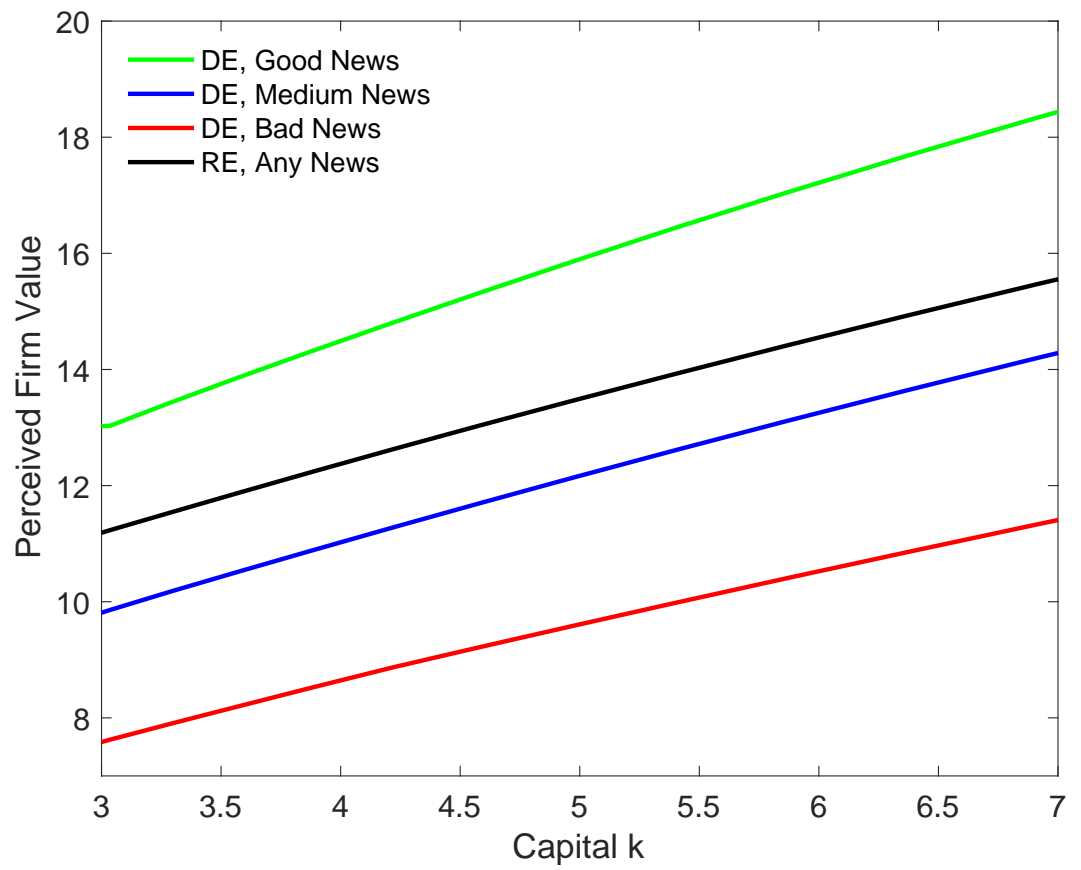

Notes: The figure plots the perceived value function $V^{\theta}$ as a function of firm capital $k$ for the estimated DE model, together with the firm's value function $V$ in the estimated RE model. All lines hold fixed micro TFP $z$, macro TFP $A$, macro news $\varepsilon_{A}$, and the firm's debt $b$ at identical representative values. The four lines reflect different realizations of micro TFP news $\varepsilon_{z}$, with positive news in the DE model (green line), medium news in the DE model (blue line), bad news in the DE model (red line), and any news in the RE model (black line). 


\section{A.3 Computing Impulse Responses}

Our approach to impulse response calculation in this nonlinear context follows Koop et al. (1996), i.e., we compute nonlinear generalized impulse responses. To understand the impact of a given sequence of shocks, we perform the following:

1. For a large number $N^{\text {irf }}$ of economies of length $T^{\text {irf }}$, simulate two different versions of the simulation, the "shock" and "no shock" versions. For each economy and each version, we simulate the macro TFP process by first drawing $T^{\text {irf }}$ uniform shocks for comparison with the macro TFP transition matrix. Then, simulate both versions unconditionally using identical macro TFP shocks until period $T^{\text {shock }}<T^{\text {irf }}$.

2. From period $T^{\text {shock }}$ and continuing as long as the desired sequence of exogenous innovations you wish to impose lasts, impose a number of periods of certain pre-determined innovations in productivity for the "shock" case, while continuing to simulate the "no shock" economy unconditionally.

3. After the imposed shocks sequence is complete, simulate macro TFP in both economies as normal.

4. After the macro TFP process is determined for each pair of economies, compute the business cycle aggregates of interest in each economy, period, and version by using the simulation approach outlined above.

5. If business cycle aggregate $X_{i, t}^{\text {shock }}$ is series $X$ in economy $i$ in period $t$ in the shock case, and $X_{i, t}^{\text {noshock }}$ is series $X$ in economy $i$ in period $t$ in the no shock case, then define the impulse response to the predetermined sequence of innovations as

$$
I R F_{t}^{X}=\frac{1}{N^{i r f}} \sum_{i=1}^{N^{i r f}} \frac{X_{i, t}^{\text {shock }}-X_{i, t}^{\text {noshock }}}{X_{i, t}^{\text {noshock }}}
$$

The main text's set of impulse response figures reports the series $I R F^{X}$ for the indicated macro-financial aggregates. Note, however, that the impulse responses presented in the text are scaled to equal an exact shock size, while the productivity grid in the model varies discretely. We achieve this by imposing movements up or down by a single grid point, imposing Step 2 above only with a certain probability chosen in each period to deliver the desired average shock size.

\section{A.4 Performing the Spread Matching Exercise}

In a classic linear setting, performing historical decompositions such as the one used in Section 6 for the Great Financial Crisis is typically a trivial matter of inverting a data path using 
simple linear algebra. However, our nonlinear model with heterogeneity and a discretized productivity process poses some additional computational challenges. Given the empirical path across two period $t=1,2$ for macro credit spreads to match $\left(S_{1}, S_{2}, \ldots, S_{T}^{\text {decomp }}\right)$, we proceed as follows.

First, we pick an initial period drawn from a representative location in the unconditional simulation of the model, fixing the associated simulated cross-sectional distribution of firmlevel states $\mu_{0}$ drawn from the simulation of the model. Call this period $t=0$, and note that at the end of period 0 a cross-sectional distribution $\mu_{1}$ is pre-determined. Then for each period $t=1, \ldots, T^{\text {decomp }}$, do the following:

1. Guess a value for macro TFP $A_{t}$, and find the bracketing interval $\left[A_{i-1}, A_{i}\right]$ together with linear interpolation weights $\omega\left(A_{t}, i\right)=\frac{A_{t}-A_{i-1}}{A_{i}-A_{i-1}}$ for the guessed value of productivity.

2. Compute the implied policies of all firms in the cross-sectional distribution $\mu_{t}$ given a macro TFP level equal to $A_{i}$, together with the implied macro spread level $S\left(A_{i}\right)$. Repeat the process for macro TFP equal to $A_{i-1}$ to obtain $S\left(A_{i-1}\right)$.

3. Assume that firms play a "mixed strategy" over the two macro TFP grid points, in which case the resulting macro spread level is $\left(1-\omega\left(A_{t}, i\right)\right) S\left(A_{i-1}\right)+\omega\left(A_{t}, i\right) S\left(A_{i}\right)$.

4. If the implied macro spread level is not equal to the desired spread value $S_{t}$ to within some tolerance, then update your guess for macro TFP $A_{t}$ and return to Step 1. Otherwise proceed.

5. Given a productivity guess which delivers exactly the correct interpolated value of macro productivity in period $t$, compute the beginning-of-period distribution $\mu_{t+1}$ of firm-level states by pushing forward a fraction $\omega\left(A_{t}, i\right)$ of the distribution $\mu_{t}$ using firm policies associated with $A_{i}$ and a fraction $1-\omega\left(A_{t}, i\right)$ of the distribution $\mu_{t}$ using firm policies associated with $A_{i-1}$.

At the end of this process, you have determined a smooth value of productivity $A_{t}$ which gives you an implied macro spread series exactly consistent with the target value in period $t$, and you have updated the cross-sectional distribution in an internally consistent fashion given the smooth value of productivity between grid points. Repeating this process for each period $t=1, \ldots, T^{\text {decomp }}$ yields a productivity path $A_{t}$, as well as a set of cross-sectional distributions $\mu_{t}$, which exactly match the target data path for spread. All other macro aggregates of interest can then be computed from the distributional and macro TFP path. Note that for the spread matching exercise for the Great Recession and financial crisis in Section 6 , we set $T^{\text {decomp }}=2$, with $t=1$ being the "Pre-Crisis" period and $t=2$ being the "Crisis" period. 


\section{A.5 Rational Counterfactual}

Table A.2 reports business cycle moments from a model with parameters identical to our estimated DE model but $\theta=0$ imposed.

Table A.2: Business Cycle Moments: Rational Counterfactual

\begin{tabular}{lccccc}
\hline \hline Correlation: & Output & Debt & Investment & Spread & (Standard Deviation) \\
\hline Output & 1.000 & 0.7806 & 0.7968 & -0.3498 & $(0.011)$ \\
Debt & & 1.000 & 0.6007 & -0.4077 & $(0.007)$ \\
Investment & & & 1.000 & -0.4694 & $(0.027)$ \\
Spread & & & & 1.000 & $(0.000006)$ \\
\hline
\end{tabular}

Notes: The table reports business cycle correlations (left) and standard deviations (right) from the rational counterfactual model. This model has parameters identical to the estimated DE model but imposes $\theta=0$. The model moments are computed from an unconditional simulation of 250 years. Model quantities refer to total values (output, debt, and investment) or average values (spread) computed from the distribution of firms. Output, debt, and investment are HP-filtered in logs with smoothing parameter 100.

\section{A.6 DE Firms with RE Lenders}

Table A.3 reports parameter estimates for a model in which firms exhibit DE with $\theta>0$ but lenders exhibit RE with $\theta=0$. Figure A.2 plots the equivalent of Figure 2, plotting investment responses to a negative TFP shock for a range of initial conditions, in this model.

Table A.3: Parameter Estimates for RE Lenders, DE Firms Model

\begin{tabular}{cclc}
\hline \hline & Parameter & Role & Value \\
\hline 1 & $\theta^{\text {firms }}$ & Diagnosticity & 0.911 \\
2 & $\rho_{z}$ & Micro TFP autocorrelation & 0.771 \\
3 & $\sigma_{z}$ & Micro TFP volatility & 0.097 \\
4 & $\eta_{k}$ & Capital adjustment cost & 3.725 \\
5 & $\phi$ & Fixed operating cost & 0.224 \\
6 & $\gamma$ & Recovery rate & 0.404 \\
7 & $\sigma_{A}$ & Macro TFP volatility & 0.007 \\
8 & $\eta_{f}$ & Equity fixed cost & 0.015 \\
9 & $\eta_{d}$ & Equity linear cost & 0.208 \\
10 & $\sigma_{\pi}$ & Earnings noise & 0.404 \\
\hline \hline
\end{tabular}

Notes: The table reports point estimates in our SMM estimation of the model with RE credit pricing by lenders and DE policies by firms. In the estimation, the weighting matrix for moments is optimal, i.e., the inverse of the moment covariance matrix. 


\section{Figure A.2: Investment Nonlinearity with Rational Pricing}

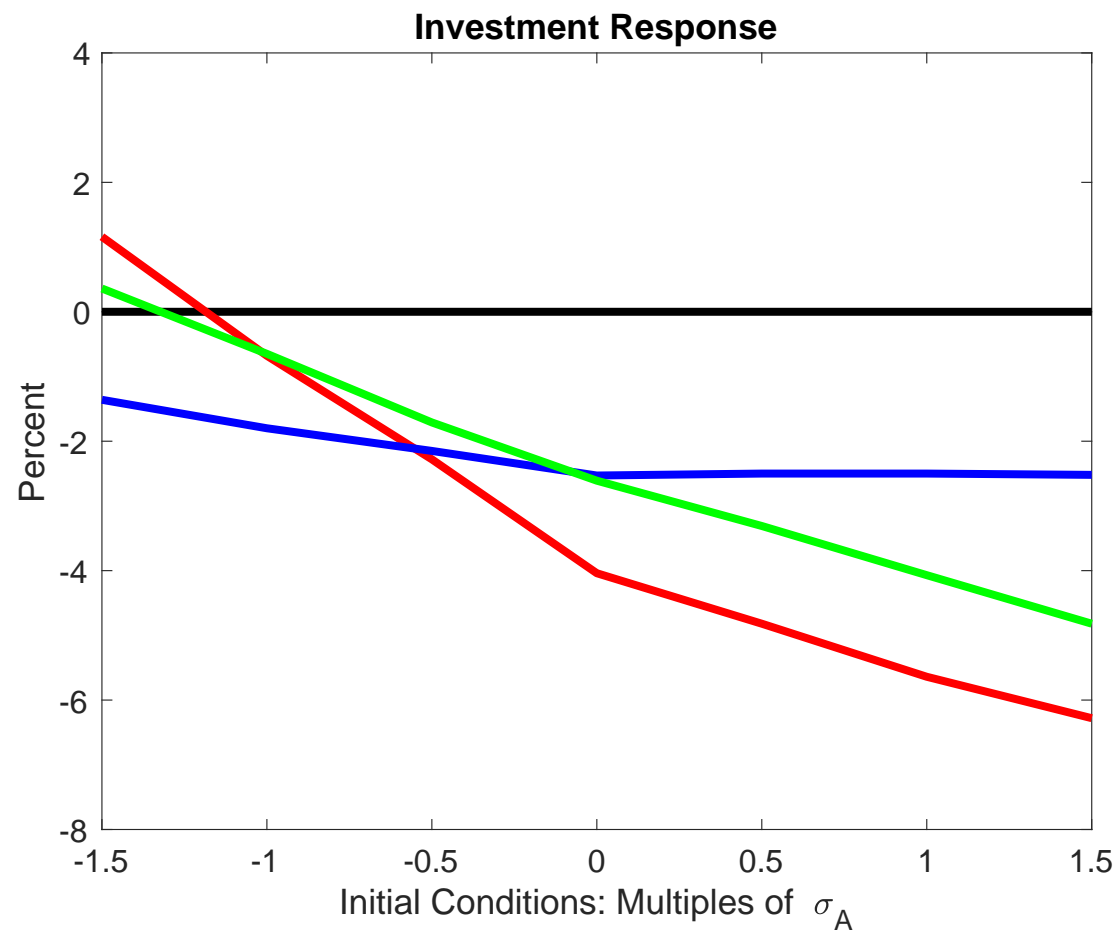

Notes: The vertical axis in the figure reports the simulated impulse response of macro investment to a one-standard deviation negative shock to macro TFP, and the horizontal axis reports the initial conditions, i.e., the magnitude of the shock to macro TFP in the previous period. The DE model (red line), RE model (blue line), and DE model with rational lenders (green line) are reported on the figure.

\section{A.7 Belief Updating versus Endogenous Sensitivity}

The IRF nonlinearity revealed in the main text in Figure 2 can in principle stem from one of two not mutually exclusive sources: i) direct reversals of overoptimistic diagnostic beliefs after good news, or ii) higher riskiness in the distribution of overoptimistic firms' endogenous states $b$ and $k$ after a good news. To piece apart the direct contribution of beliefs versus the indirect contribution of firm states, we compute the response of the diagnostic economy to a one-standard deviation negative shock to TFP after a range of different initial shocks, in each case holding the distribution of endogenous states equal to the one which would have obtained without the negative TFP shock. The light blue line in Figure A.3 reveals the resulting investment responses as a function of the initial conditions. Without the endogenously higher riskiness in capital and debt positions generated by firms, the light blue line continues to slope down but is not quite as strongly sloped as the red line. Therefore, both the direct belief reversal and endogenous distributional shifts due to diagnosticity are critical for generating the overall nonlinearity in Figure 2. 


\section{Figure A.3: Investment Nonlinearity with No Distributional Dynamics}

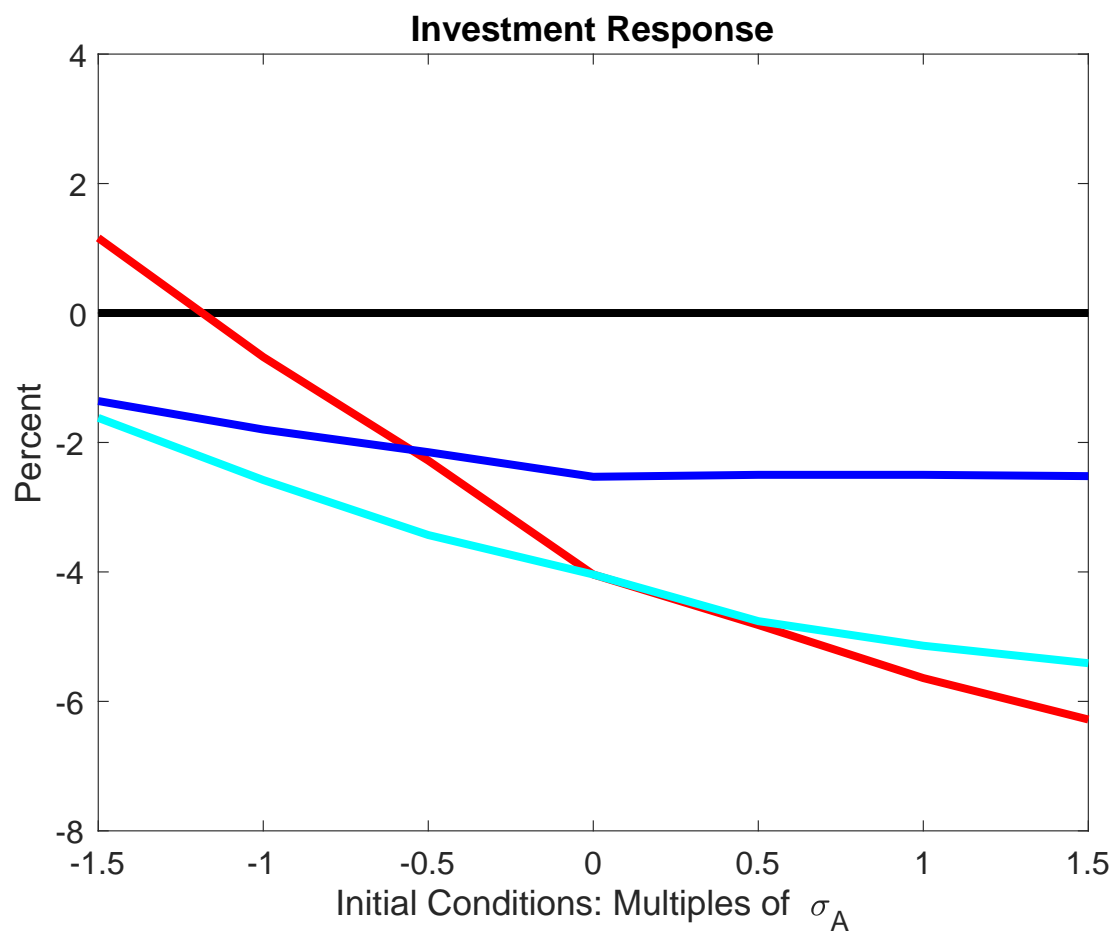

Notes: The vertical axis in the figure reports the simulated impulse response of macro investment to a one-standard deviation negative shock to macro TFP, and the horizontal axis reports the initial conditions, i.e., the magnitude of the shock to macro TFP in the previous period. The DE model (red line), RE model (blue line), and DE model with no shift in the distribution of endogenous states (light blue line) are reported on the figure.

\section{A.8 General Equilibrium Definition}

In Section 7.2 we consider an extended model with a representative household and endogenously flexible wages. Here, we outline the household, lender, and firm problems, define the equilibrium, and derive the two household first-order conditions used in the main text.

\section{A.8.1 Household}

A diagnostic representative household supplies labor $N$ and saves in a risk-free bond $B^{\prime}$ in zero-net supply according to

$$
H^{\theta}\left(\mu, A, \varepsilon_{A}, B\right)=\max _{B^{\prime}, N}\left[C-\frac{\omega}{1+\frac{1}{\lambda}} N^{1+\frac{1}{\lambda}}+\beta \mathbb{E}^{\theta}\left(H^{\theta}\left(\mu^{\prime}, A^{\prime}, \varepsilon_{A}^{\prime}, B^{\prime}\right) \mid \mu, A, \varepsilon_{A}\right)\right]
$$

The household states include the distribution $\mu(s, k, b)$ across firm states $s=\left(z, \epsilon_{z}\right), k$, and $b$, macro TFP $A$, macro news $\varepsilon_{A}$, and holdings of the bond $B$. The household's budget 
constraint is given by

$$
C+B^{\prime}=(1+R) B+W N+D^{F}+D^{L}+T .
$$

Above $D^{F}$ reflects net aggregate payouts from the firm sector, and $D^{L}$ reflects aggregate payouts from lenders, both of whom are owned by the household. $T$ reflects lump-sum transfers of corporate taxes from firms and lenders to the household. The household takes as given both the real interest rate $R$ and the wage $W$.

\section{A.8.2 Lenders}

A continuum of diagnostic risk-neutral lenders funds itself via risk-free debt, taking as given the real interest rate $R$. Each lender participates in a range of competitive credit markets for firms with state $s$, future capital $k^{\prime}$, and a desired loan amount $b^{\prime}$. If a borrower firm defaults on its debt, the lender receives the after-tax recovery rate

$$
\mathcal{R}\left(k^{\prime}, b^{\prime}\right)=\gamma(1-\tau)(1-\delta) \frac{k^{\prime}}{b^{\prime}},
$$

where $1-\gamma$ reflects a deadweight loss upon default. A lender's expected present discounted value of participating in the market for lending to firm $\left(s, k^{\prime}, b^{\prime}\right)$ given the aggregate state $\left(\mu, A, \varepsilon_{A}\right)$ is given by

$$
\begin{gathered}
-q\left(s, k^{\prime}, b^{\prime}, \mu, A, \varepsilon_{A}\right) b^{\prime} \\
+\frac{1}{1+R} \mathbb{E}^{\theta}\left[\left(1-d f\left(s^{\prime}, k^{\prime}, b^{\prime}, \mu^{\prime}, A^{\prime}, \varepsilon_{A}^{\prime}\right)\right) b^{\prime}+d f\left(s^{\prime}, k^{\prime}, b^{\prime}, \mu^{\prime}, A^{\prime}, \varepsilon_{A}^{\prime}\right) b^{\prime} \mathcal{R}\left(k^{\prime}, b^{\prime}\right) \mid s, \mu, A, \varepsilon_{A}\right] .
\end{gathered}
$$

A lender must choose to enter, or not to enter, each individual credit market, and any net profits are paid to the household owner.

\section{A.8.3 Firms}

A continuum of competitive diagnostic firms with idiosyncratic states $(s, k, b)$ owned by the household takes as given the real interest rate $R$, the wage $W$, and a debt price schedule $q\left(s, k^{\prime}, b^{\prime}, \mu, A, \varepsilon_{A}\right)$, choosing investment for future capital $k^{\prime}$, debt issuance $b^{\prime}$, static labor demand $n$, and whether to default in order to maximize the expected present discounted value of its payouts according to

$$
V^{\theta}\left(s, k, b, \mu, A, \varepsilon_{A}\right)=\max _{d f \in\{0,1\}}\left[d f V_{D}^{\theta}\left(s, \mu, A, \varepsilon_{A}\right)+(1-d f) V_{N D}^{\theta}\left(s, k, b, \mu, A, \varepsilon_{A}\right)\right]
$$




$$
\begin{gathered}
V_{N D}^{\theta}\left(s, k, b, \mu, A, \varepsilon_{A}\right)=\max _{k^{\prime}, b^{\prime}, n}\left\{d-I C(d)+\frac{1}{1+R} \mathbb{E}^{\theta}\left[V^{\theta}\left(s^{\prime}, k^{\prime}, b^{\prime}, \mu^{\prime}, A^{\prime}, \varepsilon_{A}^{\prime}\right) \mid s, \mu, A, \varepsilon_{A}\right]\right\} \\
d=\quad(1-\tau)[y-W n-A C(i, k)-\phi] \\
+q\left(s, k^{\prime}, b^{\prime}, \mu, A, \varepsilon_{A}\right) b^{\prime}-i-b+\tau(R+\delta k) \\
V_{D}^{\theta}\left(s, \mu, A, \varepsilon_{A}\right)=\left\{0+\frac{1}{1+R} \mathbb{E}^{\theta}\left[V\left(s^{\prime}, 0,0, \mu^{\prime}, A^{\prime}, \varepsilon_{A}^{\prime}\right) \mid s, \mu, A, \varepsilon_{A}\right]\right\}
\end{gathered}
$$

\section{A.8.4 Definition}

An equilibrium in this economy under diagnostic expectations is a collection including

- a wage function $W^{\theta}\left(\mu, A, \varepsilon_{A}\right)$,

- a fixed real interest rate $R$,

- a debt pricing function $q^{\theta}\left(s, k^{\prime}, b^{\prime}, \mu, A, \varepsilon_{A}\right)$,

- household value $H^{\theta}$ and policy functions $N^{\theta}, B^{\prime \theta}$ (each functions of $\left(\mu, A, \varepsilon_{A}, B\right)$ ),

- lender participation decisions for each credit market $\left(s, k^{\prime}, b^{\prime}\right)$,

- firm value and policy functions $V^{\theta}, V_{N D}^{\theta}, V_{D}^{\theta},{k^{\prime}}^{\theta}, b^{\prime \theta}, n^{\theta}$ and $d f^{\theta}$ (each functions of $\left.\left(s, k, b, \mu, A, \varepsilon_{A}\right)\right)$, and

- a transition mapping $\mu^{\prime}=\Gamma^{\theta}\left(\mu, A, \varepsilon_{A}\right)$ for the distribution $\mu(s, k, b)$ across periods

such that

- taking as given wages and the interest rate, household values and policies satisfy their dynamic problem (22) under DE beliefs from (12),

- taking as given debt prices and firm policies, lenders optimally whether to participate or not in each credit market given their payoffs (23) under DE beliefs from (12) and $(11)$,

- taking as given wages, the interest rate, and debt prices, firm values and policies satisfy their dynamic problem defined by (24), (25), and (26) under DE beliefs from (12) and $(11)$,

- labor markets clear with labor demand from firms equal to labor supply from households

$$
\int n^{\theta}\left(s, k, b, \mu, A, \varepsilon_{A}\right) d \mu(s, k, b)=N^{\theta}\left(\mu, A, \varepsilon_{A}, B\right),
$$


- individual firm credit markets clear with nonpositive expected payouts in (23) for each market $\left(s, k^{\prime}, b^{\prime}\right)$ and strictly zero expected payouts when the market is active,

- the risk-free debt market clears with risk-free debt supply from the households equal to the total funding needs of the lenders as required by firm borrowing

$$
B^{\prime \theta}\left(\mu, A, \varepsilon_{A}, B\right)=\int b^{\prime \theta}\left(s, k, b, \mu, A, \varepsilon_{A}\right) d \mu
$$

and

- the transition mapping $\Gamma^{\theta}$ accurately reflects transitions of states given firm policies and diagnostic expectations, i.e.,

$$
\begin{gathered}
\int_{\left\{\left(s^{\prime}, k^{\prime}, b^{\prime}\right) \in \mathcal{A}\right\}} d \mu^{\prime}\left(s^{\prime}, k^{\prime}, b^{\prime}\right)=\int_{\mathcal{B}} f^{\theta}\left(s^{\prime} \mid s\right) d \mu(s, k, b) \\
\mathcal{B}\left(\mathcal{A}, \mu, A, \varepsilon_{A}\right)=\left\{(s, k, b) \mid\left(s^{\prime}, k^{\prime \theta}, b^{\prime}{ }^{\theta}\right) \in \mathcal{A} \text { for some } s^{\prime}\right\}
\end{gathered}
$$

for any well behaved set $\mathcal{A}$ whenever $\mu^{\prime}=\Gamma^{\theta}\left(\mu, A, \varepsilon_{A}\right)$.

\section{A.8.5 Characterization of Prices}

Note that the linearity of household utility over consumption, together with optimal savings in risk-free debt, implies that a constant risk-free rate $R=\frac{1}{\beta}-1$, given in the main text in (20), is the only one consistent with equilibrium. Discounted payoffs of firms and lenders at this interest rate are therefore equivalent to expected present discounted value maximization at the household's stochastic discount factor (in this case degenerate to $\beta$ ). Furthermore, a household's labor supply optimality condition is given by

$$
\omega N^{\frac{1}{\lambda}}=W
$$

and since this expression doesn't depend upon consumption $C$ it must also not depend upon household debt $B$. Therefore, the labor market clearing condition above can be rewritten

$$
\left(\frac{W^{\theta}\left(\mu, A, \varepsilon_{A}\right)}{\omega}\right)^{\lambda}=\int n^{\theta}\left(s, k, b, \mu, A, \varepsilon_{A}\right) d \mu(s, k, b),
$$

which is equivalent to the Equation (21) given in the main text. Also note that linearity of the household's preferences allows us to avoid specifying the nature of aggregate resource constraints or goods market clearing, since these details do not impact firm, lender, or household policies at the margin, although it is natural and harmless to assume that the structure of taxation clears a fiscal budget constraint each period and that the household 
absorbs any unexpectedly high or low aggregate payouts from diagnostic firms and lenders. Finally, note that for any market in which lending is active, the competitive nature of lending together yields zero diagnostically expected discounted profits in Equation (23) so that

$q^{\theta}\left(s, k^{\prime}, b^{\prime}, \mu, A, \varepsilon_{A}\right)=\frac{1}{1+R} \mathbb{E}^{\theta}\left[\left(1-d f^{\theta}\left(s^{\prime}, k^{\prime}, b^{\prime}, \mu^{\prime}, A^{\prime}, \varepsilon_{A}^{\prime}\right)\right)+d f^{\theta}\left(s^{\prime}, k^{\prime}, b^{\prime}, \mu^{\prime}, A^{\prime}, \varepsilon_{A}^{\prime}\right) \mathcal{R}\left(k^{\prime}, b^{\prime}\right) \mid s, \mu, A, \varepsilon_{A}\right]$

\section{A.8.6 General Equilibrium Solution Algorithm}

One might suspect that this problem poses more difficulty than the usual rational expectations model because of diagnostic expectations. But the characterization of prices above, dependent upon the careful assumption of linear consumption utility, actually implies that we face only the usual numerical challenges that arise in any model with a "Krusell Smith problem." In other words, there are two familiar computational challenges to numerically solving the general equilibrium model laid out above. First, the distributional state $\mu$ entering into the pricing function $W^{\theta}$ is intractable. Second, the transition mapping $\Gamma^{\theta}$ (implicitly appearing in the optimal debt pricing condition and firm value functions) and the wage mapping $W^{\theta}$ appearing in firm and household problems are also intractable and unavailable in closed form.

We implement a tractable approach to addressing both problems by replacing the distributional state $\mu$ with a truncated history of length $K$ of the aggregate TFP shocks $\left(A_{t-K}, A_{t-K+1}, \ldots, A_{t-1}, A_{t}\right)$. For moderate history lengths $K$, the approximate state is more tractable than the distribution $\mu$, and the mapping $\Gamma^{\theta}$ collapses to the simple diagnostic expectations of the evolution of the exogenous process which we have already exploited. With this simplification in hand, we then follow an outer loop/inner loop approach to solving the model.

1. Guess a mapping from a truncated history of macro states

$$
\left(A_{t-K}, A_{t-K+1}, \ldots, A_{t-1}, A_{t}\right) \rightarrow W_{t}
$$

2. Solve the model conditional upon this tractable truncated history, where $\left(A_{t}, A_{t-1}, \ldots ., A_{t-K}\right)$ enters the firm's state vector and hence the Bellman equations determining investment, default, and debt issuance policies.

3. Simulate the model for a large number of periods $t=1, \ldots, T$, clearing markets with $W_{t}$ in each period $t$ by numerically solving the nonlinear equation

$$
\left(\frac{W_{t}}{\omega}\right)^{\lambda}=\int n\left(s, k, b \mid W_{t}\right) d \mu_{t}(s, k, b)
$$


for each period $t$ in the simulation. Note that this is a well behaved nonlinear equation in one variable. The analytically computable static labor policies $n\left(s, k, b \mid W_{t}\right)$ are strictly declining in $W_{t}$ on the RHS and the function on the LHS is strictly increasing in $W_{t}$. In practice, markets can be cleared robustly using bisection or another similar algorithm.

4. Based on the simulated wage data, update your wage prediction mapping from Step 1. If the mapping has converged to within some tolerance, exit. If not update the mapping and return to Step 1.

Figure A.4: Expected Wage Growth

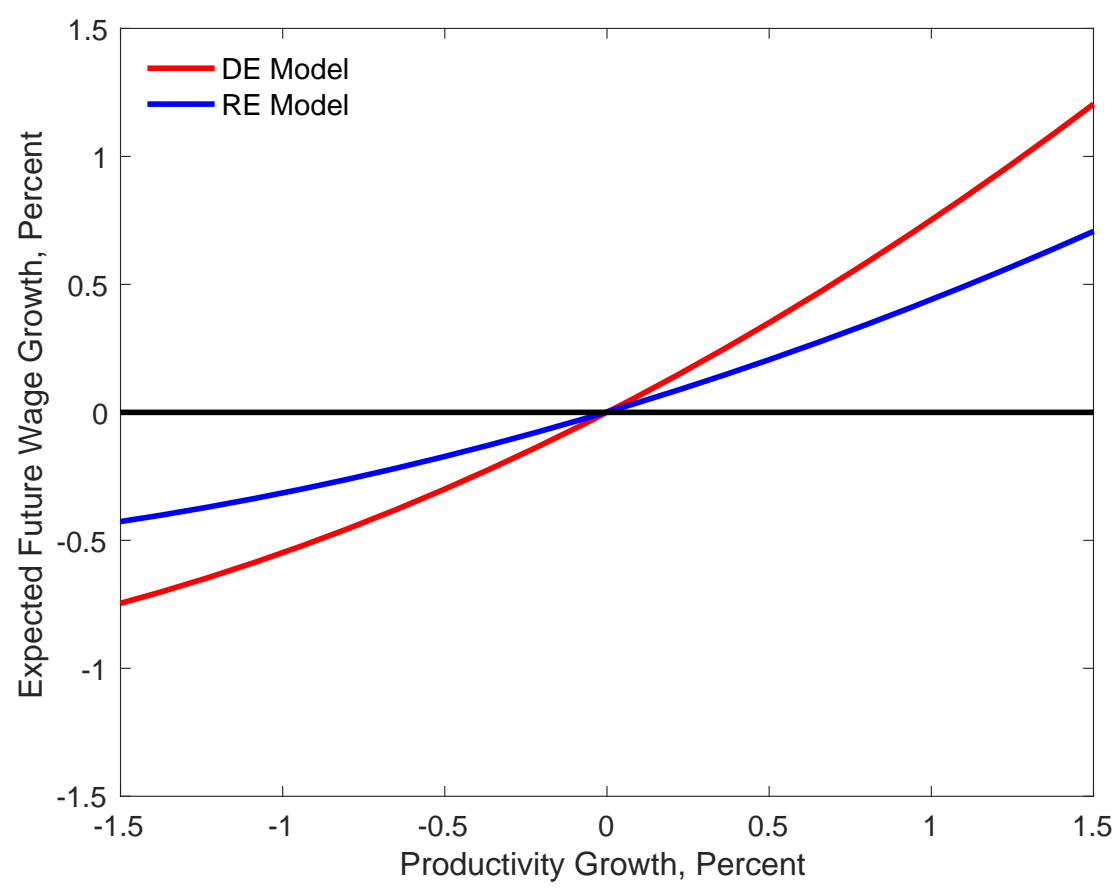

Notes: The figure plots the expected path of wage growth in the next period (vertical axis) given productivity growth today (horizontal axis) in the DE model (red) and RE model (blue).

A few practical comments are in order about this approach to solving the Krusell Smith problem, which to our knowledge is a novel, although conceptually straightforward, solution method. First, given the discretized macro TFP state space, we store the wage mapping nonparametrically as a matrix of mean wages conditional upon each combination of truncated macro TFP histories. After simulation, the wage mapping update step simply involves repeated calculations of mean wages within the appropriate subsamples of the simulated data. Figure A.4 plots the perceived wage mapping under DE and RE as a function of macro TFP growth in our converged GE solutions. Second, because the macro state is 


\section{Figure A.5: Wage Predictions and TFP Lags}

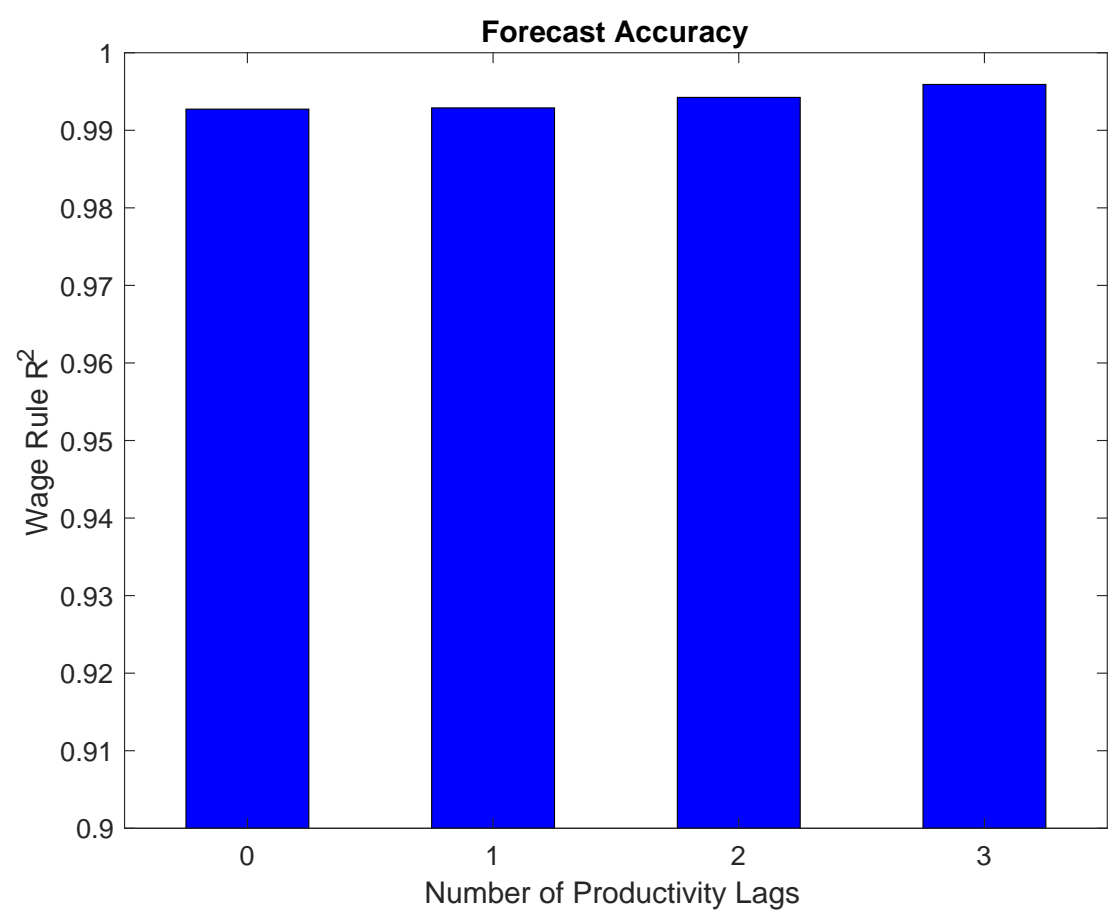

Notes: The figure plots the $R^{2}$ of nonparametric regressions of log wages on discrete histories of macro TFP of increasing length.

replaced with macro TFP shock histories rather than with an augmented endogenous macro moment, there is no need to create an approximate anticipated default rule used to price debt. Lenders simply price debt according to the usual no-arbitrage condition in Equation (27) above. Third, because no endogenous moments are forecasted in our solution method, there is no Den Haan (2010)-style distinction between static and dynamic forecasts of the wage. In other words, there is no room for forecast errors about endogenous macro moments to accumulate over time, since only exogenous shock histories are used for forecasts. So, unlike in typical adaptations of the Krusell and Smith (1998) method, the $R^{2}$ of the implicit wage forecast rule is in this case an appropriate metric of accuracy. With this in mind, Figure A.5 plots the estimated $R^{2}$ of regressions of the log wage on fully populated sets of dummies for macro TFP histories of up to a given lag length. Once a single lag is taken into account, incorporating information from yesterday's TFP level about the current distribution of capital and hence labor demand in the cross section, the $R^{2}$ measures stabilize. Our baseline case, which uses a single lag with $K=1$ in the wage prediction rule, is therefore a parsimonious but apparently accurate choice. 


\section{B Data}

\section{B.1 Microdata on Firm Beliefs from Compustat and IBES-Guidance}

In our analysis of firm financial and profit forecasts we use a combination of the Compustat Fundamentals Annual and IBES manager guidance databases. The combined sample for the Compustat-IBES data spans 1999-2017 for 8620 firm-fiscal years spanning 1320 firms. To construct our sample, we discard utilities and financials as well as any firm-years with negative values for assets, capital, employment or sales. Descriptive statistics for each variable from this sample used in our analysis, as well as firm revenues and capital, are reported in Table B.1.

\section{Table B.1: Sample Descriptive Statistics}

\begin{tabular}{c|c|c} 
Quantity & Mean & Standard Deviation \\
\hline \hline Sales & 6732.4 & 23268.8 \\
Capital & 1499.4 & 6286.3 \\
Profit & 0.448 & 1.062 \\
Investment & 0.321 & 0.238 \\
Debt Issuance & -0.404 & 3.883 \\
Forecast Error & -0.267 & 0.804 \\
Forecast & 0.823 & 0.933 \\
\hline \hline
\end{tabular}

Notes: The table reports descriptive statistics for the sample of 1320 firms from 1999-2017 in the combined Compustat-IBES database. The first two rows represent revenues and the book value of the capital stock, in $\$$ millions. The remaining rows reflect the ratio of realized earnings to the book value of the capital stock, the capital expenditures investment rate, the ratio of end of period total liabilities to the capital stock, the next-period forecast error defined as realized future profits minus manager guidance scaled by firm capital, and the next period forecast defined as manager profit guidance scaled by firm capital. The sample was winsorized before computing the descriptive statistics above.

The variable definitions are given as follows, with both empirical and model information attached:

- Earnings or profits are equal to GAAP net income, Compustat ib. The model equivalent is $\pi=(1-\tau)(y-W n-A C(i, k)-\phi)+\tau(R b+\delta k)-\delta k$.

- Capital $k$ is equal to the book value of plants, property, and equipment, Compustat ppent. The model equivalent is the state variable $k$.

- Investment $i$ is equal to the total value of capital expenditures, Compustat capxv. The model equivalent is the policy variable $i=k^{\prime}-(1-\delta) k$.

- Debt $b$ is equal to the total net value of liabilities, Compustat $\mathrm{dltt}+\mathrm{dlc}-\mathrm{che}$. The model equivalent is the state variable $b$. 
- Forecast error $f e$ is equal to the realized value of earnings $\pi$ minus the forecast level of earnings $\pi^{f}$ made from the previous fiscal year, where realized earnings are Compustat $i b$ and forecast earnings are equal to manager guidance from the IBES database. The model equivalent is the earnings value $\pi$ above, minus the forecast level implied by firm-level diagnostic expectations, the definition of $\pi$, and firm policies predetermined in the previous period.

We also use the merged Compustat-IBES guidance sample to run various robustness checks to the firm forecast error predictability regressions reported in the main text. Table B.2 shows similar forecast error predictability maintains after the Great Recession, in a sample of firms present for five or more years in the data, and after discarding all firms with high-yield debt as classified by Moody's ratings.

\section{B.2 Microdata on Bonds from FISD-TRACE}

We use the WRDS US Corporate Bond Return database, which merges the Mergent FISD and FINRA TRACE datasets with issuance and secondary market information on corporate bond issues, respectively. We consider only unsecured, unconvertible debentures and convert secondary market yields to spreads based on comparable Treasury rates, with a resulting dataset of around 80,000 issues from mid-2002 to late 2019. We link the bond return database to Compustat firm financials through the WRDS CRSP link, and we aggregate from the issue to firm level by computing average yields and bond returns for a firm in Q4 of a given year. The resulting dataset spans around 1,500 large US public firms. Linking this panel to the IBES-manager guidance data yields the sample used in Table 2 in the main text. Table B.3 replicates Table 2 conditioning only on investment grade bonds. Table B. 4 replicates Table 2 but does not include current profit controls for the investment regressions nor lagged spread controls for the spread regressions.

\section{B.3 Macro Data}

At the macro level, we use a combination of information from the NIPA accounts, the BIS, Moody's. The following variables are relevant, all at annual frequency or converted to annual frequency by averaging.

- Output $Y$ is real GDP from the NIPA accounts.

- Debt $B$ is real total nonfinancial corporate credit in the US from the BIS.

- Investment $I$ is real nonresidential private investment from the NIPA accounts in the data. 
- Spreads are the Moody's BAA spread relative to 10-year Treasury bonds, at an annualized rate.

- TFP is the annualized value of the series dtfp from John Fernald's website.

- Profit Fcst is the sum of earnings guidance across firms in a given year from our Compustat-IBES merged database.

In the empirical business cycle moments in Table 6, we reports moments from the HPfiltered values of output, investment, and debt, together with unadjusted spread levels. In the spread matching/Great Recession exercise in Figure 4, we report the average spread and the average growth of credit, output, investment, and profit forecasts in each subperiod.

\section{B.4 SMM Estimation}

Our SMM estimation exercise in Section 5.1 involves three steps: 1) moment and covariance matrix calculations, 2) model estimation, and 3) standard error calculation. We detail each of these steps in turn.

\section{B.4.1 Moment and Covariance Matrix Calculation}

Table 5 reports a set of target moments at the micro and macro levels for our SMM estimation exercise. The micro moments are a covariance matrix of the vector

$$
X_{i t}=\left(\text { Profit }_{i t}, \text { Investment }_{i t}, \text { Debt }_{i t}, \text { Spread }_{i t}\right)^{\prime}
$$

for firm $i$ in fiscal year $t$ from our merged Compustat-IBES-FISD-TRACE sample. The micro moments also include the covariance of future forecast error growth with lagged investment and debt issuance growth at a two-period horizon, together with the variance of future forecast errors. The merged sample with all of the required variables available spans 493 firms and 4697 total observations. To compute the micro moments, we use the following procedure:

- Demean $X_{i t}$ by firm and year to obtain $\hat{X}_{i t}$

- Compute the covariance matrix as the mean of $\hat{X}_{i t} \hat{X}_{i t}^{\prime}$.

- Apply the standard formula for the clustered covariance of a mean vector to obtain the moment covariance matrix $\Omega_{\text {Micro }}$, clustering across firms.

With the estimated micro moments and the estimated moment covariance matrix for the micro moments in hand, we then turn to the calculation of the macro moments and 
their covariance matrix. Note that the macro moments are the mean default rate, the mean spread, and the standard deviation of real GDP growth. We compute the mean default and spread series from our merged FISD-TRACE data on corporate debt, and we compute real GDP growth from the NIPA data. The point estimates of these macro moments are trivial to compute. We then compute an estimate of the covariance matrix of these macro moments $\Omega_{\text {Macro }}$ using a stationary block bootstrap.

Note that for our later inference based on clustering at the firm level, we will rely upon an assumption that the macro sample length $T$ and the number of firms $N$ behave proportionally with $T / N \rightarrow \gamma$ for some constant $\gamma$ as $N \rightarrow \infty$. This allows us to rely on asymptotics of the basic form

$$
\sqrt{T}(\hat{\mu}-\mu) \rightarrow_{d} N(0, \Omega)
$$

where $\hat{\mu}$ is the estimated moment vector (with micro and macro moments) and $\Omega$ is the joint moment covariance matrix. Table 5 reports $\hat{\mu}$.

\section{B.4.2 Point Estimate Calculation}

We compute the point estimates $\hat{\beta}$ for the vector of estimated parameters $\beta$ in Table 4 by solving the following standard SMM optimization problem

$$
\min _{\beta}\left(\mu^{S}(\beta)-\hat{\mu}\right)^{\prime} \hat{\Omega}^{-1}\left(\mu^{S}(\beta)-\hat{\mu}\right)
$$

where $\mu^{S}(\beta)$ is the model value of the moments given $\beta$ computed from simulated data, $\hat{\Omega}^{-1}$ is the asymptotically efficient weighting matrix given by the inverse of the estimated moment covariance matrix, and $\hat{\mu}$ is the empirical moment vector. We employ particle swarm optimization to solve this optimization problem, a stochastic global optimization routine that bears substantial similarity to simulated annealing and genetic algorithms.

\section{B.4.3 Standard Error Calculation}

Given the ratio between the number of observations $T^{\text {sim }}$ in the model simulation used to compute $\mu^{S}(\beta)$ and the empirical number of observations $T$, the SMM estimator's asymptotic covariance matrix $\Sigma$ follows

$$
\sqrt{T}(\hat{\beta}-\beta) \rightarrow_{d} N(0, \Sigma)
$$

where

$$
\Sigma=\left(1+\frac{T}{T^{\operatorname{sim}}}\right)\left(\frac{\partial \mu^{S}(\beta)}{\partial \beta^{\prime}} \Omega^{-1} \frac{\partial \mu^{S}(\beta)}{\partial \beta}\right)^{-1} .
$$

Equation (30) yields a feasible formula for $\Sigma$ after substitution of the estimated covariance 
matrix $\hat{\Omega}$ and numerical calculation of the moment Jacobian matrix $\frac{\partial \mu^{S}(\beta)}{\partial \beta^{\prime}}$ within the model using forward differentiation from the point estimates $\hat{\beta}$. With these elements in hand, Tables 4 reports standard errors based on the approximating variance from (29).

\section{B.5 GMM Regression Coefficients with Firm Fixed Effects}

In this appendix section we provide a statistical framework for the analysis of forecast overreaction allowing for firm fixed effects through the use of within-firm differences and GMM estimators. We use these results directly to provide reduced-form regression coefficients with firm fixed effects in Table 1 via GMM, and they also prove useful for generating intuition for the identification of the beliefs parameter $\theta$ in our quantitative SMM estimation of the RBC model in Section 5.1.

\section{B.5.1 Data Generating Process}

Let $x_{i t}$ be the observed value of the forecasted variable $\tilde{x}_{i t}$ (e.g., profits) for firm $i$ in period $t$, following an $\operatorname{AR}(1)$ with firm fixed effects $\mu_{i}^{x}$ and subject to measurement error $\nu_{i t}^{x}$ with MA(1) dynamics:

$$
\begin{array}{cc}
\tilde{x}_{i t}=\mu_{i}^{x}+\rho \tilde{x}_{i t-1}+\epsilon_{i t}, & \epsilon_{i t} \sim N\left(0, \sigma_{\epsilon}^{2}\right) \\
x_{i t}=\tilde{x}_{i t}+\nu_{i t}^{x}+\gamma_{x} \nu_{i t-1}^{x}, & \nu_{i t}^{x} \sim N\left(0, \sigma_{x, \nu}^{2}\right)
\end{array}
$$

Let $y_{i t}$ be the observed value of a variable $\tilde{y}_{i t}$ (e.g., investment) linked linearly to the forecasted variable, subject to its own fixed effects $\mu_{i}^{y}$ and its own MA(1) measurement error $\nu_{i t}^{y}$ :

$$
\begin{gathered}
\tilde{y}_{i t}=\mu_{i}^{y}+\alpha \tilde{x}_{i t} \\
y_{i t}=\tilde{y}_{i t}+\nu_{i t}^{y}+\gamma_{y} \nu_{i t-1}^{y}, \quad \nu_{i t}^{y} \sim N\left(0, \sigma_{y, \nu}^{2}\right) .
\end{gathered}
$$

Allow forecasts $\tilde{x}_{i t+1 \mid t}^{f}$ to follow the DE formula, but also allow for forecast bias in the form of fixed effects $\mu_{i}^{f}$ and for MA(1) measurement noise $\nu_{i t}^{f}$ in the observed value $x_{i t+1 \mid t}^{f}$

$$
\begin{gathered}
\tilde{x}_{i t+1 \mid t}^{f}=\mu_{i}^{f}+\rho \tilde{x}_{i t}+\rho \theta \epsilon_{i t} \\
x_{i t+1 \mid t}^{f}=\tilde{x}_{i t+1 \mid t}^{f}+\nu_{i t}^{f}+\gamma_{f} \nu_{i t-1}^{f}, \quad \nu_{i t}^{f} \sim N\left(0, \sigma_{f, \nu}^{2}\right) .
\end{gathered}
$$

The implied observed forecast errors $f e_{i t+1}=x_{i t+1}-x_{i t+1 \mid t}^{f}$ are then given by

$$
f e_{i t+1}=\left(\mu_{i}^{x}+\rho \tilde{x}_{i t}+\epsilon_{i t+1}+\nu_{i t+1}^{x}+\gamma_{x} \nu_{i t}^{x}\right)-\left(\mu_{i}^{f}+\rho \tilde{x}_{i t}+\rho \theta \epsilon_{i t}+\nu_{i t}^{f}+\gamma_{f} \nu_{i t-1}^{f}\right)
$$




$$
f e_{i t+1}=\left(\mu_{i}^{x}-\mu_{i}^{f}\right)+\epsilon_{i t+1}+\nu_{i t+1}^{x}+\gamma_{x} \nu_{i t}^{x}-\rho \theta \epsilon_{i t}-\nu_{i t}^{f}-\gamma_{f} \nu_{i t-1}^{f}
$$

\section{B.5.2 Nonoverlapping Difference Covariances as Useful Moments}

Choose any difference horizons $\bar{s}, \underline{s} \geq 1$. Then the data generating process laid out above implies that the covariance of future forecast error growth with current profit growth in the firm is given by

$$
\begin{gathered}
\operatorname{cov}\left(f e_{i t+\bar{s}}-f e_{i t}, x_{i t-1}-x_{i t-\underline{s}}\right)= \\
\operatorname{cov}\left(\begin{array}{cc}
\epsilon_{i t+\bar{s}}+\nu_{i t+\bar{s}}^{x}+\gamma_{x} \nu_{i t+\bar{s}-1}^{x}-\rho \theta \epsilon_{i t+\bar{s}-1}-\nu_{i t+\bar{s}-1}^{f}-\gamma_{f} \nu_{i t+\bar{s}-2}^{f} & \epsilon_{i t-1}+\nu_{i t-1}^{x}+\gamma_{x} \nu_{i t-2}^{x}+\rho \tilde{x}_{t-2} \\
-\epsilon_{i t}-\nu_{i t}^{x}-\gamma_{x} \nu_{i t-1}^{x}+\rho \theta \epsilon_{i t-1}+\nu_{i t-1}^{f}+\gamma_{f} \nu_{i t-2}^{f} & -\rho \tilde{x}_{t-2-\underline{s}}-\epsilon_{i t-1-\underline{s}}-\nu_{i t-1-\underline{s}}^{x}-\gamma_{x} \nu_{i t-1-\underline{s}-1}^{x}
\end{array}\right) \\
=\rho \theta \operatorname{cov}\left(\epsilon_{i t-1}, \epsilon_{i t-1}\right)-\gamma_{x} \operatorname{cov}\left(\nu_{i t-1}^{x}, \nu_{i t-1}^{x}\right)=\rho \theta \sigma_{\epsilon}^{2}-\gamma_{x} \sigma_{\nu, x}^{2} .
\end{gathered}
$$

We immediately obtain our first result, that the covariance of future forecast growth with profit growth can offer evidence of diagnosticity in beliefs but may be inconclusive in the presence of $\mathrm{MA}(1)$ measurement error in profits.

Result 1: If $\operatorname{cov}\left(f e_{i t+\bar{s}}-f e_{i t}, x_{i t-1}-x_{i t-\underline{s}}\right)=\rho \theta \sigma_{\epsilon}^{2}-\gamma_{x} \sigma_{\nu, x}^{2}>0$ for some $\bar{s}, \underline{s} \geq 1$ and $\gamma_{x}>0$, then $\theta>0$.

To exploit similar intuition but avoid cross-contamination with profit measurement error, we can also compute the covariance of future forecast error growth with the growth of outcomes $y_{i t}$ in the firm such as investment or debt.

$$
\operatorname{cov}\left(f e_{i t+\bar{s}}-f e_{i t}, y_{i t-1}-y_{i t-\underline{s}}\right)=\alpha \rho \theta \operatorname{cov}\left(\epsilon_{i t-1}, \epsilon_{i t-1}\right)=\alpha \rho \theta \sigma_{\epsilon}^{2}
$$

We then immediately obtain our second result, which is that covariances of future forecast error growth with investment or debt growth in the firm should be zero unless expectations are diagnostic with $\theta=0$.

Result 2: If $\operatorname{cov}\left(f e_{i t+\bar{s}}-f e_{i t}, y_{i t-1}-y_{i t-\underline{s}}\right)=\alpha \rho \theta \sigma_{\epsilon}^{2}>0$ for some $\bar{s}, \underline{s} \geq 1$ and $\alpha>0$, then $\theta>0$.

Result 2, which holds analytically in closed form and still holds approximately in our nonlinear RBC model, provides direct motivation for our use of the forecast error growth covariance moments in Section 5.1.

\section{B.5.3 Obtaining Regression Coefficients}

In this section, we derive formulas for the asymptotically normal and consistent GMM estimation of regression coefficients of future forecast errors on debt and investment outcomes in the firm, allowing for both measurement error and fixed effects in all series. In particular, using the notation of our data generating process, our goal is to estimate regression coefficients linking the following "cleansed" variables to one another: 
- Forecast errors without measurement error or fixed effects $f e_{i t+1}^{*}=\epsilon_{i t+1}-\rho \theta \epsilon_{i t}$

- The linked variable without measurement error or fixed effects $y_{i t}^{*}=\tilde{y}_{i t}-\mu_{i}^{y}$

Now, note a few simple results based on our data generating process above.

$$
\begin{gathered}
\operatorname{cov}\left(f e_{i t+1}^{*}, y_{i t}^{*}\right)=\operatorname{cov}\left(\epsilon_{i t+1}-\rho \theta \epsilon_{i t}, \alpha \epsilon_{i t}+\ldots\right)=-\alpha \rho \theta \sigma_{\epsilon}^{2} \\
\operatorname{var}\left(y_{i t}^{*}\right)=\alpha^{2} \frac{\sigma_{\epsilon}^{2}}{1-\rho^{2}} .
\end{gathered}
$$

Therefore, the probability limit of a univariate regression of forecast errors $f e_{i t+1}^{*}$ on the linked variable $y_{i t}^{*}$ is given by

$$
\beta_{y}=\frac{\operatorname{cov}\left(f e_{i t+1}^{*}, y_{i t}^{*}\right)}{\operatorname{var}\left(y_{i t}^{*}\right)}=\frac{-\alpha \rho \theta \sigma_{\epsilon}^{2}}{\alpha^{2} \frac{\sigma_{\epsilon}^{2}}{1-\rho^{2}}}=\frac{-\rho \theta \sigma_{\epsilon}^{2}}{\alpha \frac{\sigma_{\epsilon}^{2}}{1-\rho^{2}}} .
$$

Now, this is true for each linked variable $y$, and in particular for $y=i$ (investment) and $y=b^{\prime}$ (debt issuance). The statistical framework above implies the following moment relationships.

$$
\begin{gathered}
m_{1}=\operatorname{cov}\left(f e_{i t+1}-f e_{i t}, i_{i t-1}-i_{i t-1}\right)=\alpha_{i} \rho \theta \sigma_{\epsilon}^{2} \\
m_{2}=\operatorname{cov}\left(f e_{i t+1}-f e_{i t}, b_{i t-1}^{\prime}-b_{i t-1}^{\prime}\right)=\alpha_{b^{\prime}} \rho \theta \sigma_{\epsilon}^{2} \\
m_{3}=\operatorname{cov}\left(b_{i t-1}^{\prime *}, i_{i t}^{*}\right)=\alpha_{i} \alpha_{b^{\prime}} \frac{\sigma_{\epsilon}^{2}}{1-\rho^{2}}
\end{gathered}
$$

But all of these are estimable consistently. $m_{1}$ and $m_{2}$ are probability limits of covariances of differences. $m_{3}$ is the probability limit of the covariance of residualized investment and debt. Consider a general central limit theorem

$$
\sqrt{N}(m(X)-m) \rightarrow_{d} N(0, \Sigma)
$$

where $m(X)=\left(m_{1}, m_{2}, m_{3}\right)^{\prime}$ is the moment estimate from the data $X, N$ is the observation count and $\Sigma$ is the asymptotic variance of $m(X)$ allowing for firm-level clustering. Note that $\Sigma$ can be estimated via off-the-shelf closed-form form econometric formulas. Then consider the vector of regression coefficients $\beta=\left(\beta_{i}, \beta_{b^{\prime}}\right)^{\prime}$, which is a function of the underlying vector $m$ given by

$$
\beta(m)=\left(\begin{array}{c}
-\frac{m_{2}}{m_{3}} \\
-\frac{m_{1}}{m_{3}}
\end{array}\right) .
$$

Via the Delta method we have

$$
\sqrt{N}(\hat{\beta}-\beta) \rightarrow_{d} N(0, \Omega),
$$


where the asymptotic variance of the regression coefficient vector is given by

$$
\Omega=\frac{\partial \beta}{\partial m^{\prime}} \Sigma \frac{\partial \beta}{\partial m}
$$

All of these objects have feasible estimators, since the Jacobian has a simple form given by

$$
\frac{\partial \beta}{\partial m^{\prime}}=\left[\begin{array}{ccc}
0 & \frac{-1}{m_{3}} & \frac{m_{2}}{m_{3}^{2}} \\
\frac{-1}{m_{3}} & 0 & \frac{m_{1}}{m_{3}^{2}}
\end{array}\right] .
$$

With this framework in hand, we note that Table 1 in columns (2) and (4) reports the regression coefficient point estimates $\hat{\beta}=\beta(\hat{m})$ as well as the standard errors $\sqrt{\frac{\operatorname{diag} \hat{\Omega}}{N}}$. 


\section{B.6 Robustness Tables}

\section{Table B.2: Predictable Forecast Errors: Robustness}

\begin{tabular}{lcccc}
\hline \hline & $(1)$ & $(2)$ & $(3)$ & $(4)$ \\
& \multicolumn{4}{c}{ Forecast Error $_{t+1}$} \\
Sample: & Baseline & Inv. Grade & $\geq 5$ Yrs. & Post G.R. \\
\hline Panel A: Investment & & \\
\hline Investment $_{t}$ & $-0.618^{* * *}$ & $-0.628^{* * *}$ & $-0.784^{* * *}$ & $-0.954^{* * *}$ \\
& $(0.119)$ & $(0.128)$ & $(0.097)$ & $(0.182)$ \\
\hline Panel B: Debt $^{5}$ & & & \\
\hline Debt $_{t}$ & $-0.562^{* * *}$ & $-0.538^{* * *}$ & $-0.621^{* * *}$ & $-1.051^{* * *}$ \\
& $(0.187)$ & $(0.200)$ & $(0.130)$ & $(0.312)$ \\
\hline Year Effects & $\mathrm{X}$ & $\mathrm{X}$ & $\mathrm{X}$ & $\mathrm{X}$ \\
Years & $1999-2018$ & $1999-2018$ & $1999-2018$ & $2010-2018$ \\
Firm-Years & 4449 & 3893 & 5331 & 2139 \\
\hline \hline
\end{tabular}

Notes: The table reports panel OLS estimates from the merged Compustat-IBES sample of the coefficients of a regression of forecast errors on the indicated variable. Each column, across rows, reports coefficients for a particular sample of interest. The standard errors are clustered at the firm level. All variables are scaled by the firm's tangible capital stock and measured at the firm-fiscal year level. Forecast errors in $t+1$ are realized earnings in $t+1$ minus firm forecasts in $t$. Investment in $t$ is capital expenditures. Debt is long-term and short-term liabilities at the end of t. $*=10 \%$ level, $* *=5 \%$ level, and $* * *=1 \%$ level. The standard deviations of each variable in the baseline sample are 0.305 (forecast errors), 0.067 (investment), and 0.056 (debt), where $0.01=1 \%$ relative to the firm's capital stock. 
Table B.3: Linking Forecast Errors and Firm Reversals: Investment Grade Firms

\begin{tabular}{|c|c|c|c|c|c|c|}
\hline & (1) & (2) & (3) & $(4)$ & $(5)$ & $(6)$ \\
\hline $\begin{array}{l}\text { Panel A: Second Stage } \\
\text { Estimation Method: }\end{array}$ & $\begin{array}{l}\text { Return }_{t} \\
\text { OLS }\end{array}$ & $\begin{array}{l}\text { Return }_{t} \\
\text { IV }\end{array}$ & $\begin{array}{l}\Delta \text { Spread }_{t} \\
\text { OLS }\end{array}$ & $\begin{array}{l}\Delta \text { Spread }_{t} \\
\text { IV }\end{array}$ & $\begin{array}{l}\Delta \text { Investment }_{t} \\
\text { OLS }\end{array}$ & $\begin{array}{c}\Delta \text { Investment }_{t} \\
\text { IV }\end{array}$ \\
\hline Forecast Error $_{t}$ & $\begin{array}{l}0.00004 \\
(0.0005)\end{array}$ & $\begin{array}{c}0.007^{*} \\
(0.003)\end{array}$ & $\begin{array}{c}-0.001^{* *} \\
(0.0004)\end{array}$ & $\begin{array}{c}-0.007^{* * *} \\
(0.003)\end{array}$ & $\begin{array}{l}0.020^{* *} \\
(0.009)\end{array}$ & $\begin{array}{c}0.409^{* * *} \\
(0.074)\end{array}$ \\
\hline Panel B: First Stage & \multicolumn{6}{|c|}{ Forecast Error ${ }_{t}$} \\
\hline Investment $_{t-1}$ & & $\begin{array}{c}-0.568^{* * *} \\
(0.118)\end{array}$ & & $\begin{array}{c}-0.568^{* * *} \\
(0.118)\end{array}$ & & $\begin{array}{c}-0.568^{* * *} \\
(0.118)\end{array}$ \\
\hline Year Effects & $\mathrm{X}$ & $\mathrm{X}$ & $\mathrm{X}$ & $\mathrm{X}$ & $\mathrm{X}$ & $\mathrm{X}$ \\
\hline Years & 2003-2018 & $2003-2018$ & 2003-2018 & 2003-2018 & 2003-2018 & 2003-2018 \\
\hline Firm-Years & 1984 & 1984 & 1984 & 1984 & 1984 & 1984 \\
\hline First Stage F & & 23.27 & & 23.27 & & 23.27 \\
\hline
\end{tabular}

Notes: The table reports estimates of specifications on the merged Compustat - IBES - FISD/TRACE sample at the firm-fiscal year level, restricting to firms with Moody's rated investment grade debt. The top panel plots OLS and IV second-stage estimates. The bottom panel, where relevant, reports IV first-stage estimates. Columns (3)-(4) control for lagged spreads, and columns (5)-(6) control for current profits in the second stage. Standard errors are clustered at the firm level. $*=10 \%$ level, $* *=5 \%$ level, and $* * *=1 \%$ level. The standard deviation of the bond return is 0.014 , the standard deviation of spread growth is 0.024 , the standard deviation of investment growth is 0.090 , the standard deviation of the forecast error is 0.438 , and the standard deviation of lagged investment is 0.133 . For all series, $0.01=1 \%$ relative to a firm's tangible capital stock. 
Table B.4: Linking Forecast Errors and Firm Reversals: No Controls

\begin{tabular}{|c|c|c|c|c|c|c|}
\hline & (1) & $(2)$ & $(3)$ & $(4)$ & $(5)$ & $(6)$ \\
\hline $\begin{array}{l}\text { Panel A: Second Stage } \\
\text { Estimation Method: }\end{array}$ & $\begin{array}{l}\text { Return }_{t} \\
\text { OLS }\end{array}$ & $\begin{array}{l}\text { Return }_{t} \\
\text { IV }\end{array}$ & $\begin{array}{l}\Delta \text { Spread }_{t} \\
\text { OLS }\end{array}$ & $\begin{array}{l}\Delta \text { Spread }_{t} \\
\text { IV }\end{array}$ & $\begin{array}{l}\Delta \text { Investment }_{t} \\
\text { OLS }\end{array}$ & $\begin{array}{c}\Delta \text { Investment }_{t} \\
\text { IV }\end{array}$ \\
\hline Forecast Error $_{t}$ & $\begin{array}{c}0.001 \\
(0.001)\end{array}$ & $\begin{array}{c}0.007^{*} \\
(0.004)\end{array}$ & $\begin{array}{c}-0.003^{* * *} \\
(0.001)\end{array}$ & $\begin{array}{c}-0.007^{* *} \\
(0.004)\end{array}$ & $\begin{array}{c}0.008 \\
(0.007) \\
\end{array}$ & $\begin{array}{c}0.453^{* * *} \\
(0.096)\end{array}$ \\
\hline Panel B: First Stage & \multicolumn{6}{|c|}{ Forecast Error ${ }_{t}$} \\
\hline Investment $_{t-1}$ & & $\begin{array}{c}-0.562^{* * *} \\
(0.105)\end{array}$ & & $\begin{array}{c}-0.562^{* * *} \\
(0.105)\end{array}$ & & $\begin{array}{c}-0.562^{* * *} \\
(0.105)\end{array}$ \\
\hline Year Effects & $\mathrm{X}$ & $\mathrm{X}$ & $\mathrm{X}$ & $\mathrm{X}$ & $\mathrm{X}$ & $\mathrm{X}$ \\
\hline Years & 2003-2018 & 2003-2018 & 2003-2018 & $2003-2018$ & 2003-2018 & 2003-2018 \\
\hline Firm-Years & 2852 & 2852 & 2852 & 2852 & 2852 & 2852 \\
\hline First Stage F & & 28.94 & & 28.94 & & 28.94 \\
\hline
\end{tabular}

Notes: The table reports estimates of specifications on the merged Compustat - IBES - FISD/TRACE sample at the firm-fiscal year level. The top panel plots OLS and IV second-stage estimates. The bottom panel, where relevant, reports IV first-stage estimates. Standard errors are clustered at the firm level. $*=10 \%$ level, $* *=5 \%$ level, and $* * *=1 \%$ level. The standard deviation of the bond return is 0.014 , the standard deviation of spread growth is 0.024 , the standard deviation of investment growth is 0.090 , the standard deviation of the forecast error is 0.438 , and the standard deviation of lagged investment is 0.133. For all series, $0.01=1 \%$ relative to a firm's tangible capital stock. 


\section{Table B.5: Linking Forecast Errors and Industry Reversals in the Data: SIC2 Sectors}

\begin{tabular}{|c|c|c|c|c|}
\hline IV Stage: & $\begin{array}{c}(1) \\
\text { Forecast Error }_{t} \\
\text { First }\end{array}$ & $\begin{array}{c}(2) \\
\text { Return }_{t} \\
\text { Second }\end{array}$ & $\begin{array}{c}(3) \\
\Delta \text { Spread }_{t} \\
\text { Second }\end{array}$ & $\begin{array}{c}(4) \\
\Delta \text { Investment }_{t} \\
\text { Second }\end{array}$ \\
\hline Forecast Error $_{t}$ & & $\begin{array}{c}0.048^{* * *} \\
(0.014)\end{array}$ & $\begin{array}{c}-0.099^{* * *} \\
(0.023)\end{array}$ & $\begin{array}{c}0.570^{* * *} \\
(0.047)\end{array}$ \\
\hline Investment $_{t-1}$ & $\begin{array}{c}-0.869^{* * *} \\
(0.246)\end{array}$ & & & \\
\hline Industry Effects & $\mathrm{X}$ & $\mathrm{X}$ & $\mathrm{X}$ & $\mathrm{X}$ \\
\hline Industries & 35 & 35 & 35 & 35 \\
\hline Industry-Years & 453 & 453 & 453 & 453 \\
\hline First Stage F & 12.46 & & & \\
\hline
\end{tabular}

Notes: The table reports first- and second-stage IV estimates based on industry aggregated data from the Compustat- IBES-FISD/TRACE sample at the SIC2 $\times$ fiscal year level. Column (1) reports the first stage, and columns (2)-(4) report second-stage regressions. Standard errors are clustered at the industry level. $*=10 \%$ level, $* *=5 \%$ level, and $* * *=1 \%$ level. Forecast error is average realized minus expected profits normalized by capital stocks. Investment is the average investment rate, i.e., capital expenditures normalized by the capital stock. Return is the average realized bond return, and spread is the average realized bond spread relative to the risk-free rate. Columns (2)-(4) control for the lagged spread and current profits relative to the capital stock. For all series, $0.01=1 \%$. 


\section{Table B.6: Linking Forecast Errors and Industry Reversals in the Data: No Controls}

\begin{tabular}{lcccc}
\hline \hline & $(1)$ & $(2)$ & $(3)$ & $(4)$ \\
IV Stage: & $\begin{array}{c}\text { Forecast Error }_{t} \\
\text { Return }\end{array}$ & $\Delta$ Spread $_{t}$ \\
Second & Second $^{*}$ & $\begin{array}{c}\Delta \text { Investment }_{t} \\
\text { Second }\end{array}$ \\
\hline Forecast Error & & $0.049^{* * *}$ & $-0.109^{* *}$ & $1.321^{* * *}$ \\
& & $(0.017)$ & $(0.042)$ & $(0.437)$ \\
Investment $_{t-1}$ & $-0.457^{* * *}$ & & & \\
& $(0.150)$ & & $\mathrm{X}$ & $\mathrm{X}$ \\
& $\mathrm{X}$ & $\mathrm{X}$ & 111 & 111 \\
Industry Effects & 111 & 111 & 1291 & 1291 \\
Industries & 1291 & 1291 & & \\
Industry-Years & 9.23 & & & \\
First Stage F & &
\end{tabular}

Notes: The table reports first- and second-stage IV estimates based on industry aggregated data from the Compustat- IBES-FISD/TRACE sample at the SIC3 $\times$ fiscal year level. Column (1) reports the first stage, and columns (2)-(4) report second-stage regressions. Standard errors are clustered at the industry level. $*=10 \%$ level, $* *=5 \%$ level, and $* * *=1 \%$ level. Forecast error is average realized minus expected profits normalized by capital stocks. Investment is the average investment rate, i.e., capital expenditures normalized by the capital stock. Return is the average realized bond return, and spread is the average realized bond spread relative to the risk-free rate. For all series, $0.01=1 \%$.

Table B.7: Linking Forecast Errors and Industry Reversals in the Data: No Industry Effects

\begin{tabular}{|c|c|c|c|c|}
\hline IV Stage: & $\begin{array}{c}(1) \\
\text { Forecast Error }_{t} \\
\text { First }\end{array}$ & $\begin{array}{c}\text { (2) } \\
\text { Return }_{t} \\
\text { Second }\end{array}$ & $\begin{array}{c}(3) \\
\Delta \text { Spread }_{t} \\
\text { Second }\end{array}$ & $\begin{array}{c}(4) \\
\Delta \text { Investment }_{t} \\
\text { Second }\end{array}$ \\
\hline${\text { Forecast } \text { Error }_{t}}$ & & $\begin{array}{c}0.009^{* * *} \\
(0.003)\end{array}$ & $\begin{array}{c}-0.026^{* * *} \\
(0.007)\end{array}$ & $\begin{array}{c}0.247^{* * *} \\
(0.026)\end{array}$ \\
\hline Investment $_{t-1}$ & $\begin{array}{c}-0.936^{* * *} \\
(0.141)\end{array}$ & & & \\
\hline Industries & 111 & 111 & 111 & 111 \\
\hline Industry-Years & 1291 & 1291 & 1291 & 1291 \\
\hline First Stage F & 46.90 & & & \\
\hline
\end{tabular}

Notes: The table reports first- and second-stage IV estimates based on industry aggregated data from the Compustat- IBES-FISD/TRACE sample at the SIC3 $\times$ fiscal year level. Column (1) reports the first stage, and columns (2)-(4) report second-stage regressions. Standard errors are clustered at the industry level. $*=10 \%$ level, $* *=5 \%$ level, and $* * *=1 \%$ level. Forecast error is average realized minus expected profits normalized by capital stocks. Investment is the average investment rate, i.e., capital expenditures normalized by the capital stock. Return is the average realized bond return, and spread is the average realized bond spread relative to the risk-free rate. Columns (2)-(4) control for the lagged spread and current profits relative to the capital stock. For all series, $0.01=1 \%$. 